CENTRO UNIVERSITÁRIO FEI

SAMUEL MONTEIRO JUNIOR

APLICAÇÃO DO CONTROLE DE IMPEDÂNCIA PARA ASSISTÊNCIA AO OPERADOR DE UM SISTEMA DE MOVIMENTAÇÃO DE CARGAS 
SAMUEL MONTEIRO JUNIOR

\title{
APLICAÇÃO DO CONTROLE DE IMPEDÂNCIA PARA ASSISTÊNCIA AO OPERADOR DE UM SISTEMA DE MOVIMENTAÇÃO DE CARGAS
}

\author{
Dissertação de Mestrado apresentada ao Centro \\ Universitário FEI, como parte dos requisitos necessários à \\ obtenção do Título de Mestre em Engenharia Mecânica, \\ orientado pelo Prof. Dr. Fabrizio Leonardi
}

São Bernardo do Campo 
Monteiro Junior, Samuel .

Aplicação do controle de impedância para assistência ao operador de um sistema de movimentação de cargas / Samuel Monteiro Junior. São Bernardo do Campo, 2016.

95 p. : il.

Dissertação - Centro Universitário FEI.

Orientador: Prof. Dr. Fabrizio Leonardi.

1. Controle de impedância. 2. Motor CC. Robótica. 3. Cadeira de rodas assistida. I. Leonardi, Fabrizio, orient. II. Título.

Elaborada pelo sistema de geração automática de ficha catalográfica da FEI com os dados fornecidos pelo(a) autor(a). 
Aluno: Samuel Monteiro Junior

Título do Trabalho: Aplicação do controle de impedância para assistência ao operador de um sistema de movimentação de cargas.

Área de Concentração: Sistemas da Mobilidade

Orientador: Prof. Dr. Fabrizio Leonardi

Data da realização da defesa: 29/04/2016

\section{MEMBROS DA BANCA EXAMINADORA}

Prof. Dr. Fabrizio Leonardi

Prof. Dr. Marko Ackermann

Prof. Dr. Fuad Kassab Junior
Ass. :

Ass.:

Ass. :

A Banca Julgadora acima-assinada atribuiu ao aluno o seguinte resultado:
APROVADO $\bigotimes$
REPROVADO

\section{VERSÃO FINAL DA DISSERTAČ̃̃O}

APROVO A VERSÃO FINAL DA DISSERTAÇÃO EM QUE FORAM INCLUÍDAS AS RECOMENDAÇÕES DA BANCA

EXAMINADORA
Aprovação do Coordenador do Programa de Pós-graduação

Prof. Dr. Rodrigo Magnabosco 
SAMUEL MONTEIRO JUNIOR

\section{APLICAÇÃO DO CONTROLE DE IMPEDÂNCIA PARA ASSISTÊNCIA AO OPERADOR DE UM SISTEMA DE MOVIMENTAÇÃO DE CARGAS}

\section{Dissertação de Mestrado \\ Centro Universitário FEI}

Comissão Julgadora

Orientador e Presidente: Prof. Dr. Fabrizio Leonardi

Examinador: Prof. Dr. Marko Ackermann

Examinador: Prof. Dr. Fuad Kassab Junior 
À minha esposa Letícia

Aos meus filhos Samuel, Suellen e Lívia À memória de meus pais Samuel e Ruth 


\section{AGRADECIMENTOS}

A Deus por me proporcionar essa experiência única, por ter me dado força e sabedoria para enfrentar as dificuldades que, direta ou indiretamente cruzaram meu caminho.

À minha esposa Leticia, pelo apoio, paciência e carinho em todos os momentos dessa jornada.

Aos meus filhos Samuel e Suellen por entenderem a minha ausência.

Ao meu orientador Fabrizio Leonardi, que esteve sempre presente me orientando e ajudando com muita dedicação e atenção.

Aos professores Sergio Delijaicov e Marko Ackermann, pelas informações que contribuíram para o projeto.

Aos colegas de estudos que me auxiliaram.

Ao Centro Universitário FEI pela concessão da bolsa de estudo.

Aos colegas dos Centro de laboratórios Elétricos do Centro Universitário FEI pelo auxílio e fornecimento de equipamentos necessário para as pesquisas.

Aos colegas dos Centro de laboratórios Mecânicos do Centro Universitário FEI pelo incentivo e auxílio na usinagem de peças necessárias para adequação dos equipamentos nas pesquisas.

Aos meus familiares. 
"Se te mostrares desanimado diante de suas dificuldades, nunca terás forças de enfrentá-las”

Ruth Simioni Monteiro 


\section{RESUMO}

O presente trabalho propõe o projeto e a implementação de um sistema de controle de impedância de um sistema de movimentação de cargas por meio de um motor elétrico para auxílio ao operador. O sistema de controle visa impor a relação dinâmica entre a força aplicada e a velocidade do transportador, ou seja, impor uma impedância mecânica aparente desejada. A metodologia proposta foi inspirada na técnica de linearização por realimentação a fim de promover uma alteração aparente na massa e no coeficiente de atrito viscoso do sistema. Mostra-se que, com essa técnica, pode-se obter um controle de impedância sem o uso de sensores de força, mas com uma possível redução de robustez às incertezas do modelo quando comparada às técnicas que medem a força. Nos experimentos é utilizado um conjunto de motor e tacogerador de $5 \mathrm{~V}$ da LJ Technical Systems. O controlador requer as informações da velocidade e da aceleração angular, mas somente a velocidade é medida diretamente, sendo a aceleração estimada numericamente. A lei de controle proposta gera termos aditivos à equação diferencial do modelo a fim de alterar sua característica dinâmica, inclusive viabilizando compensar parte do atrito de Coulomb. Como a força externa não é utilizada na lei de controle, não é gerado um erro de acompanhamento da impedância. Assim, incertezas paramétricas e dinâmicas não são consideradas explicitamente no projeto do controlador e a possível degradação no desempenho do sistema de controle é investigada com o auxílio de um sensor e de um estimador de força. Simulações numéricas sugerem que o controle de impedância proposto pode ser efetivo mesmo na presença de incertezas dos parâmetros do modelo. O bom desempenho do sistema de controle foi obtido com um esforço de controle compatível com o motor real.

Palavras-chave: Controle de impedância. Motor CC. Robótica. Cadeira de rodas assistida 


\begin{abstract}
This paper proposes the design and implementation of an impedance control system of a load handling system by means of an electric motor to assist the operator. The control system aims to establish the dynamic relationship between the applied force and the cart speed, that is, imposing a desired apparent mechanical impedance. The proposed methodology was inspired by feedback linearization technique to promote an apparent change in mass and viscous friction coefficients of the system. It is shown that, with this technique, one can obtain an impedance control without the use of force sensors, but with a possible reduction of robustness to model uncertainty compared to techniques that explicitly measure the external force. In the experiments it is adopted a set of motor and tachogenerator of $5 \mathrm{~V}$ from LJ Technical Systems. The controller requires information on angular velocity and acceleration, but only the velocity is measured directly, with a numerically estimated acceleration. The proposed control law generates additional terms to the model of differential equation to change its dynamic characteristics also allowing to compensate part of the Coulomb friction. As the external force is not used in the control law, an impedance tracking error is not generated. Thus, parametric and dynamic uncertainties are not explicitly considered in the controller design and possible deterioration in the control system performance is investigated with the aid of a force sensor and an estimator. Numerical simulations suggest that the proposed impedance control can be effective even in the presence of uncertainty of the model parameters. The reasonable performance of the control system was obtained with a control effort compatible with the real motor.
\end{abstract}

Keywords: Impedance control. DC motor. Robotics. Power assisted wheelchair 


\section{LISTA DE ILUSTRAÇÕES}

Figura 1-Quadriciclo para pessoas com mobilidade reduzida............................................. 15

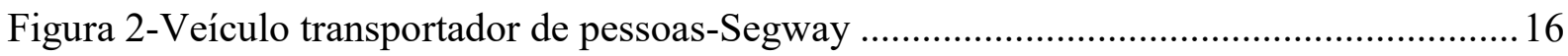

Figura 3- Esquema de ligação e acoplamentos de uma cadeira PAPAW ...............................21

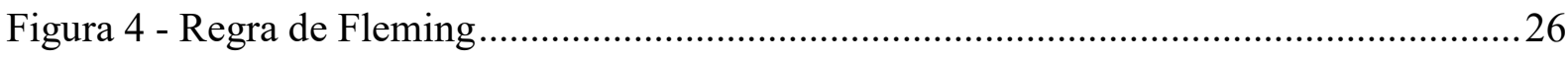

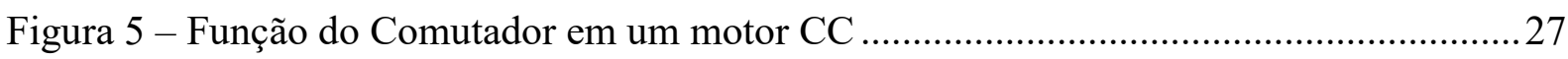

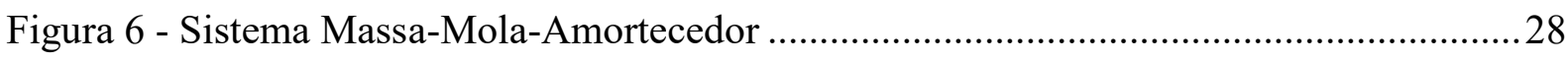

Figura 7-Diagrama de blocos com controle da impedância em um robô.................................. 31

Figura 8 - Controle de Impedância aplicado em uma Órtese .................................................. 34

Figura 9- Esquema de um Motor de corrente contínua com redução........................................ 35

Figura 10 - Diagrama de blocos de um motor CC com redução ..............................................37

Figura 11 - Diagrama de Blocos com torques refletidos à entrada. ....................................... 37

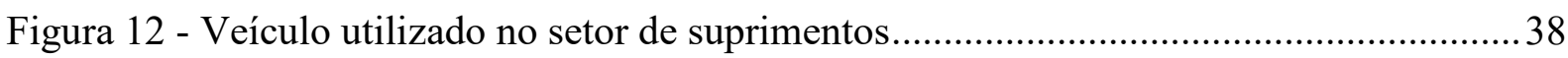

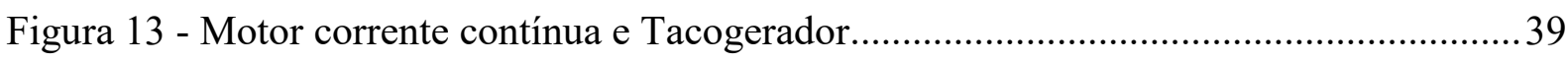

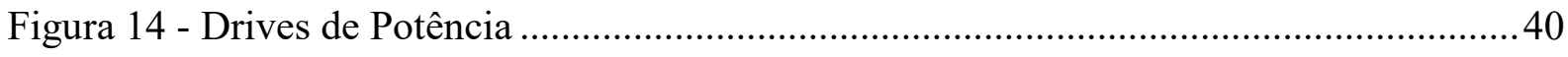

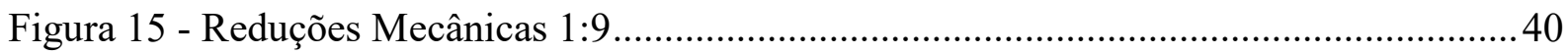

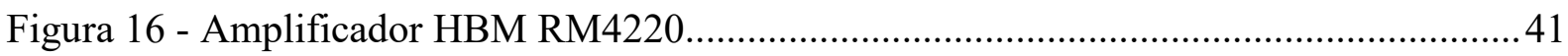

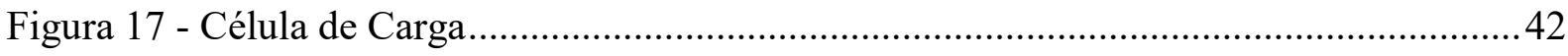

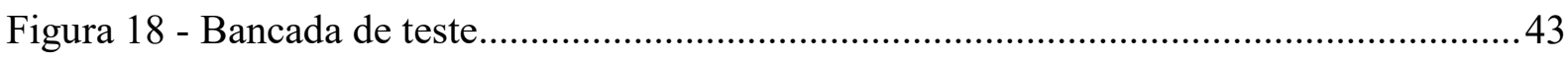

Figura 19- Diagrama de blocos associado ao modelo do sistema LJ .................................... 44

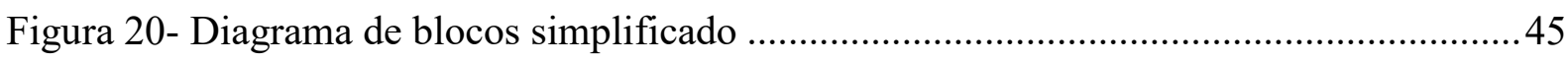

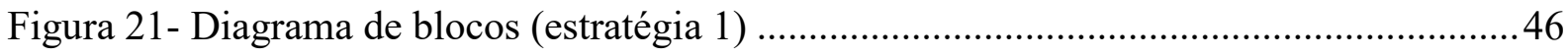

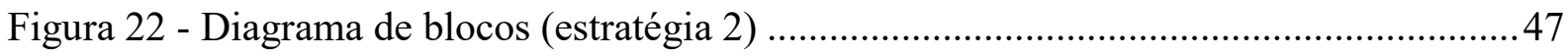

Figura 23 -Diagrama de blocos para identificação dos parâmetros $\lambda, k$ e $\eta$............................ 49

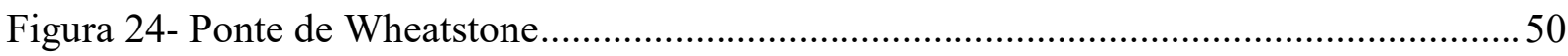

Figura 25 - Diagrama de blocos com estimador do torque externo......................................... 51

Figura 26-Diagrama de blocos dos sistemas da planta real e modelada ................................54

Figura 27 - Comparação entre Torque medido pela célula de carga e Torque Estimado para uma excitação aleatória no eixo de saída do sistema LJ.......................................................55 
Figura 28- Comparação entre Torque medido pela célula de carga e Torque Estimado para uma excitação senoidal no eixo de saída do sistema LJ ............................................................56

Figura 29-Análise da frequência de oscilação da Manivela de torque ...................................58 Figura 30 - Torque externo aplicado no sistema como forma similar ao torque aplicado pelo operador

Figura 31- Velocidade e Tensão de armadura para alterações de $\pm 25 \%$ na Inércia e $-100 \%$ no atrito de Coulomb.

Figura 32- Velocidade e Tensão de armadura para alterações de $\pm 50 \%$ na Inércia e $-100 \%$ no atrito de Coulomb.

Figura 33 - Impedância Mecânica para alterações de $\pm 25 \%$ na Inércia aparente. 64

Figura 34- Velocidade e Tensão de armadura para alterações de $\pm 25 \%$ no coeficiente de atrito viscoso e $-100 \%$ no atrito de Coulomb

Figura 35- Impedância mecânica para alterações de $+25 \%$ no atrito viscoso aparente $-100 \%$ no atrito de Coulomb

Figura 36-Velocidade e Tensão de armadura para alterações de $\pm 50 \%$ no coeficiente de atrito viscoso e $-100 \%$ no atrito de Coulomb

Figura 37- Impedância mecânica para alterações de $\pm 50 \%$ no coeficiente de atrito viscoso e $-100 \%$ no atrito de Coulomb 68

Figura 38-Velocidade e Esforço de Controle para alterações $\pm 100 \%$ e $\pm 50 \%$ no atrito de Coulomb.

Figura 39- Impedância mecânica para alteração de $\pm 100 \%$ e $\pm 50 \%$ no atrito de Coulomb... 71

Figura 40-Conjunto de possibilidades para aplicação dos parâmetros alterados ..................... 72

Figura 41-Diagrama de blocos com subsistemas no Simulink ................................................91

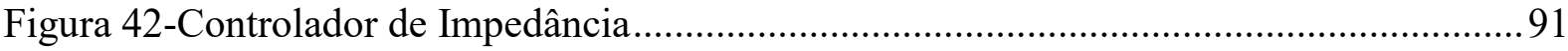

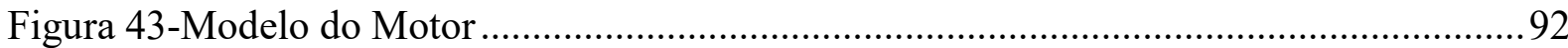

Figura 44-Motor real (entrada e saída da Placa HBM 6221) ................................................. 92

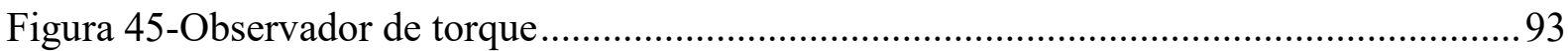

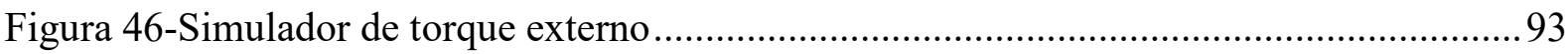

Figura 47- Célula de Carga para medição de flexão. ............................................................. 95 


\section{LISTA DE TABELAS}

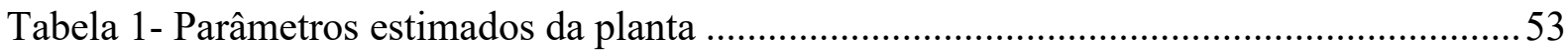

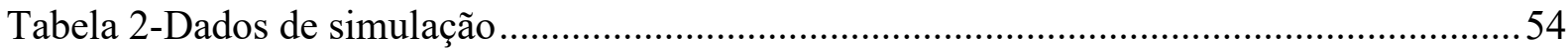

Tabela 3-Velocidade angular $\omega$ e frequência $f$ da oscilação induzida pelo movimento da manivela de aplicação do torque externo 58

Tabela 4 - Dados da constante de tempo $\tau$ e da constante de ganho $\mathrm{kg}_{\mathrm{g}}$ do sistema para uma alteração da Inércia aparente em $\pm 25 \%$ e $-100 \%$ no atrito de Coulomb. 62

Tabela 5 - Dados da constante de tempo $\tau$ e da constante de ganho $\mathrm{k}_{\mathrm{g}}$ do sistema para uma alteração da Inércia aparente em $\pm 50 \%$ e $-100 \%$ no atrito de Coulomb

Tabela 6 - Dados da constante de tempo $\tau$ e da constante de ganho kg do sistema para uma alteração do coeficiente de atrito viscoso aparente em $\pm 25 \%$ e $-100 \%$ no atrito de Coulomb 66 Tabela 7-Dados da constante de tempo $\tau$ e da constante de ganho $\mathrm{k}_{\mathrm{g}}$ do sistema para uma alteração do Coeficiente do Atrito Viscoso aparente em $\pm 50 \%$ e $-100 \%$ no atrito de Coulomb.

Tabela 8-Variação da compensação do atrito de Coulomb analisado em regime permanente. 69 


\section{LISTA DE ABREVIATURAS, SIGLAS E SÍMBOLOS}

\begin{tabular}{|c|c|}
\hline$\dot{\omega}$ & Aceleração angular \\
\hline SEA & Atuadores Elásticos em Série \\
\hline$\eta$ & Coeficiente de atrito de Coulomb global \\
\hline$B$ & Coeficiente de Atrito viscoso \\
\hline $\mathrm{C}$ & Coeficiente de Atrito Viscoso Global \\
\hline$K_{e}$ & Constante de força contra eletromotriz \\
\hline$\tau$ & Constante de tempo \\
\hline$K_{m}$ & Constante de torque do motor \\
\hline $\mathrm{CC}$ & Corrente Contínua \\
\hline$I_{a}$ & Corrente de armadura \\
\hline$D$ & Diâmetro do eixo \\
\hline AI & Entrada analógica \\
\hline$e$ & Força contra eletromotriz \\
\hline $\mathrm{Hz}$ & Hertz \\
\hline$Z$ & Impedância Mecânica \\
\hline$L_{a}$ & Indutância de armadura \\
\hline$G$ & Modulo de elasticidade \\
\hline$J$ & Momento de Inércia \\
\hline$W_{t}$ & Momento de inércia polar \\
\hline$M_{t}$ & Momento torsor \\
\hline PWC & Power Wheel Chair \\
\hline PWM & Pulse Width Modulation \\
\hline PAPAW & Pushrim-Activated Power Assist Wheel chair \\
\hline$R_{a}$ & Resistência de armadura do motor \\
\hline $\mathrm{RPM}$ & Rotações por Minutos \\
\hline $\mathrm{AO}$ & Saída analógica \\
\hline$V_{a}$ & Tensão de armadura \\
\hline$V_{t}$ & Tensão do Tacogerador \\
\hline$\sigma$ & Tensão máxima \\
\hline$T_{a t}$ & Torque de atrito \\
\hline
\end{tabular}


$T_{l}$

$T_{m}$

$\omega$
Torque de Carga

Torque do motor

Velocidade angular 


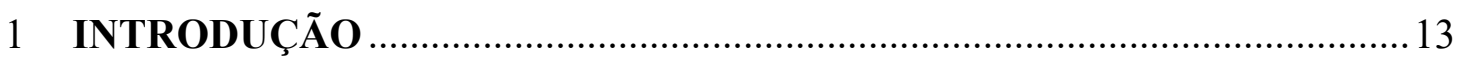

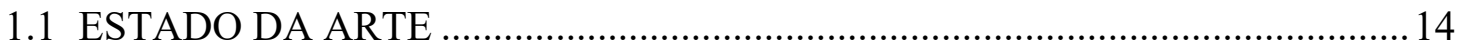

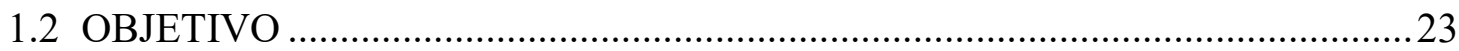

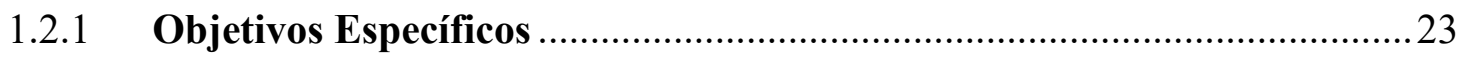

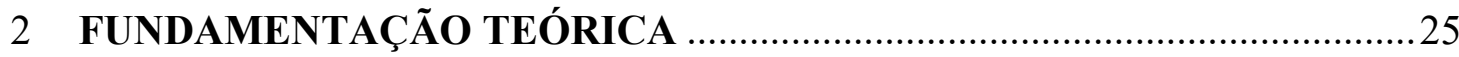

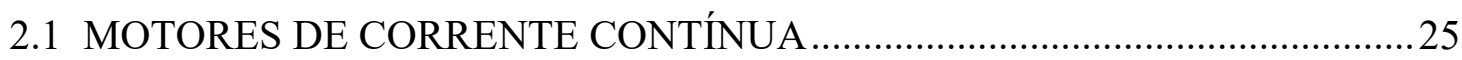

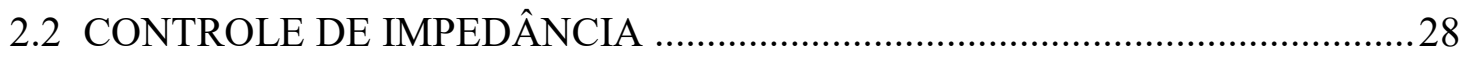

2.3 MODELAGEM DE SISTEMAS ELETROMECÂNICOS ………….........................35

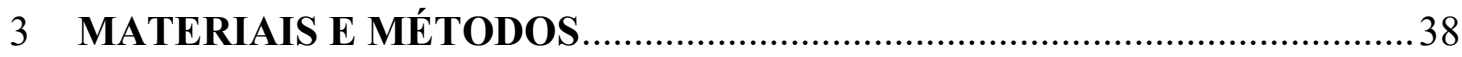

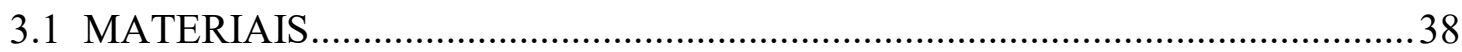

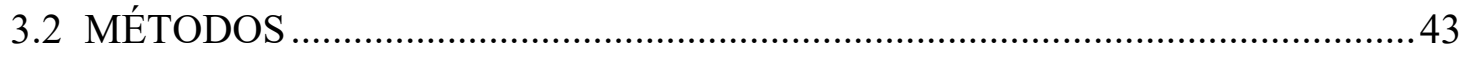

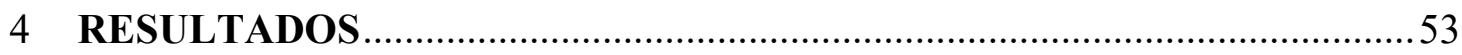

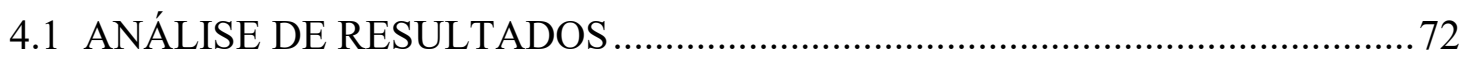

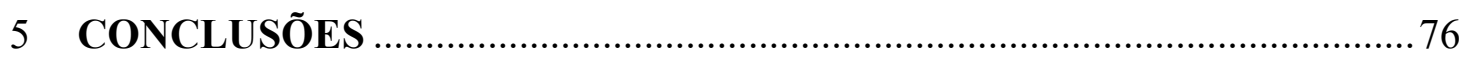

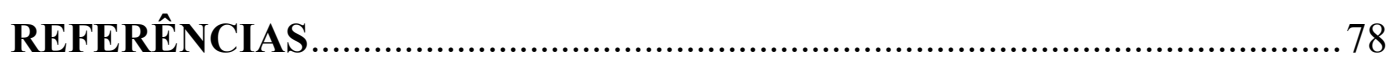

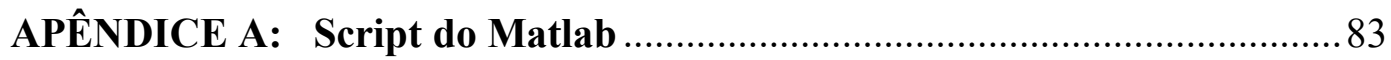

APÊNDICE B: Arquivo do Simulink ……………………............................ 90

APÊNDICE C: Célula de Carga ....................................................................94 


\section{INTRODUÇÃO}

O uso de motores elétricos em sistema de mobilidade é realidade estabelecida e são encontrados em aplicações tais como no transporte de carga, bicicletas, locomoção de pessoas com mobilidades reduzidas e muitas outras.

O transporte de pequenas cargas por carros transportadores cuja movimentação é feita apenas com a força humana, tem desempenho bastante restrito. A velocidade do transporte e o peso máximo ficam limitados pela carga e pela capacidade do operador. $\mathrm{O}$ uso de um motor elétrico, adaptado ao sistema pode substituir a força humana totalmente ou complementar essa força na forma de uma assistência. Essa assistência pode ser pré-programada ou mais elaborada no sentido de prover mais segurança e conforto ao operador, adaptando-se à sua solicitação. A assistência pré-programada pode ser vista no sentido de o motor sempre atuar da mesma forma, independentemente da atuação do operador, normalmente aplicando uma força (torque) constante assim que habilitada. A assistência que se adapta à condição operacional será denominada aqui assistência controlada e pode ter várias características como, por exemplo, ser função da declividade do movimento. Neste trabalho, argumenta-se que a assistência na forma da alteração da massa aparente do transportador com carga e de outras características dinâmicas, tais como amortecimento, é conveniente e segura. É conveniente, pois o operador ainda participa da locomoção permitindo que ele tenha

sensibilidade nas manobras. É segura, pois a alteração aparente da dinâmica é percebida pelo operador, mas não altera o movimento independente dele. Portanto para promover a assistência controlada da forma descrita, é suficiente impor a impedância mecânica associada ao movimento criado pelo operador. Logo, essa característica dinâmica deve ser imposta pela atuação do motor.

O controle de impedância consiste em fazer com que a relação dinâmica entre a força aplicada e a cinemática do movimento seja mantida conforme um modelo de referência, ou impedância de referência.

O controle de impedância vem sendo muito utilizado na área robótica quando se tem a necessidade de controlar a cinemática do movimento robótico, e quando há interação com o meio ambiente ou com usuários humanos. Hogan (1985) foi um dos primeiros a relatar como abordar esse problema. 
O controle de impedância é aplicado em áreas, onde exista uma interação máquinaambiente, como é o caso de braços robóticos que precisam ter uma sensibilidade para agarrar objetos de várias densidades, casos como os ligados à área de reabilitação com aplicações em próteses, órteses e outros meios de mobilidade, que necessitam de movimentos complacentes.

Baseado na observação do comportamento dos usuários de cadeira de rodas quando trafegam em piso de diferentes características e diferentes inclinações, nota-se a necessidade de alteração da força aplicada pelo cadeirante. Tais situações fazem com que esses usuários fiquem mais suscetíveis a problemas como: lesões por esforços repetitivos (LER), quedas, entre outros. Argumenta-se aqui que a técnica utilizada para a assistência na movimentação de cargas, o controle de impedância, pode também ser adequado e seguro como forma de assistência ativa para cadeirantes.

\subsection{ESTADO DA ARTE}

Até 1980 predominavam dois tipos de movimentação, manuais e motorizadas, a primeira sem assistência e a segunda com assistência total. Porém, com o avanço tecnológico e científico, características específicas puderam ser implementadas e surgiu um terceiro tipo de movimentação, os movimentos parcialmente assistidos, para os quais ainda se faz necessária a intervenção humana nos movimentos, tal como na movimentação manual, mas com intensidade controlada.

Analisam-se nesta seção algumas das principais aplicações de assistências, iniciando pela assistência elétrica a locomoção humana por meio de quadriciclos, conforme ilustrado na figura 1, que em países como a Inglaterra, Estados Unidos e Alemanha são amplamente utilizados, principalmente por idosos que tem sua mobilidade reduzida. Seu controle tipicamente é feito por meio de um atuador do tipo PWM (Pulse Width Modulation) que é responsável por alterar o valor médio da tensão no motor, modificando assim sua velocidade. Normalmente, utiliza-se um potenciômetro para variar a referência da velocidade desejada, porém, a maioria dos triciclos e quadriciclos não utiliza um sistema de controle automático em malha fechada, fazendo com que os distúrbios externos tais como as condições do ambiente, irregularidade do piso, entre outros, precisem ser compensados pelo operador. 
Figura 1-Quadriciclo para pessoas com mobilidade reduzida.

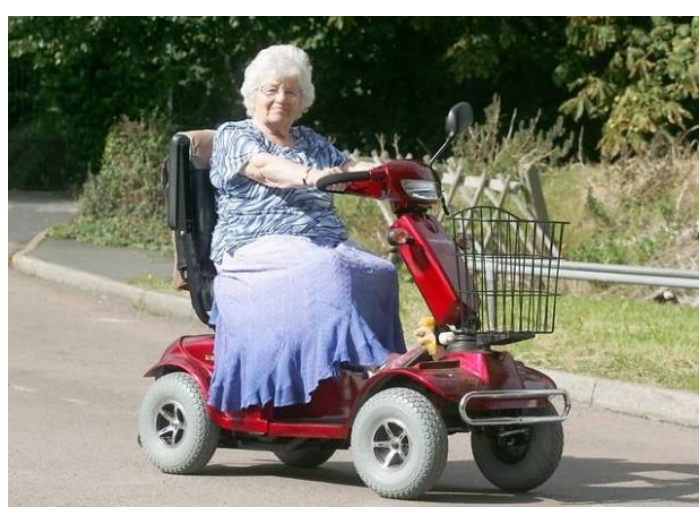

Fonte: Adaptado de Nation Wide Mobility, 2015

Cooper (1994) estudou a controlabilidade e a observabilidade desse tipo de veículo, considerando a dinâmica do piloto humano como controlador. Para modelar as correções feitas pelo condutor para corrigir a direção do veículo em face dos desvios da trajetória desejada, o autor propõe o uso de um sistema linear de primeira ordem com um zero como modelo. Esse modelo incorpora o tempo de reação e o tempo de previsão do condutor. $\mathrm{O}$ modelo completo proposto do sistema quadriciclo-condutor é linear de terceira ordem e foi representado no espaço de estados. Com base nessa representação, o autor verificou que o sistema é completamente observável, viabilizando a construção de um estimador. Considerando que, na prática, para o projeto de um sistema de controle para o quadriciclo a controlabilidade total dos estados não é nem necessária e nem suficiente para garantir o controle da direção do quadriciclo, o autor verificou apenas a controlabilidade da saída. Como consequência da observabilidade e controlabilidade do sistema, o autor argumenta sobre as implicações favoráveis como, por exemplo, permitir que um sistema de identificação possa ser usado junto com o observador para determinar como os vários tipos de deficiências físicas afetam o controle de direção de um quadriciclo. Como proposta de continuidade, o autor propôs o uso de um esquema de controle compartilhado com um controlador Fuzzy para ser usado para caracterizar o condutor para depois compensar as dificuldades relacionadas com o controle da direção. Outra forma de assistência à locomoção humana são os biciclo, para o caso comercial desse tipo chamado Segway, ilustrado na figura 2, marca registrada por seu criador e lançado em 2001, e considerado o primeiro veículo de duas rodas auto balanceado, onde a intervenção humana é na forma de mudança do centro de massa do sistema. O veículo 
consiste de uma pequena plataforma sobre duas rodas e uma haste que além de servir como sustentação do usuário, auxilia a determinação do sentido de movimento. Quando o usuário inclina a haste para frente usando seu peso, automaticamente o centro de massa de todo o conjunto (veículo e usuário) muda, fazendo com que, pela atuação do controlador, seja acionado o motor para a movimentação do veículo para frente. Da mesma forma, quando se inclina a haste para a esquerda ou para a direita, o veículo tomará a direção imposta. Para que o veículo seja frenado, basta colocá-lo na posição inicial e, caso deseje um movimento de retrocesso, deve-se inclinar a haste para trás.

Figura 2-Veículo transportador de pessoas-Segway

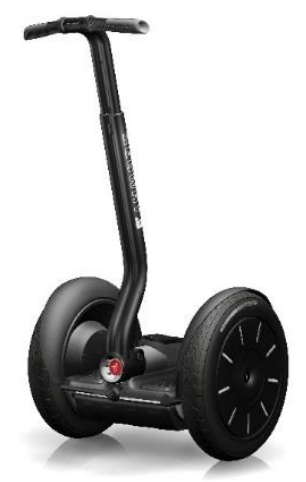

Fonte: Adaptado de Prague Segway, 2015

O veículo que tem características de um pêndulo invertido e, por meio de um controlador e um conjunto de giroscópios, faz com que o equipamento se auto equilibre. $\mathrm{O}$ sistema de controle faz a movimentação baseada nessa mudança, mantendo o equilíbrio durante a manobra por meio das tensões que são aplicadas nos motores, conforme descreve Sawatzky et al.(2007), Com essa motivação, alguns pesquisadores como, por exemplo, Cooper (1994), Sawatzky et al. (2007), Boniface et al. (2011) e Chen (2012), estudaram formas de identificar e prevenir possíveis acidentes com o uso desses aparelhos, determinando quais os meios mais seguros de se utilizar esses dispositivos de locomoções. Além da locomoção humana assistida, investigou-se também outros tipos de assistência como aquelas para o auxílio a movimentação de cargas por meio de talhas em ambientes fabris, cadeiras de rodas, e outras aplicações cujo emprego do controle de impedância é viável e aparentemente 
vantajoso. A implementação desse tipo de sistema de controle pode não ser trivial por conta do uso de sensores de força e cinemática, normalmente necessários para a construção da lei de controle e por causa da variação de parâmetros do modelo do sistema. Para contornar o problema da disponibilidade dos sensores não é comum o uso de estimadores e, para o caso da variação de parâmetros várias estratégias podem ser empregadas desde o controle robusto até técnicas adaptativas. O uso do controle de impedância costuma ser uma solução razoável quando há interações da máquina com o usuário e viabiliza movimentações assistidas ajustadas as condições do usuário, evitando lesões, por exemplo.

O modelo matemático do sistema Segway é não linear e, no trabalho de Chen (2012) esse modelo foi obtido a partir da formulação Euler-Lagrange e linearizado para pequenos desvios em torno da posição vertical para viabilizar o projeto de um controlador linear. O controlador utilizado consiste de uma realimentação de ganhos constantes, obtida pela solução de um problema de controle ótimo. O controlador obtido faz com que o veículo se estabilize mesmo para grandes variações da haste.

Para utilizar esse veículo, faz-se necessário o conhecimento de inúmeras normas de segurança, pois devido a facilidade de manuseio, os riscos de acidentes são eminentes e podem não ter a devida atenção. Com essa motivação, Boniface et al. (2011) estudaram os possíveis acidentes que o Segway poderia causar, propondo formas de evitá-las. No trabalho de Sawatzky et al. (2007) também se estudou o Segway, mas como uma forma de mobilidade alternativa para pessoas portadoras de necessidades especiais, embora seu inventor, Dean Kamen, tenha criado um outro veículo de mobilidade para essas pessoas e o registrou como Independência biot. 3000, que permite subir escadas, entre outras manobras especiais. Em seu trabalho, Sawatzky et al. (2007) propuseram testes para pessoas com mobilidade reduzida devido a doenças como Parkinson, esclerose múltipla, amputações, artrite, síndrome de paralisia, síndrome da fadiga crônica, cerebral postpolio (PPS), lesão medular (SCI), e fibromialgia. A elas foram impostas um percurso para que, sem interferência humana alguma, elas pudessem percorrer esse caminho com o equipamento e, através de análises dos fisioterapeutas e outros médicos, puderam determinar se o equipamento seria ou não adequado para as pessoas portadoras daquela deficiência. A análise consistiu em descrever as facilidades ou dificuldades de cada participante e, como conclusão geral, não houve impedimentos na utilização do Segway por portadores de mobilidade reduzida. 
Como em muitos casos, devido a acidentes ou doenças degenerativas, pacientes tem diminuição ou perda total de suas mobilidades e são obrigados a utilizar aparelhos que os auxiliem. Ibarra e Siqueira (2014) apresentaram uma revisão das alternativas de estratégias de controle de impedância para aplicação em próteses robóticas para realizar terapias em pacientes com deficiências nos membros inferiores. As motivações apresentadas para a aplicação do controle de impedância se referem, por exemplo, à possibilidade de alteração da inércia aparente e do atrito viscoso aparente, para que o paciente recupere seus movimentos ou até mesmo seja auxiliado por aparelhos para sua locomoção. Quando se faz a alteração do atrito viscoso aparente e/ou da inércia aparente para menos, pretende-se auxiliar o paciente na sua locomoção, porém, quando o objetivo é a realização de exercícios físicos, o atrito viscoso aparente e/ou da inércia aparente devem ser aumentados. Os autores mostraram a forma geral de um controle de impedância aplicado a um sistema de reabilitação robô-paciente cujo modelo é o de um sistema mecânico multicorpos conectados por juntas. Discutem-se as formas de se implementar o controle de impedância por meio de controladores de força e de controladores de cinemática conectados pelo modelo da impedância ou da admitância desejada. Discute-se também a necessidade de um nível de controle superior que permite a alteração da impedância desejada, enquanto que o nível inferior de controle apenas garante a realização adequada dessa impedância.

Quando pacientes perdem a sensibilidades de seus membros, principalmente quando os problemas são nos músculos, há uma certa tendência desses membros modificarem sua rigidez tornando-os mais flácidos. Para auxiliar esses pacientes, pode-se utilizar dispositivos que mantêm o membro em uma única posição, porém acarretando em elevada rigidez, mas que pode ser um problema caso, por exemplo, o paciente venha a chocar a mão com algum obstáculo. Com essa motivação, Nakamura et al. (2008) apresentaram uma solução onde o dispositivo para estender os dedos da mão possui um sensor de força ligado a um atuador que, por meio de um controle de impedâncias, determina a posição que deva ficar o dedo. Para que não haja uma rigidez elevada num caso de choque da mão com algum objeto, foi proposto incluir entre o sensor de força e o atuador, um conjunto de elementos passivos do tipo mola/amortecedor que também se presta a diminuir a região de instabilidade do sistema. A instabilidade do sistema ocorre quando os parâmetros da impedância são muito pequenos na tentativa de conseguir uma boa condição de manobra. Essa instabilidade ocorre por causa do atraso da malha de posição, principalmente quando o dispositivo assistido toca algo do 
ambiente com elevada rigidez tal como uma parede. Ao aplicar o sistema de controle de impedância proposto, o movimento da mão acontece a partir de um mínimo estímulo, ou seja, a mínima força que o paciente aplica, impõe a velocidade correspondente do atuador, reduzindo a vulnerabilidade a acidentes.

Mehling e O' Malley (2014) propuseram o uso de uma estrutura de controle do tipo model matching com o projeto feito pela técnica $\mathrm{H}_{\infty}$ como forma de obter o controle de impedância para sistemas com atuadores elásticos em série (SEA). A estrutura utilizada para projeto é similar àquela proposta por Skogestad e Postlethwaite (1996) em que as matrizes de penalização do problema de sensibilidade mista penalizam também o erro de casamento entre a resposta do modelo de referência (impedância desejada) e a resposta da planta. Os autores argumentam que, ao contrário das técnicas tradicionais de controle PD (proporcional derivativo) normalmente utilizadas em controladores de impedância, o projeto do controlador $\mathrm{H}_{\infty}$ não requer acesso a todos os estados e um estimador de estados é implicitamente incorporado à solução. Simulações numéricas mostram que é possível alterar simultaneamente todos os coeficientes da impedância desejada ao preço de uma elevação do esforço de controle à medida que a impedância desejada mais difere da impedância original do sistema. Os autores também apontam algumas limitações do uso do controlador model matching obtido por meio da técnica $\mathrm{H}_{\infty}$. O controlador resulta de ordem relativamente elevada quando comparado com o controlador de estrutura PD e com ganhos tipicamente elevados, o que torna difícil a implementação prática.

Devido ao fato de a sociedade cada vez mais integrar pessoas com necessidades especiais, a adequação dos espaços e ambientes está aumentando. Com isso, são dadas autonomia que antes não era possível. Para os cadeirantes, por exemplo, essa maior autonomia, entretanto, pode implicar em problemas relacionados à ergonomia, tais como as lesões por esforços repetitivos (LER). Em seu trabalho, Dellabianca, Porcellini e Merolla. (2013) apresentaram um estudo que relacionou uma correta posição dos membros superiores e, principalmente dos ombros, que são os mais afetados na propulsão da cadeira de rodas. Ele concluiu que $70 \%$ dos cadeirantes sofrem de problemas, tais como dores e doenças crônicas por não aplicarem corretamente as forças para propulsionar a cadeira de rodas e ou por aplicar forças excessivas, ocasionando lesões. Uma solução natural para esses problemas seria o uso de cadeiras com propulsão assistida. 
Por causa dos inúmeros problemas que os cadeirantes sofrem e, além disso, para pessoas cuja força nos membros superiores é de pouca intensidade, foi desenvolvido uma cadeira de rodas que inclui um motor de assistência. Até a década de 90 predominaram apenas duas variações de cadeiras de rodas: as manuais e aquelas automáticas com propulsão elétrica, designadas pela sigla PWC (Power Wheel Chair). Depois desse período, houve uma fusão das duas tecnologias, surgindo então as cadeiras com assistência parcial por motor elétrico, designadas pela sigla PAPAW (Pushrim-Activated Power Assist Wheelchair). Essas cadeiras consistem em um motor que normalmente só é acionado por uma solicitação do cadeirante por meio de um contato no aro da roda. Quando a solicitação é detectada, faz-se com que o motor seja acionado e auxilie o cadeirante na movimentação da cadeira, sendo que essa assistência é contínua enquanto houver a solicitação por meio do contato na roda. COOPER et al. (2002) estudaram o desempenho de uma cadeira PAPAW determinando assim seu desempenho em relação ao de cadeiras manuais. Além disso, eles descreveram a construção dessa cadeira, composta de sensores de torque acoplados nos aros de propulsão que são ligados a um conversor analógico/digital para permitir envio dos dados para um microprocessador. Esse microprocessador gera um sinal PWM que modula a tensão enviada aos motores que aplicam torque nas caixas de redução que serão transmitidos às rodas. Nas rodas estão acoplados sensores de velocidades e, na estrutura da cadeira estão acoplados sensores de força para medição da carga (usuário e tara). O microprocessador fecha malha por meio da medição de velocidade e, quando a carga é aumentada ou o sensor de torque percebe a atuação do usuário, o microprocessador envia os sinais para que os motores auxiliem o movimento com os torques necessários. Na Figura 3, mostra-se o fluxograma dos sinais dessa estratégia de controle. Note-se que cada roda possui um subsistema de controle independente, e que o sistema de controle faz a coordenação dos movimentos em função das velocidades de cada roda e da carga. 
Figura 3- Esquema de ligação e acoplamentos de uma cadeira PAPAW

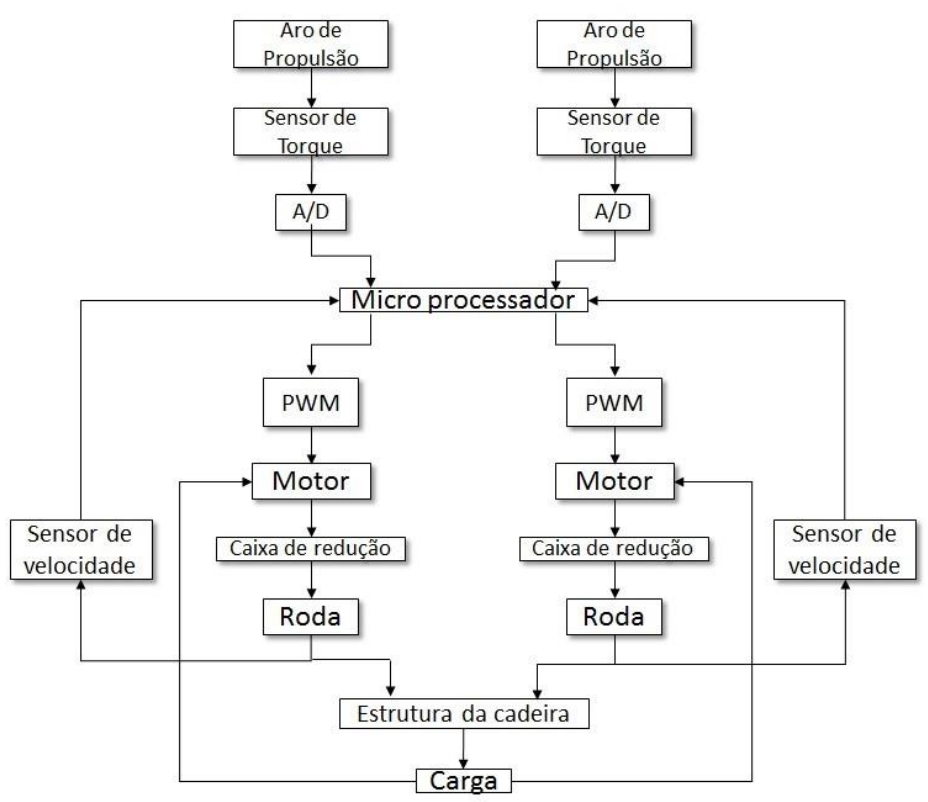

Fonte: Autor “adaptado de” Arc. Phys Med. Rehabil

O trabalho de Arva et al. (2001) estudou a eficiência mecânica das cadeiras e a qualidade de vida dos usuários e comprovou que os usuários de cadeiras assistidas apresentaram uma menor taxa de elevação cardíaca pela menor força aplicada e um aumento na mobilidade com melhores desempenhos nos testes propostos. Isso fez com que a auto estima melhorasse e reforça a ideia de que o uso de assistência à mobilidade não elimina a participação do cadeirante, permitindo que ele se exercite durante a propulsão, sem exceder seus limites.

Em muitos casos, o cadeirante tem limitações que requerem a presença de um cuidador seja para a propulsão da cadeira, seja para outras atividades tal como chamar um elevador ou abrir uma porta. Para lidar com casos desse tipo Iwase, Zhang e Kuno (2006) apresentaram um protótipo de cadeira de rodas que, por meio de sensores infravermelho reconhece o cuidador ao redor da cadeira e segue seus movimentos no plano. Os autores não tratam explicitamente do auxílio à propulsão e supõem que o protótipo pode realizar autonomamente os movimentos para seguir o cuidador. O presente trabalho poderia ser interpretado como um complemento ao trabalho de Iwase, Zhang e Kuno (2006) no sentido de 
que dá condições adequadas de propulsão ao cuidador quando este decidir assumir a movimentação da cadeira de rodas em situações inesperadas ou mais delicadas.

Shibata e Murakami (2012) propuseram um controle assistido para uma cadeira de rodas elétrica que implementa uma estratégia complacente de forças de reação que não requer sensor de força, pois usa um estimador. A estratégia de controle permite que o usuário faça a propulsão da cadeira por meio da força de reação gerada quando ele empurra/puxa um obstáculo e de forma complacente. A estratégia de controle também utiliza um estimador de distúrbios para garantir a robustez do sistema de controle em face às perturbações do meio. Para validar os resultados simulados os autores avaliam o controlador de reação complacente quando o operador empurra uma mesa e quando o operador empurra e abre uma porta. Os autores relatam que os experimentos foram bem-sucedidos com comportamentos estáveis.

A assistência também é usada em bicicletas e designada pelo nome comercial pedelec. A assistência é feita por um sistema que contém um sensor de torque, geralmente no próprio eixo do motor, um sensor de velocidade acoplado junto à catraca e, com os dados obtido dos sensores, um controlador aciona o motor assistindo o usuário ao pedalar, poupando esforços. Conforme a Federação Europeia de Ciclistas, para que seja considerada uma pedelec a bicicleta deve atender a alguns critérios, são eles: fornecer uma potência de 250 Watts em regime contínuo e ter sensores para que, se a velocidade ultrapassar $25 \mathrm{~km} / \mathrm{h}$, o motor seja desligado, restando somente os torques externos dos pedais.

A assistência dada pelos motores é normalmente feita por controladores e baseada em informações de forças e grandezas cinemáticas. A relação dinâmica entre cinemática do movimento e forças atuantes é denominada impedância mecânica. Popa e Liu (2001) implementaram um controle de impedância em uma talha com capacidade de carga de até 450 kg. Eles consideraram sistemas de movimentação de carga que são acionados por força humana, o que, dependendo da carga içada, pode gerar lesões ao operador. Os movimentos longitudinal e transversal do carro são feitos pelo operador através do cabo que iça a carga. Os autores trataram o sistema equivalentemente à um pêndulo e consideraram a força que gera a movimentação como um estado, dessa forma foi possível construir um observador para estimar essa força. A estratégia proposta faz a relação dinâmica entre a força estimada e a velocidade do conjunto ser próxima à impedância desejada, com a inércia aparente desejada e com o amortecimento aparente desejado. Os autores linearizaram o modelo do sistema e aplicaram a técnica de realimentação de estado por meio do observador com seus ganhos 
obtidos por meio da alocação dos polos de malha fechada. Os experimentos foram efetuados sem variar comprimento do cabo de içamento e obtiveram uma resposta satisfatória e próxima das respostas simulações. Como o modelo é incerto e há distúrbios, na implementação práticas os autores utilizaram zonas mortas tanto nos sinais estimados como no controle e argumentam que essa solução empírica permitiu um controle de melhor qualidade.

A presente pesquisa foi motivada pela observação do sistema manual de movimentação de cargas do setor de suprimentos do Centro Universitário FEI. O sistema atual consta com um pequeno carro com quatro rodas e com uma assistência fixa por meio de um motor elétrico cuja tensão é determinada pelo usuário. Com esse sistema são transportadas cargas diversas, muitas vezes em condições não ideais de conforto e segurança, por causa da simplicidade da assistência. Esta pesquisa visa estudar o controle de assistência à movimentação de cargas por meio de um controle de impedância mecânica de tal forma que possa auxiliar o funcionário a movimentar o sistema de uma maneira mais automatizada, confortável e segura do que o sistema atual.

\subsection{OBJETIVO}

O presente trabalho tem por objetivo propor o projeto e a implementação de um sistema de controle de impedância para avaliar sua aplicabilidade em um sistema de movimentação de cargas por meio de um motor elétrico para assistência ao operador. O sistema de controle deve promover uma alteração aparente na massa, no coeficiente de atrito viscoso do sistema e no atrito de Coulomb. O controlador deve utilizar apenas a medida da velocidade do sistema para viabilizar economicamente a aplicação real. O estudo será efetuado no servomecanismo da LJ System.

\subsubsection{Objetivos Específicos}

Projetar e construir as adaptações necessárias ao servomecanismo da LJ System visando análises experimentais para a prova de conceito. 
Projetar, construir e calibrar uma célula de carga para auxiliar na identificação dos parâmetros do modelo.

Modelar e identificar os parâmetros do sistema eletromecânico e validar o modelo por comparação da sua resposta com os dados experimentais.

Projetar um controlador de impedância baseado somente na informação da velocidade angular instantânea do motor.

Implementar digitalmente o controlador de impedância por meio do Simulink e do Real Time Windows Target através de uma placa de E/S.

Investigar o desempenho do sistema de controle comparando a impedância especificada com a impedância medida com o auxílio da uma célula de carga e por meio de um estimador de torque. 


\section{FUNDAMENTAÇÃO TEÓRICA}

Este capítulo faz uma revisão sobre assuntos e técnicas que são básicos para a metodologia proposta. Faz-se um breve resumo sobre os motores CC para justificar a escolha do modelo usado na metodologia. As estratégias de controle de impedância são revistas evidenciando suas características e aplicações típicas. Uma seção sobre a modelagem de sistemas eletromecânicos completa a revisão, já que o sistema de movimentação de cargas tem que considerar simultaneamente o atuador elétrico e o sistema mecânico acoplado.

\subsection{MOTORES DE CORRENTE CONTÍNUA}

De acordo com Fitzgerald, Kingsley e Umans (2008), os motores de corrente contínua são classificados de acordo com ligação do circuito de campo e o circuito de armadura. Nos servo motores $\mathrm{CC}$ o circuito de campo é substituído por imãs permanentes.

Existem ao menos 6 tipos de motores de corrente continua sendo eles, o motor com excitação independente, o motor com derivação (shunt), o motor série, o motor composto, o motor de imãs permanentes e o motor sem escovas (brushless).

Os motores CC são compostos por duas peças principais, o estator e o rotor. O estator se subdivide em carcaça, polos de excitação, polos de comutação, enrolamento de compensação e conjunto porta escovas e escovas. O rotor é composto do enrolamento, comutador e eixo.

Seu princípio de funcionamento é baseado na circulação da corrente elétrica pelo enrolamento do rotor que está imerso em um campo magnético produzido por imãs permanentes ou bobinas de campo. A corrente sob o campo magnético, pela regra de Fleming, gera um binário de forças que produz um conjugado. Na figura 4 ilustram-se os sentidos da força, campo e corrente, juntamente com o comutador e as escovas. 
Figura 4 - Regra de Fleming

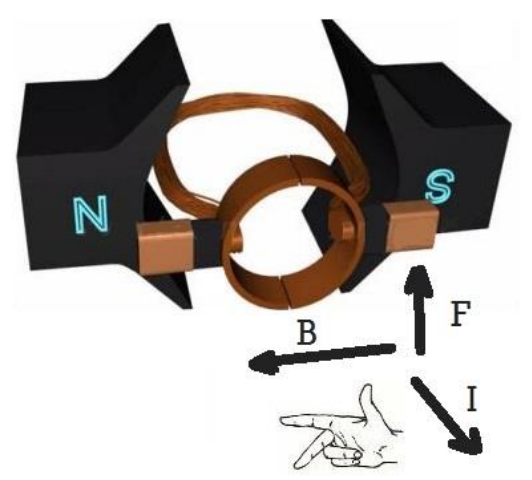

Fonte: “adaptado de” Learn engineering, 2015

A força gerada $(F)$ é proporcional à posição da armadura $(\theta)$ em relação ao fluxo magnético $(B)$, ao comprimento do fio da armadura $(l)$ e à corrente $\left(i_{a}\right)$ que por ele circula, como mostra na equação (1). Essa força multiplicada pelo raio do induzido é o torque gerado pelo motor.

$$
F=B(\theta) i_{a} l
$$

Se a corrente circula em um único sentido no circuito de armadura, a força de um quadrante se opõe a do quadrante seguinte. Devido a esse problema, utiliza-se um comutador que tem a função de inverter o sentido da corrente que circula no enrolamento para que a força gerada esteja sempre no mesmo sentido de rotação. Na figura 5 ilustra-se esse funcionamento. 
Figura 5 - Função do Comutador em um motor CC

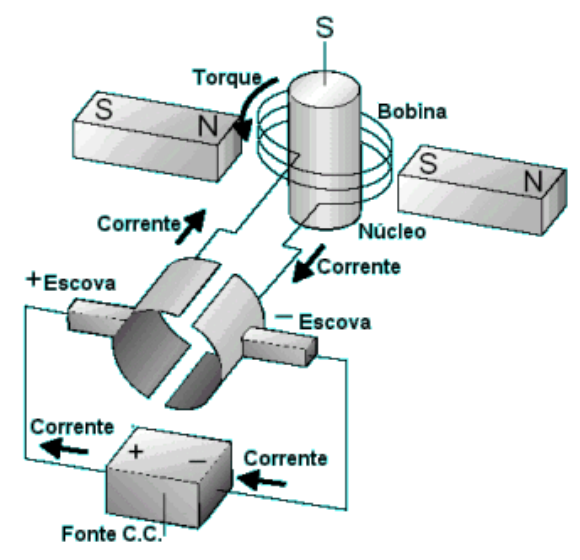

Fonte: Autor

Motor com excitação independente tem seu campo magnético gerado independente da ligação do rotor, ou seja, uma fonte alimenta o circuito do campo magnético e a outra o circuito de armadura. O campo, normalmente, possui um enrolamento com grande quantidade de espiras de fios relativamente finos, pois a corrente que circula pelo enrolamento de campo é pequena quando comparada com a corrente de armadura.

Motor de excitação em derivação, também denominado de motores Shunt, são aqueles em que o circuito de excitação está ligado em paralelo com a armadura do motor e na mesma fonte de alimentação, dessa forma o torque varia linearmente com a corrente de armadura.

Motor de excitação em série possuem o circuito de armadura ligado em série com o circuito de campo, fazendo com que a corrente que produz o campo seja a mesma que alimenta o circuito de armadura. É um motor que, para baixas velocidades, apresenta um torque muito elevado. Isso faz com que ele apresente alto torque de partida e adapte automaticamente sua velocidade às variações de carga.

Motor de excitação composta possui a soma das duas características anteriores, o alto torque de partida e com um aumento de carga, aumenta também o fluxo magnético e reduz-se a velocidade, possuindo um torque tipicamente maior do que os motores shunt.

Em motor de imãs permanentes, o campo magnético é constante devido ao imã não variar seu fluxo e, por não precisar alimentar a bobina para induzir o fluxo, esses motores consomem menos energia. 
Motores de corrente contínua também podem ser implementados sem escovas e comutadores mecânicos. Nos assim chamados motores brushless, a comutação é feita eletronicamente o que evita os faiscamentos no comutador e suas consequências, tais como geração de ruído sonoro e elétrico.

No presente trabalho, o motor CC utilizado é de imã permanente com comutador por escovas.

\subsection{CONTROLE DE IMPEDÂNCIA}

Comumente usada na área elétrica, a palavra impedância tem significado análogo em outras áreas como a mecânica e é associada a movimentos de corpos, fenômenos acústicos, transmissão de calor, etc. Em linhas gerais significa um impedimento ou oposição de um fluxo ou uma transferência de energia.

Para ilustrar o conceito de impedância mecânica, considere o sistema massa-molaamortecedor ilustrado na figura 6 , cuja massa $M$ adquire velocidade $v(t)$, sujeita à força externa $f(t)$.

Figura 6 - Sistema Massa-Mola-Amortecedor

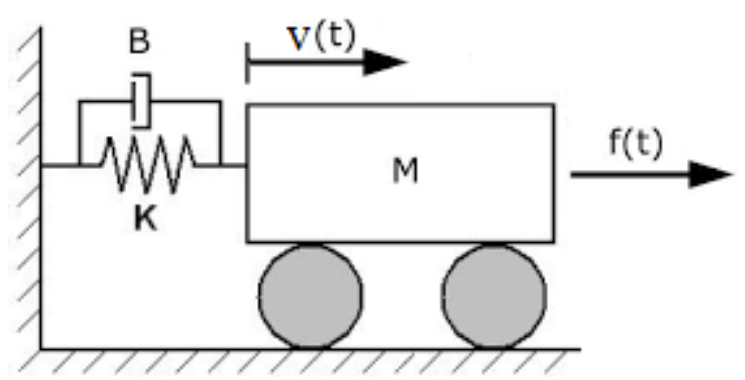

Fonte: Autor 
A equação do movimento é dada por

$$
f(t)-K \int_{0}^{t} v(t) d t-B v(t)=M \frac{d}{d t}(v(t))
$$

Para condições iniciais nulas e para os sistemas lineares, a impedância é definida por

$$
Z(s)=\frac{F(s)}{V(s)}
$$

onde $F(s)$ é a força e $V(s)$ a velocidade no domínio da frequência complexa. No caso da ilustração da figura 6 , a impedância resulta

$$
Z(s)=\left(\frac{s}{M s^{2}+B s+K}\right)^{-1}
$$

Note-se que alterar a impedância do sistema consiste em alterar as características físicas do sistema, ou seja, a massa, o atrito viscoso e a rigidez da mola. Essas alterações podem ser feitas pela troca de componentes do sistema, mas isso normalmente não é viável. A estratégia de controle de impedância faz uma alteração aparente dessas características por meio de uma força $u(t)$, extra ao sistema, normalmente produzida por um motor.

Hogan (1985) pioneiramente propôs uma maneira de se controlar sistemas que levam em consideração tanto a cinemática como as forças envolvidas, o chamado controle de impedância. Esse trabalho se diferenciou dos demais pelo fato de que as interações mecânicas entre o objeto a ser manipulado, o manipulador, e o próprio ambiente, são consideradas simultaneamente. O controle de posição, tipicamente utilizado em robôs em tarefas industriais tais como para soldagem e pintura, são suficientes para essas manobras, pois as forças de interações com o meio ambiente são normalmente desprezíveis. Porém, em certas aplicações como a montagem, por exemplo, essas forças de interação não podem ser desprezadas e controlar só a posição não garantirá que as forças de interação com o ambiente sejam consideradas. Por outro lado, só o controle de força não garante que a trajetória seja executada. Hogan (1985) propõe então controlar, para cada grau de liberdade de um sistema, a 
relação dinâmica entre velocidade e força, a chamada Admitância do sistema, ou o seu recíproco, ou seja, a relação dinâmica entre força e velocidade do movimento, a chamada Impedância do sistema.

Os sistemas a serem controlados, em sua maior parte, são sistemas não lineares, o que torna desafiador o projeto do controlador. Para que essa situação seja contornada, em boa parte dos casos, se opta por fazer uma linearização em torno de um determinado ponto de operação, essa linearização é feita através do método de truncamento da série de Taylor. Porém, essa aproximação deixa de ser representativa, quando o sistema estiver em um outro ponto de operação.

Para contornar o problema da validade do modelo linear fora da vizinhança do ponto de operação onde o modelo foi obtido, Slotine e Li (1991) apresentaram uma forma de se obter um modelo linear a partir de um sistema não linear, o chamado método de linearização por realimentação não linear, de tal forma que o modelo seja válido em todos os pontos de operação do sistema e não somente nas vizinhanças do ponto de linearização. Slotine e Li (1991) consideraram um sistema não linear dinâmico, função da variável de estrado $(x)$ e da entrada $(u)$, tal que

$$
\dot{x}=f(x, u)
$$

Para a linearização desse sistema, eles usaram uma transformação de estado

$$
z=z(x)
$$

e uma transformação de entrada

$$
u=u(x, v)
$$

de modo que o sistema não linear seja transformado em um sistema equivalente linear e invariante no tempo

$$
\dot{z}=A z+b v
$$

A ideia por trás do método da linearização por realimentação também se aplica a sistemas lineares com a finalidade de se impor as características do modelo linear (model matching). De acordo com Leonardi (2002), existem duas formas de tratar o problema de model matching, o denominado de aproximado, onde se minimiza o erro da diferença entre a resposta do modelo de referência e do sistema a ser controlado, e o model matching exato, o 
qual será usado neste trabalho, neste último, a função de transferência do sistema em malha fechada se torne idêntica à matriz de referência, desconsiderando erros de modelagem.

Uma forma de se fazer isso é por meio da realimentação de estados de tal forma que o modelo da planta no espaço de estados seja alterado para a representação de um modelo de referência pré-estabelecido. Como ilustração, considere um modelo de referência na forma de um duplo integrador, semelhante ao modelo buscado com a aplicação da técnica de controle de torque calculado. Faz-se então uma realimentação direta de estados de tal forma que a nova equação de estado seja a de um duplo integrador. Contudo, note-se que a lei de controle é dependente do modelo da planta, o que pode implicar numa baixa robustez do sistema em face a erros de modelagem. A figura 7 ilustra essa estratégia onde a realimentação em torno do robô impõe a alteração do modelo para que ele resulte igual ao duplo integrador. Os demais blocos do sistema são responsáveis por impor a impedância desejada, que é caracterizada pelas matrizes $\mathrm{K}_{\mathrm{d}}$, $\mathrm{B}_{\mathrm{d}}$, e $\mathrm{M}_{\mathrm{d}}$ (IBARRA e SIQUEIRA, 2014).

Figura 7-Diagrama de blocos com controle da impedância em um robô.

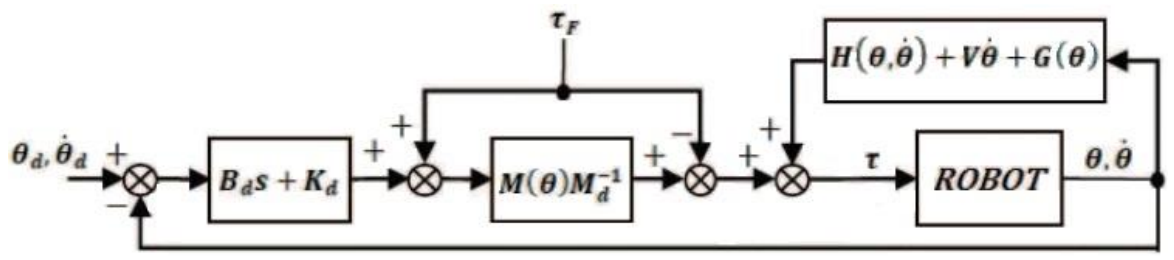

Fonte: "adaptado de" Impedance Control of rehabilitation robots for lower limbs , 2014

Embora o objetivo principal do controle de impedância seja garantir a relação dinâmica entre a força externa e a cinemática do movimento, que na ilustração são dados por $\tau_{\mathrm{F}}$ e $\theta$, pode-se adicionar uma referência cinemática $\theta_{\mathrm{d}}$ (vide figura 7 ), tal que o movimento possa também ser definido. Note, contudo, que os elementos no ramo direto não são controladores propriamente ditos, no sentido que não foram escolhidos de forma a minimizar o erro cinemático e, portanto, o acompanhamento preciso da trajetória pode não ocorrer.

O projeto do controlador proposto nesta pesquisa tem as características análogas a um model matching por realimentação dos estados, embora uma das variáveis realimentadas não possa ser caracterizada como um estado. A realimentação de estados será usada para alterar a massa aparente e o atrito viscoso aparente do sistema, alterando a impedância mecânica do 
sistema. Adicionalmente, será feita uma compensação de parte do atrito de Coulomb pela adição de uma força constante à lei de controle.

Na técnica de casamento por realimentação, ou método direto, a lei de controle não é baseada no erro de casamento do modelo. Entretanto, pode-se formular um problema de controle baseado na tentativa de redução do erro de casamento, ou método indireto.

O método indireto de casamento vem sendo usado em várias aplicações, podendo ser com controle interno de força ou com controle interno de cinemática. Um exemplo são os braços robóticos que fazem movimentação e acoplamento de peças. Essa aplicação é desafiadora, pois o robô precisa realizar uma tarefa com especificações sobre a cinemática do movimento e também em relação ao esforço de acoplamento das peças. Quando as tarefas do robô são de contato, costuma existir uma instabilidade quanto às colisões ou sensibilidades táteis, principalmente quando o modelo do ambiente não está bem detalhado. Em alguns casos, são adotadas estratégias que permutam a lei de controle, mas conforme afirmaram Okamura et al. (2000), com essa troca de controle, é necessário prever a perda de contato e também considerar algumas características dinâmicas que, dependendo do sistema, a demanda do tempo de resposta pode ser significativa. Pedro et al. (2013) estudaram o desempenho do controle de impedância pelo método indireto usando um controle interno de posição, em robôs industriais. Dessa forma, com a implementação do controle de impedância, fizeram o estabelecimento de contato com um pequeno tempo de resposta, sem oscilações e com pequenos sobressinais.

Ibarra e Siqueira (2014) discutiram estratégias de controle de impedância aplicadas a um sistema de reabilitação robô-paciente cujo modelo é de um sistema mecânico multicorpos conectados por juntas. O objetivo é a alteração da inércia aparente e do atrito viscoso aparente, para que o paciente recupere seus movimentos através de exercícios, ou seja, auxiliado por aparelhos para realizar os movimentos dos membros inferiores que tenham mobilidade reduzida. Discutem-se as formas de se implementar o controle de impedância por meio de controladores de força e de controladores de cinemática conectados pelo modelo da impedância ou da admitância desejada, onde os torques envolvidos são aqueles aplicados pelo motor e o torque externo, aplicado pelo paciente.

Aplicações de controle de impedância são atualmente encontradas em várias áreas, desde as industriais até as áreas militares. Como exemplo da área automobilística, Silva (2013) aplicou o controle de impedância em uma suspensão ativa na forma de um emulador 
de diferentes componentes de força da suspenção, ou seja, as molas e os amortecedores. Nos dias atuais, a determinação do coeficiente de dissipação de energia dos amortecedores, ainda é empregado de forma empírica, ou seja, os testes ainda são feitos substituindo um a um os amortecedores em projeto e determinando um que se adeque ao projeto desejado. Luna (2013) apresentou duas estratégias de controle para um quarto de carro, sendo uma delas inspirado no controle por torque calculado. Dessa forma, ele variou os coeficientes de rigidez e de amortecimento de um sistema equivalente acoplado ao dispositivo de simulação, alterando assim a impedância do sistema e analisando o comportamento da massa suspensa e não suspensa do conjunto estudado, obtendo resultados satisfatórios, sem ser necessário a substituição física dos componentes.

$\mathrm{Na}$ área militar, o controle de impedância foi utilizado para a movimentação de veículos miliares em terrenos acidentados para diminuir a lentidão de movimentação e as colisões entre os veículos. Com esta motivação, Yi e Chong (2004) estudaram a aplicação de um controle de impedância para controle da distância e da velocidade relativa entre carros a fim de evitar engarrafamentos e manter um fluxo constante de veículos. Nessa aplicação, o sistema controla a relação entre a velocidade e posicionamento dos veículos em relação ao torque produzido por cada viatura. O primeiro carro da fila (principal) impõe o fluxo dos demais que pode variar de acordo com as condições do terreno, de tal forma que sua velocidade permite determinar a distância relativa e velocidade dos demais. Os autores propuseram um método robusto às incertezas do modelo e aos ruídos de medida. As incertezas do modelo estão relacionadas com a variação do posicionamento em função dos ângulos entre os carros no percurso. Foi proposto então um controle de impedância do tipo mola-amortecedor entre os veículos, tendo como referência a impedância do veículo principal.

No trabalho de Farivarnejad e Moosavian (2014) estuda-se um caso de implementação de um controle múltiplo de impedância (MIC) para um veículo subaquático que foi desenvolvido para realizar reparos e montagem. Para cada montagem deve haver um reconhecimento do ambiente e um controle da interação ambiente/robô e robô/peça. O autor argumenta que, nesse cenário, um simples controle de impedância não é suficiente e, para contornar os problemas, utilizou-se um MIC que permitiu que o veículo executasse as tarefas de montagem ou reparação com a mínima colisão possível entre o robô e as peças, sem perder contato com o ambiente que, até certo ponto, é desconhecido devido ao ambiente subaquático. 
$\mathrm{Na}$ área da saúde também se utiliza o controle de impedância em diversas situações, aliás, o ser Humano já nasce com diversos sistemas de controle que estão associados aos movimentos dos músculos, à manutenção da temperatura corpórea, e diversos outros. Porém, alguns indivíduos perdem ou mesmo já nascem sem a capacidade de controlar alguns desses sistemas, e é esse um ponto que a ciência vem estudando para propor formas de recuperar ou substituir esses controles. Jardim, Martins e Siqueira (2009), implementaram um controle de impedância em uma órtese tornozelo-pé. O projeto consiste de um atuador elástico em série, conforme ilustração da figura 8, e foi modelado como um sistema massa-mola-amortecedor, usando a posição como variável controlada na realimentação interna. Nos experimentos, uma força oscilatória foi aplicada e investigaram-se os efeitos das variações na rigidez aparente e no atrito viscoso aparente impostos pelo controle de impedância.

Figura 8 - Controle de Impedância aplicado em uma Órtese

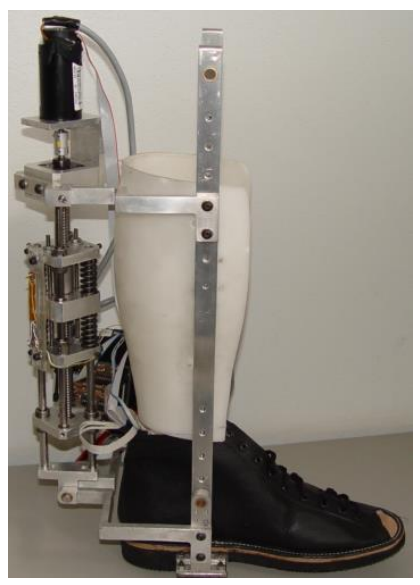

Fonte: "adaptado de" Controle de Impedância aplicado a uma Órtese tornozelo-pé

Estudo semelhante a esse foi feito por Mehling e O'Malley (2014), que propuseram o uso de uma estrutura de controle do tipo model matching como forma de obter o controle de impedância para sistemas com atuadores elásticos em série e utilizaram a técnica $\mathrm{H}_{\infty}$ para projeto do controle de impedância. 


\subsection{MODELAGEM DE SISTEMAS ELETROMECÂNICOS}

O motor é um componente eletromecânico que converte energia elétrica em energia mecânica. Nise (2007) detalha o modelamento desse sistema. Na Figura 9 mostra-se um esquema de um motor CC com uma redução de 1:9.

Figura 9- Esquema de um Motor de corrente contínua com redução

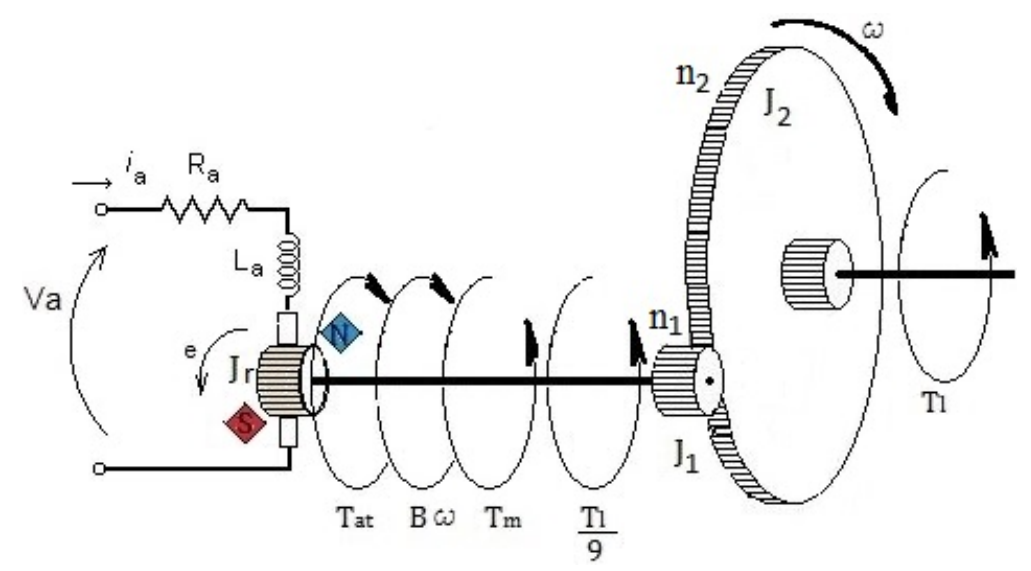

Fonte: Autor

Aplicando-se a lei de Kirchhoff ao circuito de armadura, obtém-se

$$
V_{a}(t)=R_{a} i_{a}(t)+L_{a} \frac{d i_{a}(t)}{d t}+e(t)
$$

E, pela lei de indução de Faraday, pode-se escrever que

$$
e(t)=K_{e} \omega(t)
$$

Onde,

$V_{a}=V_{a}(t)$ é a tensão de armadura [V],

$R_{a}$ é a resistência de armadura $[\Omega]$,

$L_{a}$ é a indutância de armadura $[\mathrm{H}]$,

$i_{a}=i_{a}(t)$ é a corrente de armadura [A], 
$e=e(t)$ é a força contra eletromotriz, e

$\omega=\omega(t)$ é a velocidade angular $[\mathrm{rad} / \mathrm{s}]$.

Como usual em muitas aplicações, consideraremos que a indutância de armadura $L_{a}$ é muito pequena. Portanto, reescrevendo a equação (9) e substituindo pela equação (10), temos

$$
V_{a}(t)=R_{a} i_{a}(t)+K_{e} \omega(t) .
$$

Como o motor considerado é de imã permanente, o fluxo magnético é constante. Logo, o torque produzido pelo motor é proporcional à corrente de armadura, ou seja,

$$
T_{m}(t)=\frac{K_{m}}{R_{a}}\left(V_{a}(t)-K_{m} \omega(t)\right)
$$

onde, $T_{m}$ é o torque produzido pelo motor, $K_{m}$ é a constante de proporcionalidade de torque do motor, numericamente igual a $K_{e}$, que é a proporcionalidade da força contra eletromotriz, determinado pela lei de Lenz.

O movimento do rotor pode ser caracterizado pela aplicação do Teorema do Momento Angular (TMA).

$$
\begin{gathered}
T_{m}(t)-B \omega(t)+\frac{T_{l}}{9}(t)-T_{a t}(t)=J \dot{\omega}(t) \\
J r+J_{1}+J_{2}\left(\frac{n_{1}}{n_{2}}\right)^{2}=J
\end{gathered}
$$

onde $B$ é o coeficiente de atrito viscoso $[\mathrm{Ns} / \mathrm{rad}], \frac{T_{l}}{9}$ é o torque de carga refletido ao eixo do motor por meio da redução $[N . m], T_{a t}$ é o torque de atrito de Coulomb $[N . m]$, o $J$ é a somatória dos momentos de inércia do sistema refletido no eixo do rotor $\left[\mathrm{kgm}^{2}\right]$, e $\dot{\omega}$ é a aceleração angular $\left[\mathrm{rad} / \mathrm{s}^{2}\right]$.

O modelo do motor CC de imã permanente com o redutor, dado pelas equações (9) a (14) pode ser equivalentemente representado pelo diagrama de blocos da Figura 10. 
Figura 10 - Diagrama de blocos de um motor CC com redução

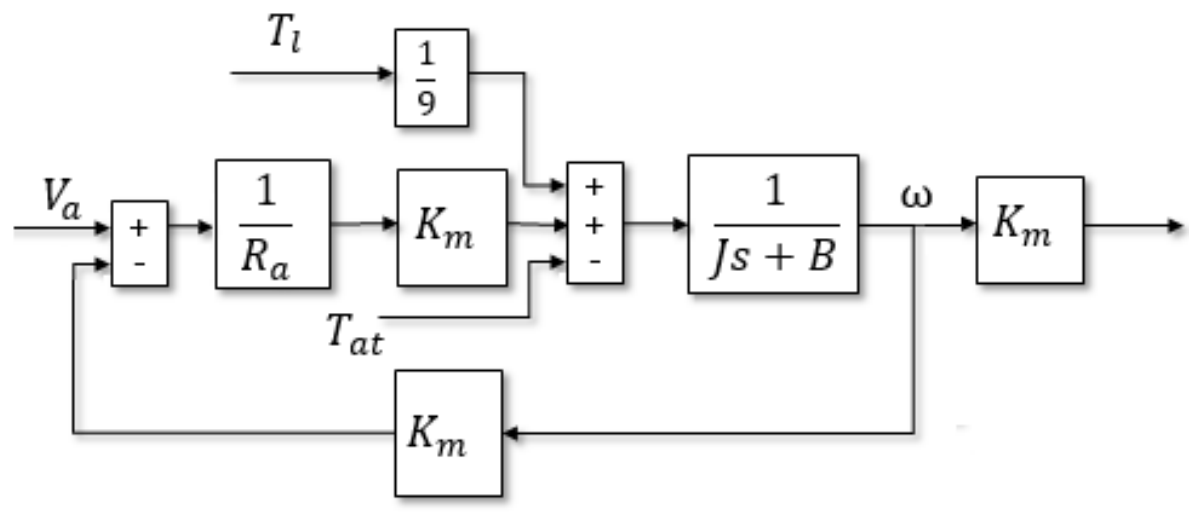

Fonte: Autor

Note-se no diagrama de blocos da Figura 10 que a força contra eletromotriz aparece na forma de uma realimentação, cujo efeito é análogo a um atrito viscoso.

Esse diagrama pode ser representado na forma equivalente da figura 11 onde os torques externos aparecem refletidos à entrada. Essa representação é conveniente pois mostra que existem tensões equivalentes aos torques externos.

Figura 11 - Diagrama de Blocos com torques refletidos à entrada.

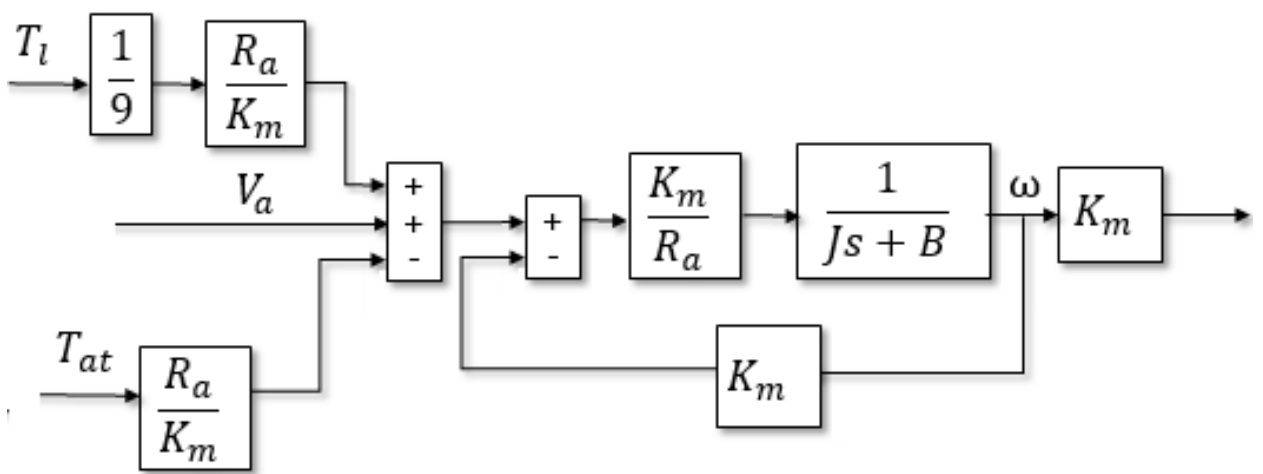

Fonte: Autor 


\section{MATERIAIS E MÉTODOS}

Nesse capítulo são descritos os materiais utilizados no experimento e a metodologia proposta.

\subsection{MATERIAIS}

O Centro Universitário FEI possui um setor de suprimentos de onde é feita toda a distribuição de produtos e insumos para suas diversas unidades. Devido à grande dimensão do Campus, os diferentes níveis topográficos e as diversas inclinações do piso, a distribuição de produtos pode ser uma tarefa difícil em função do peso e do volume da carga a ser transportada. Por questões de ergonomia, o que antes era distribuído por um veículo de transporte com propulsão humana passou a ser distribuído com um veículo de propulsão elétrica, guiado pelo usuário. Essa solução foi aperfeiçoada com a inclusão de um controlador em malha aberta que permite alterar a velocidade do veículo e, portanto, aumentar a duração da carga da bateria, duração essa que limitava as tarefas de distribuição. Na foto da Figura 12 mostra-se o veículo de distribuição onde se pode observar o motor elétrico e as proteções laterais que podem ser abertas para carga e descarga. O veículo foi projetado para uma movimentação de cargas até $200 \mathrm{~kg}$, sendo essa limitação principalmente função do que o operador consegue conduzir com a assistência.

Figura 12 - Veículo utilizado no setor de suprimentos

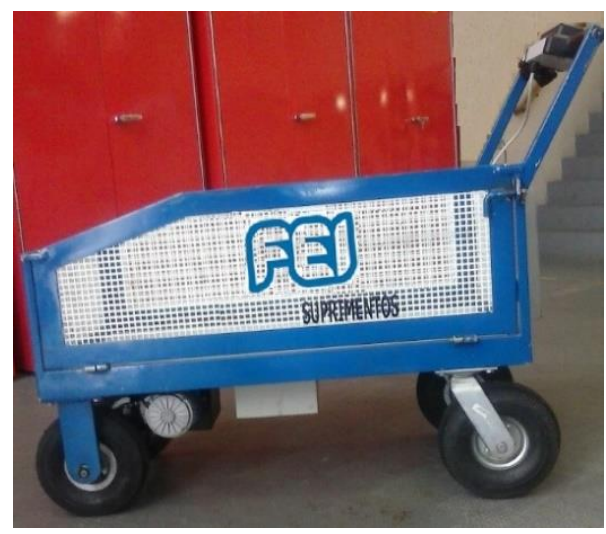

Fonte: Autor 
A presente pesquisa propõe a análise, o projeto e a aplicação de um controle de assistência à movimentação de cargas do Centro Universitário FEI por meio de um controle de impedância mecânica de tal forma que possa auxiliar o funcionário a movimentar o sistema de uma maneira mais automatizada, confortável e segura do que o sistema atual. Para tanto, como bancada de testes, foi utilizado um sistema didático da LJ Technical Systems que reproduz parcialmente as características do veículo de distribuição de carga.

O sistema LJ consiste de um motor de corrente contínua acoplado no mesmo eixo de um tacogerador, e esses, por meio de uma redução estão acoplados a um eixo instrumentado com sensores de deformações utilizado como sensor de torque, que servirá para validar o controle proposto. Na Figura 13, mostram-se detalhes do motor elétrico e do tacogerador.

Figura 13 - Motor corrente contínua e Tacogerador

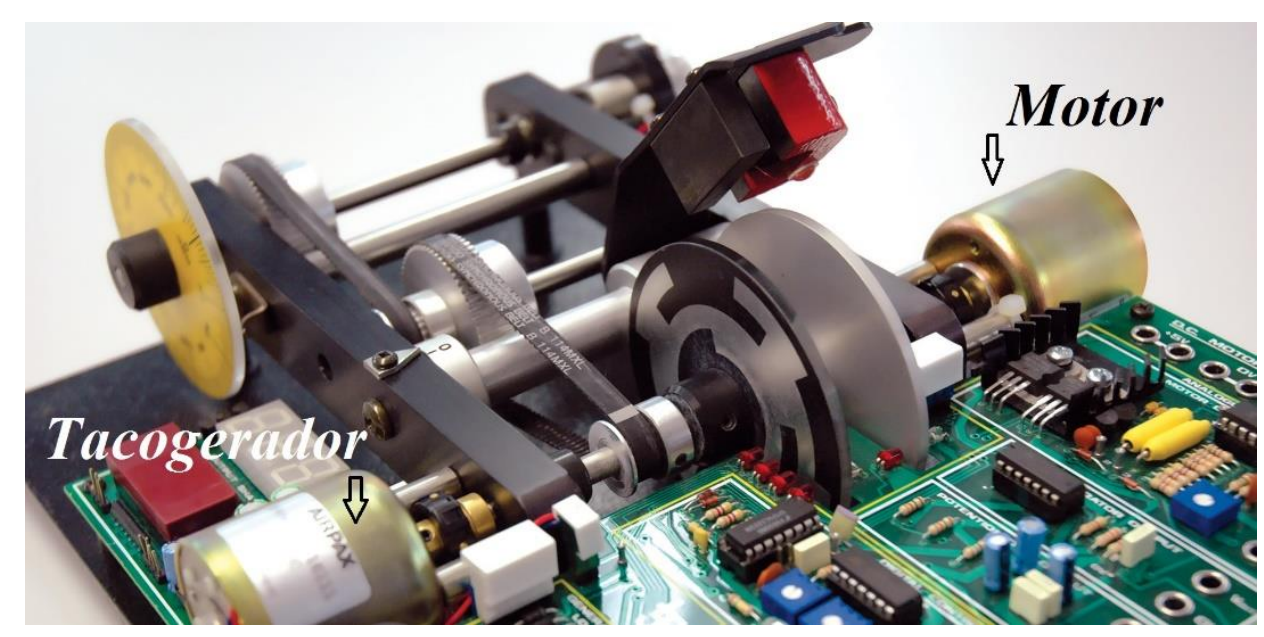

Fonte: Autor

$\mathrm{Na}$ foto da Figura 14, é possível se identificar o driver de potência com seus transistores em arranjo push-pull e os bornes de ligações 
Figura 14 - Drives de Potência

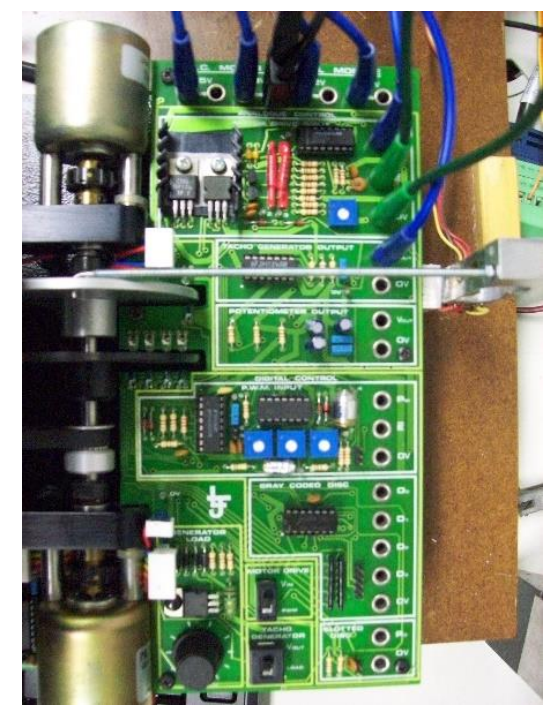

Fonte: Autor

$\mathrm{Na}$ figura 15, mostram-se os detalhes das reduções mecânicas. Com o número de dentes das engrenagens se obtém a relação de redução 1:9.

Figura 15 - Reduções Mecânicas 1:9

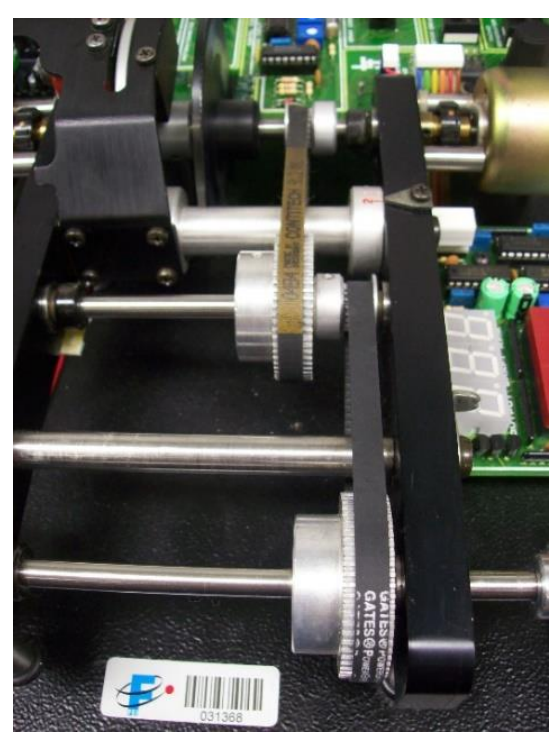

Fonte: Autor 
O motor CC é de imã permanente fixo à carcaça e envolvendo todo o rotor. De modo semelhante ao veículo transportador de cargas, o eixo do motor da bancada movimenta a carga por meio de duas reduções por correias dentadas resultando numa redução de 1:9.

Para medição da força que o operador aplica ao sistema, foi desenvolvida uma célula de carga instalada numa haste que está acoplado ao eixo movido, conforme ilustrado na figura 17. O sinal da célula de carga é condicionado pelo amplificador analógico RM 4220 da HBM onde a faixa de medição está selecionada para $\pm 10 \mathrm{~V}$ e a ligação da célula de carga está selecionada para 4 vias, embora seja possível configurá-lo de outras formas, tais como medição de 0 a $10 \mathrm{~V}$ e esquema de ligação da célula de carga para 6 vias, ligação essa usada quando é necessário compensar o efeito de dilatação do material da célula de carga em relação ao ambiente.

Esse amplificador RM4220 possui sua carcaça em poliamida que pode ser facilmente montada sobre um suporte padronizado. A conexão elétrica é efetuada por meio de encaixe em terminais, podendo ser conectado em transdutores strain gage individuais ou vários em paralelo e sua alimentação é de 18 a 24 V. A foto da Figura 16 ilustra alguns detalhes do amplificador.

Figura 16 - Amplificador HBM RM4220

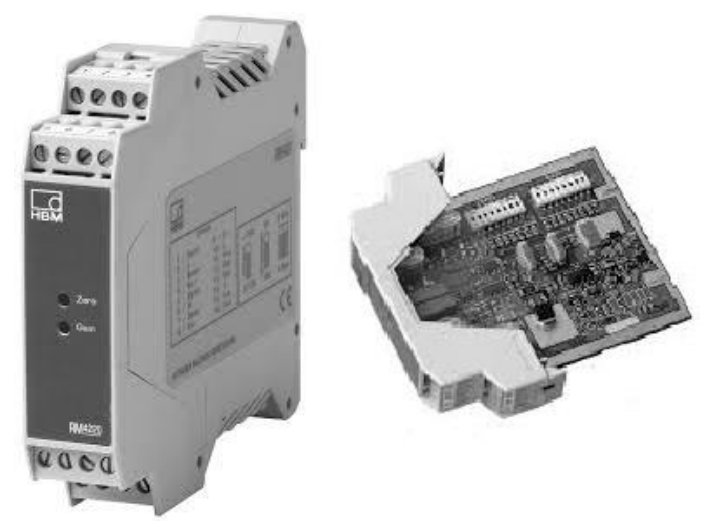

Fonte: HBM,2015 
$\mathrm{Na}$ foto da figura 17, mostram-se o eixo, a manivela e os strain-gauge que realizam a função de célula de carga, a qual servirá para medir o torque produzido pelo usuário. De fato, a estratégia de controle de impedância proposta não requer a medida de força, mas ele é utilizado no processo de validação do controlador de impedância.

Figura 17 - Célula de Carga

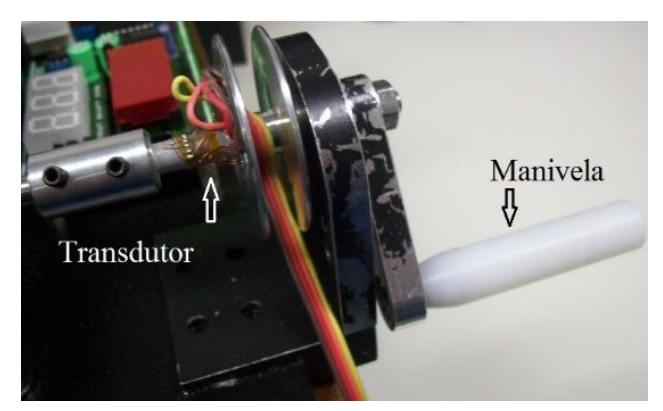

Fonte: Autor

Por analogia, admite-se que o torque aplicado no eixo pode representar a força que é aplicada no veículo transportador de cargas pelo operador. O sinal da célula de carga, devido a pequenas deformações no eixo, requer a amplificação do sinal analógico pelo transmissor RM 4220 da HBM que é enviado ao Simulink por meio da placa de aquisição de dados NI6221 da National Instruments e do toolbox Real Time Windows Target do Matlab, onde esse sinal será usado para a validação da alteração de impedância imposta pelo controlador.

Para a medição da velocidade no eixo da carga, utiliza-se um tacogerador analógico de mesma especificação do motor do sistema. Esse sinal de velocidade também é enviado ao Simulink para a síntese da lei de controle de impedância. Essa lei de controle também usa a informação de aceleração, mas esse sinal não é medido diretamente com um sensor e deverá ser estimado por meio de diferenciação do sinal da velocidade em relação ao tempo.

Uma foto de todo o conjunto eletromecânico é mostrada na Figura 18. Nessa figura, é possível identificar no lado direito da foto uma outra célula de carga instalada no sistema LJ, célula essa usada para se determinar a constante de torque do motor. Isso é conseguido pela aplicação de uma tensão constante de armadura com seu eixo bloqueado, ou seja, sem movimento. 
Figura 18 - Bancada de teste

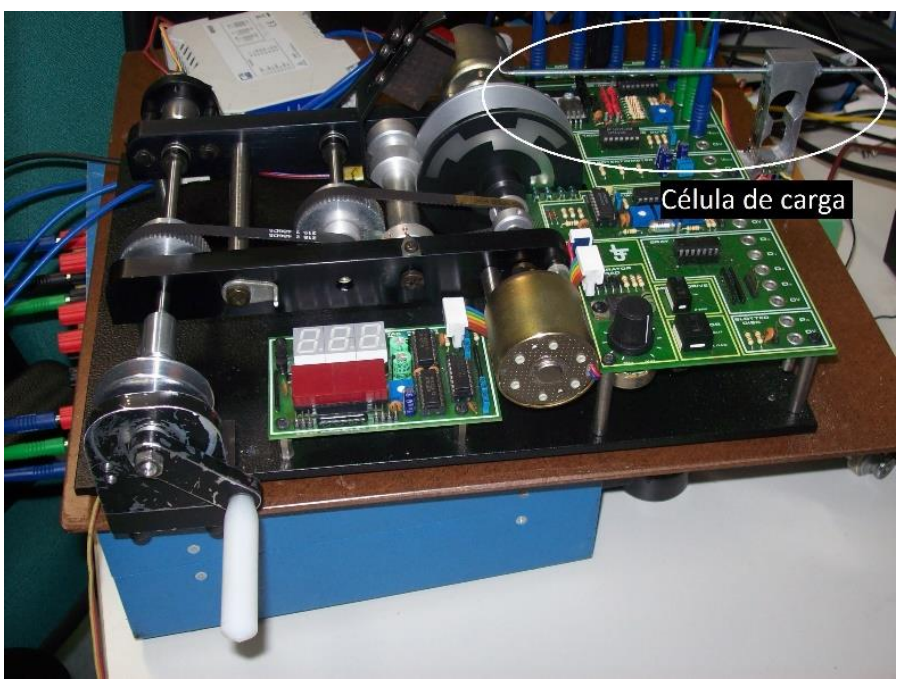

Fonte: Autor

\subsection{MÉTODOS}

A hipótese a ser investigada nesta pesquisa é a de que alterações aparentes na massa, no atrito viscoso e no atrito de Coulomb do sistema, implica numa assistência mais adequada ao operador de um sistema de movimentação de cargas quando comparada com outras formas de assistência, em especial quando comparada à forma usual de assistência baseada na aplicação de uma força complementar constante.

Seja um sistema eletromecânico constituído de motor de corrente contínua com imã permanente e indutância de armadura desprezível, seu modelo linear pode ser representado pelo diagrama de blocos da Figura 19, onde $V_{\mathrm{a}}$ é a tensão de armadura, $T_{l}$ é o torque de carga, $i=1 / 9$ é a relação de transmissão e $\omega$ é a velocidade angular do rotor, e, pelo fato de o motor e o tacogerador serem iguais, utiliza-se o mesmo valor numérico da constante de força contra eletromotriz $\mathrm{K}_{\mathrm{m}}$. 
Figura 19- Diagrama de blocos associado ao modelo do sistema LJ

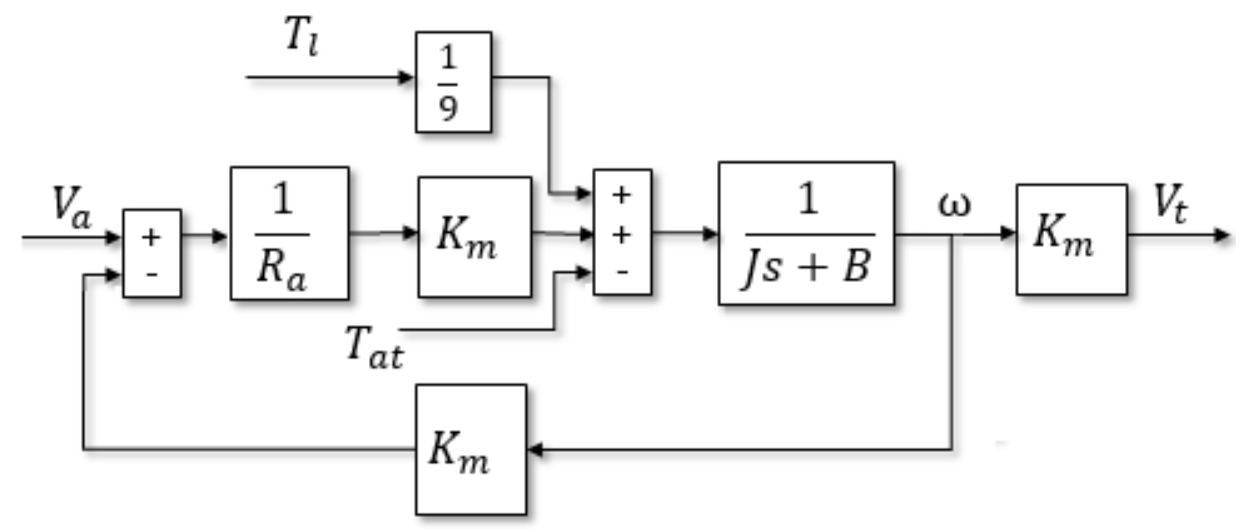

Fonte: Autor

Do diagrama da Figura 19 é imediato escrever que

$$
J \dot{\omega}(t)+B \omega(t)=-\frac{K_{m}^{2}}{R_{a}} \omega(t)+T_{l}(t) i-T_{a t}+\frac{K_{m}}{R_{a}} V_{a}(t)
$$

Isolando $\dot{\omega}$, para $i=\frac{1}{9}$, tem-se:

$$
\dot{\omega}=\frac{K_{m}}{J R_{a}} V_{a}(t)-\frac{T_{a t}}{J}+\frac{T_{l}(t)}{9 J}-\left(\frac{K_{m}^{2}+B R_{a}}{J R_{a}}\right) \omega(t)
$$

Por simplicidade de notação e para fins de identificação experimental de parâmetros, adotam-se as seguintes definições

$$
\begin{gathered}
\frac{K_{m}}{J R_{a}}=k, \\
\frac{R_{a}}{K_{m}} T_{a t}=\eta, \\
\left(\frac{K_{m}^{2}}{J R_{a}}+\frac{B}{J}\right)=\lambda \\
\frac{R_{a}}{9 K_{m}}=\alpha,
\end{gathered}
$$


Reescrevendo a equação (16) com base nas definições, temos

$$
k\left(V_{a}+T_{l} \alpha-\eta\right)-\lambda \omega(t)=\dot{\omega}(t)
$$

Admita-se que o modelo da equação (21) é adequado para representar com boa aproximação a dinâmica do veículo de movimentação de cargas. O diagrama de blocos associado a essa equação é representado na figura 20.

Figura 20- Diagrama de blocos simplificado

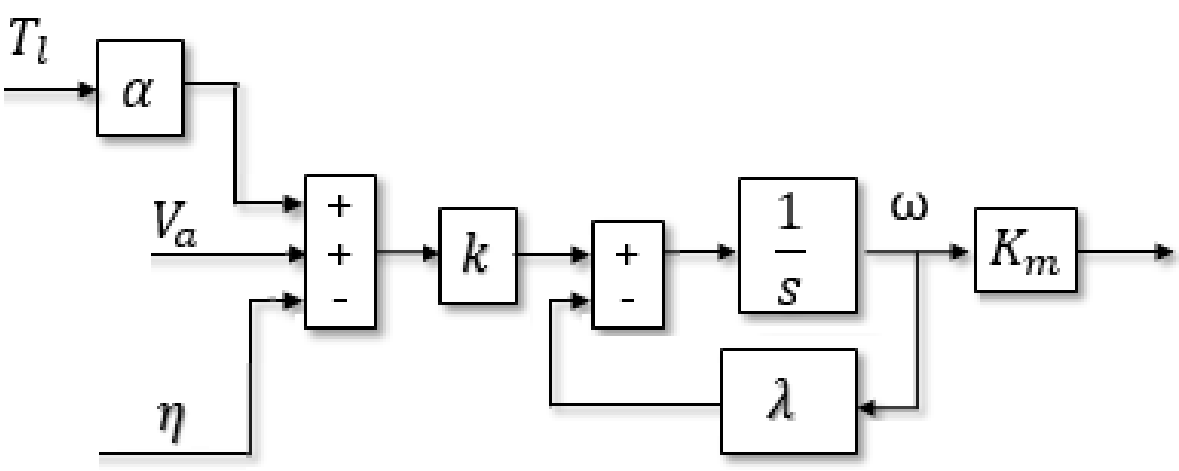

Fonte: Autor

Ao menos três estratégias de controle podem ser consideradas na assistência de movimentação de cargas.

Uma primeira estratégia é aquela que não requer o uso de sensores, seja de força ou da cinemática do movimento. O diagrama de blocos da Figura 21 ilustra essa estratégia onde a função sinal da esquerda é usada para indicar que houve contato do operador com o transportador e que, portanto, a assistência deve ser acionada. Na prática o acionamento da assistência pode ser feito por uma chave tipo "on-off”. O valor do ganho $\delta$ é ajustável e representa o nível de assistência que o operador deseja. 
Figura 21- Diagrama de blocos (estratégia 1)

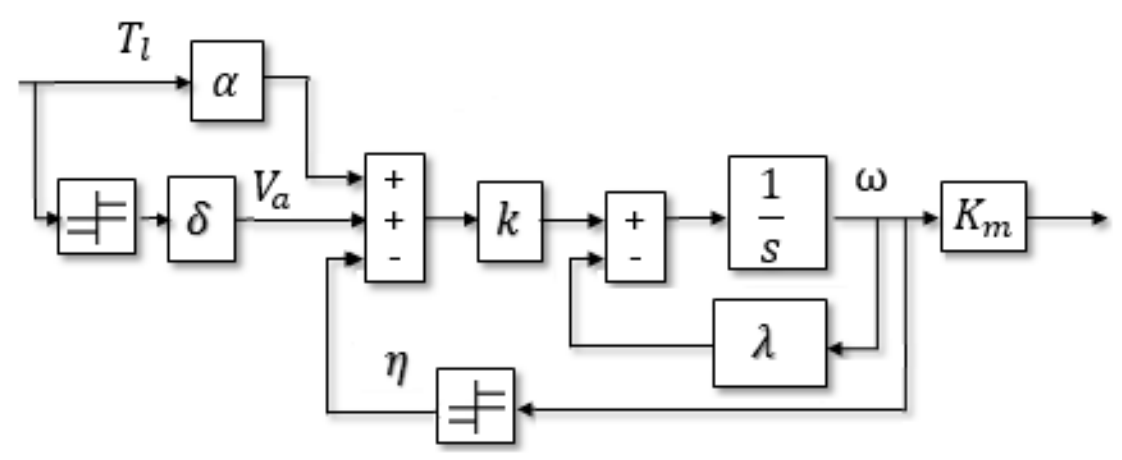

Fonte:Autor

A lei de controle da estratégia 1 é dada por

$$
V_{a}(s)=\operatorname{sgn}\left(T_{l}\right) \delta,
$$

e o sistema passa a ser descrito por

$$
\left(T_{l} \alpha+\operatorname{sign}\left(T_{l}\right) \delta-\eta \operatorname{sign}(\omega)\right) k=\dot{\omega}(t)+\lambda \omega(t) .
$$

O sistema fica sujeito ao torque que o operador aplica, mais um torque constante. Com esse tipo de estratégia costuma-se escolher um valor alto para $\delta$ de tal forma que o operador faça apenas pequenos ajustes na condução do sistema. Nesse cenário, o operador faz um esforço mínimo, porém perde a sensibilidade da movimentação.

Ao analisar (23), percebe-se que, em regime permanente, o valor de $\delta$ tem influência justamente na amplitude da velocidade de regime permanente. Entretanto, como a assistência é na forma de uma força externa que independe da cinemática do movimento, a impedância aparente do sistema não é alterada.

A segunda estratégia considerada requer um sensor da força aplicada pelo operador, pois a estratégia é baseada na amplificação da força que ele aplicada. No diagrama da Figura 22 ilustra-se essa estratégia onde $\beta$ é um ganho positivo e ajustável. 
Figura 22 - Diagrama de blocos (estratégia 2)

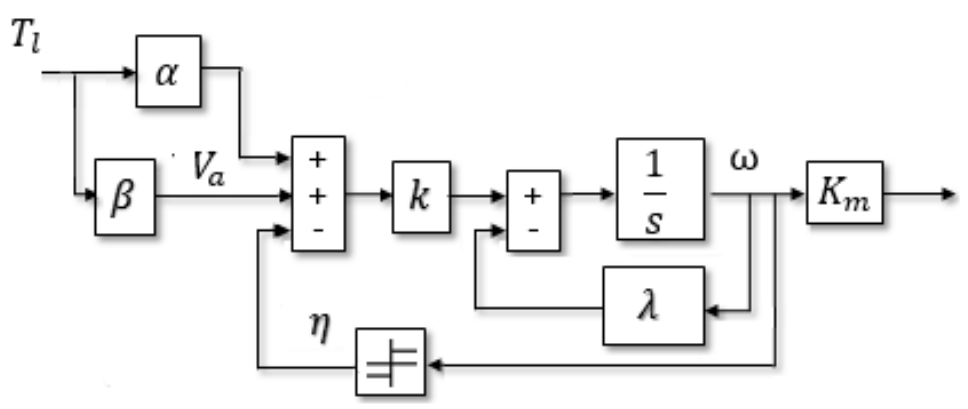

Fonte: Autor

A lei de controle dessa segunda estratégia é dada por

$$
V_{a}(t)=\beta T_{l}(t)
$$

e o sistema passa a ser descrito por

$$
\left(T_{l} \alpha+\beta T_{l}(t)-\eta \operatorname{sign}(\omega)\right) k=\dot{\omega}(t)+\lambda \omega(t)
$$

Essa segunda estratégia de assistência é mais elaborada, pois permite a alteração da impedância aparente do sistema. Entretanto, tanto o momento de inércia como o coeficiente de amortecimento são alterados na mesma razão, implicando que a constante de tempo não possa ser alterada. Ou seja, a característica dinâmica do sistema, de fato, não é alterada, mas somente seu ganho.

A terceira estratégia, que é aquela proposta neste trabalho, permite fazer a alteração aparente da inércia, do atrito viscoso e do atrito de Coulomb do sistema, todos de forma independente. Esta estratégia é baseada num controle de impedância por casamento direto por meio da realimentação das variáveis cinemáticas. A equação 21 pode ser escrita evidenciando-se a inércia

$$
J k *\left(V_{a}+T_{l} \alpha-\eta\right)-J \lambda \omega(t)=J \dot{\omega}(t)
$$


que resulta em

$$
\frac{k_{m}}{R_{a}}\left(V_{a}+T_{l} \alpha-\eta\right)-C \omega(t)=J \dot{\omega}(t)
$$

em que $C=J \lambda$ é coeficiente global de atrito viscoso e $J$ é o momento de inércia do sistema.

No controle de impedância, a tensão de armadura $V_{a}$ é utilizada para transformar o modelo (27) no sistema descrito por

$$
\left(J-J_{1}\right) \dot{\omega}(t)+\left(C-C_{1}\right) \omega(t)=\frac{k_{m}}{R_{a}}\left(T_{l} \alpha-\left(\eta-\eta_{1}\right)\right)
$$

em que $J_{1}, C_{1}, \eta_{1}$ representam as alterações de momento de inércia, do coeficiente de atrito viscoso e do atrito de Coulomb, respectivamente.

A lei de controle que leva (27) para (28) é dada por

$$
V_{a}(t)=\frac{R_{a}}{k_{m}}\left(J_{1} \dot{\omega}(t)+C_{1} \omega(t)+\frac{k_{m}}{R_{a}} \eta_{1}\right)
$$

Ou seja, o operador, ao aplicar uma força, percebe o momento de inércia aparente $\left(J-J_{1}\right)$, o coeficiente de atrito viscoso aparente $\left(C-C_{1}\right)$, e o atrito de Coulomb aparente $\left(\eta-\eta_{1}\right)$.

Note-se que a lei de controle (29) requer a informação instantânea da velocidade angular $\omega(t)$ e da aceleração angular $\dot{\omega}(t)$.

Para se analisar o sistema por meio simulação numérica se faz necessário identificar seus parâmetros, ou seja, a constante do motor $\left(K_{m}\right)$, o momento de inércia $(J)$, o atrito viscoso aparente $(\lambda)$ e o atrito de Coulomb do sistema $\eta$

Utilizando (21) e num experimento sem torque externo, pode-se determinar a constante de tempo $\tau=1 / \lambda$ a partir da resposta do sistema a uma excitação tipo degrau. 
A figura 23 mostra o diagrama de blocos do Simulink utilizado para a obtenção da constante de tempo. O bloco Analog Output (AO) envia a tensão do Simulink para a tensão de entrada $V_{a}$ do sistema LJ. O bloco Analog Input (AI) recebe a tensão $V_{\text {taco }}$ do sensor de velocidade do LJ.

Figura 23 -Diagrama de blocos para identificação dos parâmetros $\lambda, k e \eta$.

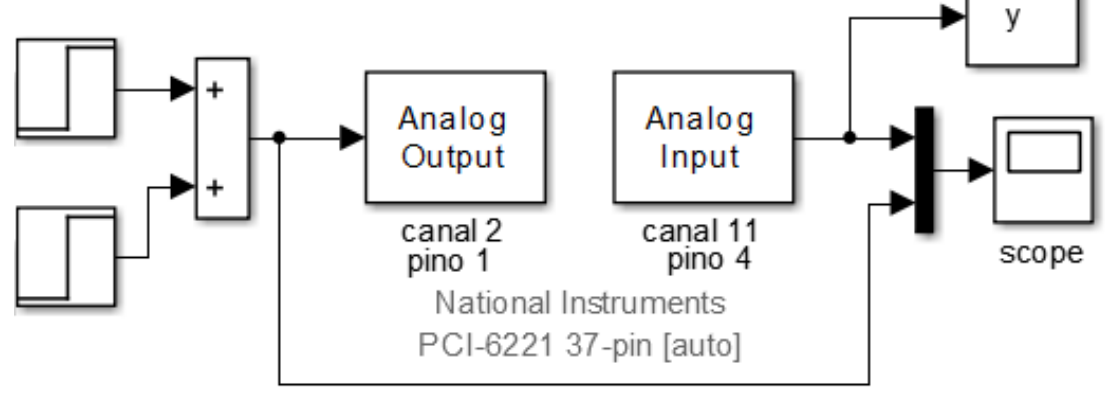

Fonte: Autor

Foram impostas duas tensões constantes em instantes diferentes e medida a resposta transitória da velocidade $\omega$. Pelo gráfico gerado, pode-se determinar o valor correspondente a $63 \%$ da velocidade de regime e o corresponde tempo decorrido desde a aplicação do sinal tipo degrau. Essa duração é a constante de tempo $\tau=1 / \lambda$.

Com o sistema em regime e sem o torque externo, a equação (21) resulta

$$
\lambda \omega(t)+k \eta=V_{a}(t) k
$$

Substituindo os valores de regime das duas tensões e as duas velocidades em (30), e subtraindo uma equação da outra, é possível determinar o parâmetro $k$

$$
\lambda \frac{\left(\omega_{2}-\omega_{1}\right)}{\left(V_{a_{2}}-V_{a_{1}}\right)}=k
$$

Com os valores de $\lambda$ e $k$ e com os valores de regime de $V_{a}$ e $\omega$, obtém-se o valor de $\eta$ a partir de (30).

A resistência de armadura pode ser medida através de uma ponte de Wheatstone conforme ilustração da Figura 24. Ou seja, dois resistores iguais e conhecidos, $R_{1} e R_{2}$, são conectados a um resistor variável e aos terminais do rotor que é a resistência desconhecida. O 
resistor variável é ajustado de tal forma que a razão entre o resistor variável e a resistência de armadura seja igual a razão dos resistores $R_{1} e R_{2}$. Nessa situação a tensão $V_{A B}$ entre o terminal do motor e o terminal do resistor conhecido é nula. Lê-se o valor do resistor variável que é numericamente igual a resistência de armadura. Porém nesse trabalho não será determinado o valor de $R_{a}$ diretamente, pois é suficiente determinar-se a relação $\frac{K_{m}}{R_{a}}$. O valor dessa relação é obtido por meio de um dinamômetro, ou seja, uma célula de carga conectada ao eixo do motor e com o uso da equação (9). O eixo do motor é mantido imóvel enquanto uma tensão constante conhecida é aplicada na armadura do motor CC. Nessas condições a relação $\frac{K_{m}}{R_{a}}$ pode ser determinada por

$$
T_{\text {célula }}=\frac{K_{m}}{R_{a}} V_{a}
$$

onde $T_{\text {célula }}$ é o torque medido pela célula de carga.

Figura 24- Ponte de Wheatstone

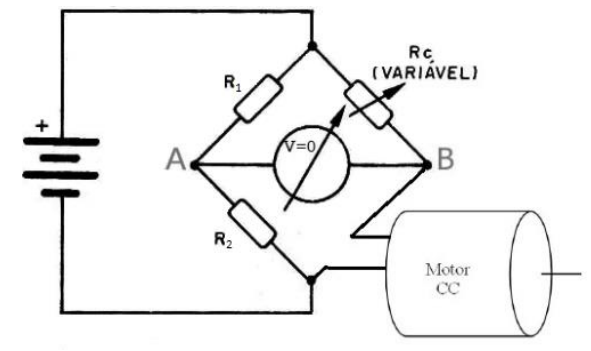

Fonte: Autor

Para a determinação da constante $K_{m}$ do motor utiliza-se a tensão gerada pelo tacogerador, já que eles são iguais. A tensão gerada em vazio pelo tacogerador é dada pela lei de Lenz

$$
K_{m}=\frac{V_{a}(t)}{\omega(t)}
$$

Embora (32) valha para qualquer velocidade $\omega(t)$, utiliza-se uma velocidade constante imposta por uma tensão constante aplicada ao motor. A tensão $V_{a}$ é medida diretamente nos 
terminais do tacogerador e a velocidade é medida por meio de um sensor ótico presente no sistema LJ. Com a frequência dos pulsos do sensor ótico obtém-se a velocidade $\omega$.

O momento de inércia $J$ é indiretamente determinado pela equação (17), resultando em

$$
J=\frac{K_{m}}{R_{a} k}
$$

Por fim, através da equação (20) determina-se

$$
\alpha=\frac{R_{a}}{9 K_{m}}
$$

A estratégia adotada neste trabalho não requer o uso de sensores de força, mas, como mencionado anteriormente, o valor da força se faz necessário para a validação do controlador de impedância. Como forma redundante, criou-se um estimador do torque aplicado, afim de validar a medida do torque dado pela da célula de carga.

O estimador do torque externo $T_{l}$ aplicado é baseado no modelo do sistema e na medida da velocidade angular. A essência do estimador usado é a inversão do modelo da planta por meio de um sistema de controle. O diagrama de blocos da figura 25 mostra o modelo da planta e a estimativa $\hat{x}$.

Figura 25 - Diagrama de blocos com estimador do torque externo

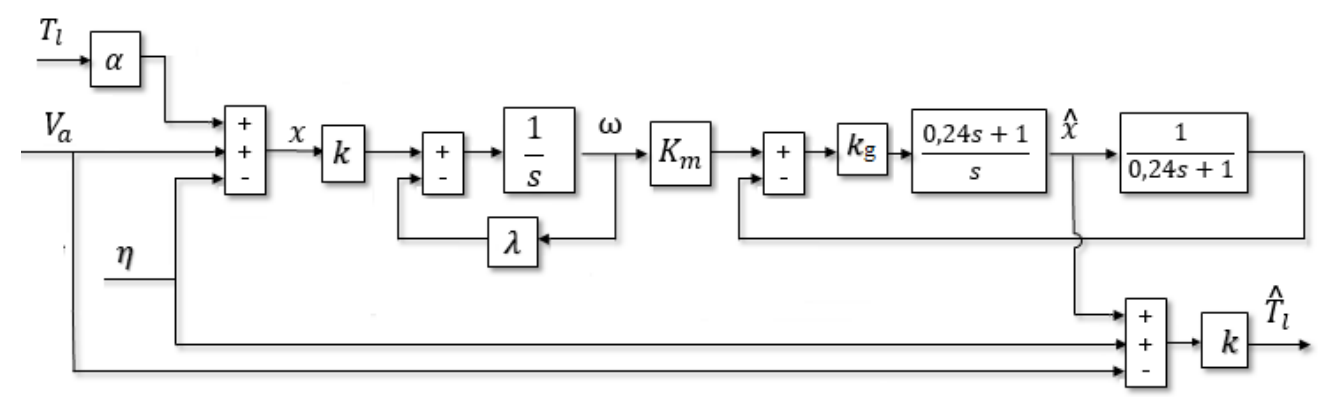

Fonte: Autor

Admitindo que $x \cong \hat{x}$, 


$$
\left(T_{l} \alpha+V_{a}-\eta\right) \cong \hat{x}
$$

Portanto, o torque estimado é expresso por

$$
\widehat{T}_{l}=\frac{\hat{x}+\eta-V_{a}}{\alpha} .
$$




\section{RESULTADOS}

Neste capítulo, são apresentados os resultados simulados e os experimentos com a bancada de testes.

As simulações foram feitas no Simulink. A implementação em tempo real da lei de controle de alteração da impedância mecânica, da medição de torque externo e do observador de entrada, também foram feitas no Simulink utilizando-se a toolbox Real Time Windows Target por meio da placa NI-6221da National Instruments. O sistema consiste de quatro subsistemas conforme ilustrados na figura 27. O subsistema do observador estima o torque externo aplicado; há dois blocos, um de saída e um de entrada analógicas que fazem a interface com a placa NI-6221; o subsistema da lei de controle faz a alteração da impedância; e o subsistema do modelo que representa a planta cujos parâmetros foram estimados experimentalmente.

A tabela 1 contém os dados obtidos a partir dos métodos descrito no capítulo 3.

Tabela 1- Parâmetros estimados da planta

\begin{tabular}{c|c|c}
\hline$K_{m}$ & 0,0171 & $N \cdot m / W^{2}$ \\
\hline$K_{m} / R_{a}$ & $1,2185 * 10^{-2}$ & $N \cdot m / V$ \\
\hline$J$ & $4,933 * 10^{-5}$ & $k g \cdot m^{2}$ \\
\hline$\eta$ & 0,4397 & $N \cdot m$ \\
\hline$\lambda$ & 4,153 & $s^{-1}$ \\
\hline$C$ & $2,05 * 10^{-5}$ & N.m.s \\
\hline
\end{tabular}

Fonte: Autor 
Figura 26-Diagrama de blocos dos sistemas da planta real e modelada

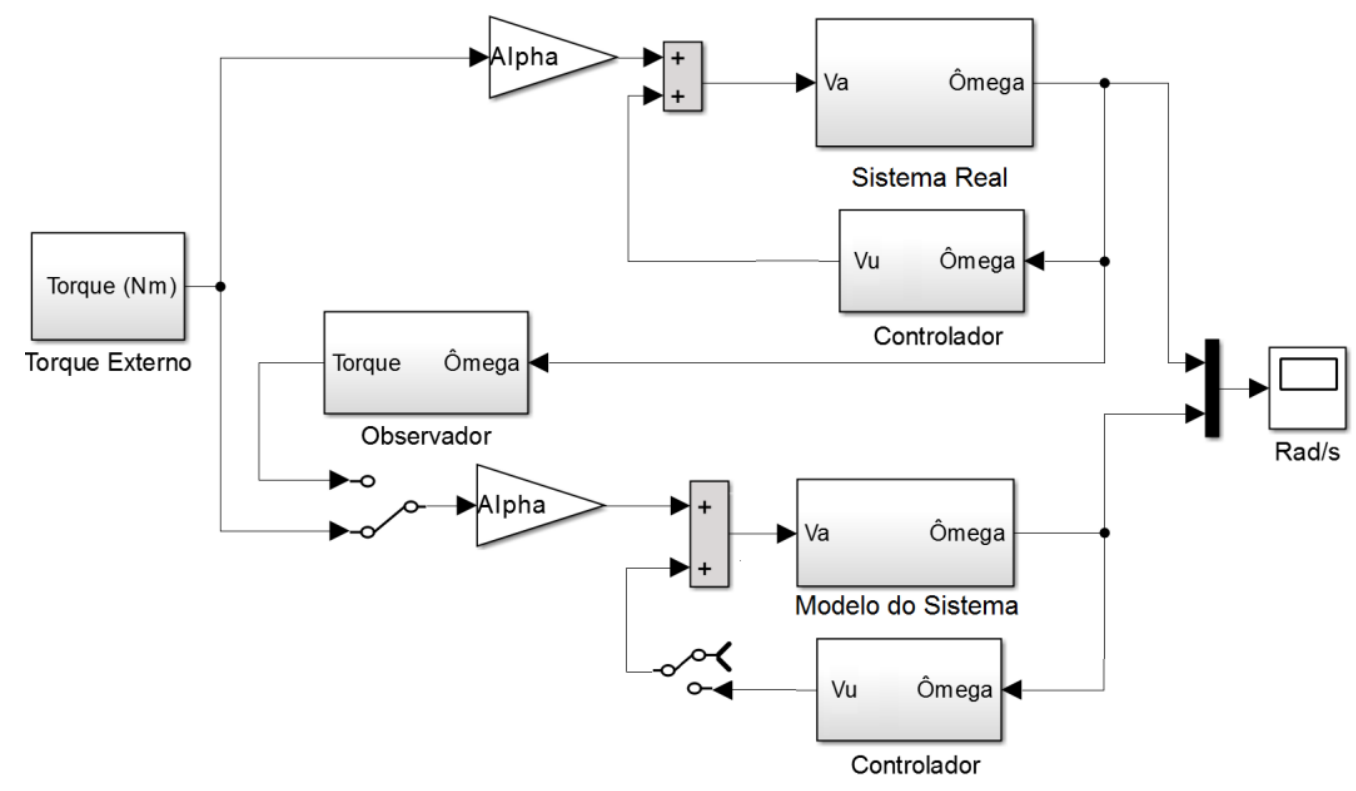

Fonte: Autor

Com a aplicação da lei de controle (28) pretende-se investigar as alterações impostas em $J$ e $C$.

Foram feitas 8 simulações, sendo que os valores desejados de $J, C$ e $\eta$ foram alterados conforme a tabela 2 e corresponde ao sistema modificado.

Tabela 2-Dados de simulação

\begin{tabular}{c|c|c|c|c}
\hline \multicolumn{5}{c}{$J\left[\mathrm{~kg} \cdot \mathrm{m}^{2}\right]$} \\
\hline Original & $+25 \%$ & $-25 \%$ & $+50 \%$ & $-50 \%$ \\
\hline $4,93 \mathrm{E}-05$ & $6,17 \mathrm{E}-05$ & $3,70 \mathrm{E}-05$ & $7,40 \mathrm{E}-05$ & $2,47 \mathrm{E}-05$ \\
\hline \multicolumn{5}{c}{$\mathrm{C}[N . m . s]$} \\
\hline Original & $+25 \%$ & $-25 \%$ & $+50 \%$ & $-50 \%$ \\
\hline 4,153 & 5,191 & 3,115 & 6,229 & 2,076 \\
\hline \multicolumn{5}{c}{$\eta[N . m]$} \\
\hline Original & $+100 \%$ & $-100 \%$ & $+50 \%$ & $-50 \%$ \\
\hline 0,4397 & 0,8793 & 0,00 & 0,6595 & 0,2198 \\
\hline \multicolumn{3}{c}{ Fonte: Autor }
\end{tabular}


Para a validação do observador, foi aplicado manualmente um torque aleatório por meio da alavanca adaptada ao eixo de saída do sistema LJ. A resposta do estimador de torque foi comparada com o torque medido pela célula de carga, conforme ilustra a figura 28.

Figura 27 - Comparação entre Torque medido pela célula de carga e Torque Estimado para uma excitação aleatória no eixo de saída do sistema LJ.

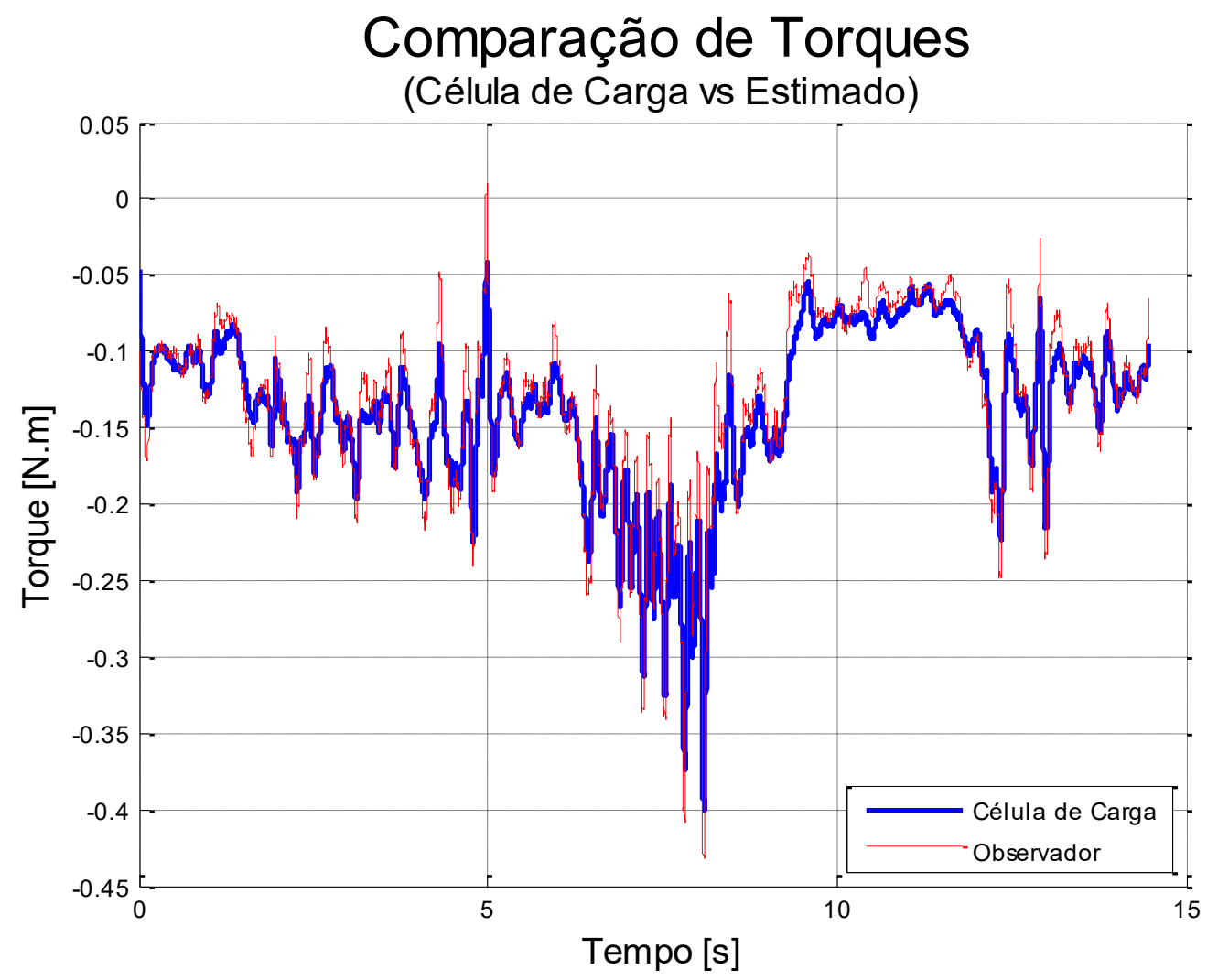

Fonte: Autor

Para completar a validação do observador de torque, foram feitos também experimentos com sinais elétricos bem determinados, adicionados à entrada do sistema $\mathrm{LJ}$, de forma a representar torques externos conhecidos, tal como o ensaio senoidal ilustrado na figura 29. Em seu trabalho, Winter (1983) determinou que a velocidade média de uma caminhada em cadência lenta é de 87,4 passos por minutos, ou 1,46 passos por segundo, que corresponde a uma frequência de contato de um dos pés de aproximadamente 0,73 Hz. Com esta motivação, a frequência utilizada para os sinais de teste foi de $0,73 \mathrm{~Hz}$, pois considerando 
que é um sistema de movimentação de carga, o operador tende a ter uma mesma cadência para movimentar o sistema.

Não foi realizada nenhuma validação quantitativa, mas apenas a comparação qualitativa da resposta do estimador em relação ao sinal equivalente de torque adicionado como tensão à entrada do sistema LJ. Entre o eixo de saída onde ocorre a aplicação real do torque externo até o eixo do motor, existem dinâmicas não modeladas a exemplo da rigidez da correia e mesmo não linearidades, tal com folgas. Além desses erros de modelagem, o próprio modelo do motor tem outras incertezas associadas, tal como a dinâmica do circuito de armadura, cuja indutância foi desprezada. Por causa desse panorama, buscou-se apenas comparar as componentes fundamentais dos sinais, que podem ser consideradas próximas nas figuras 28 e 29.

Figura 28- Comparação entre Torque medido pela célula de carga e Torque Estimado para uma excitação senoidal no eixo de saída do sistema LJ

Comparação de Torques

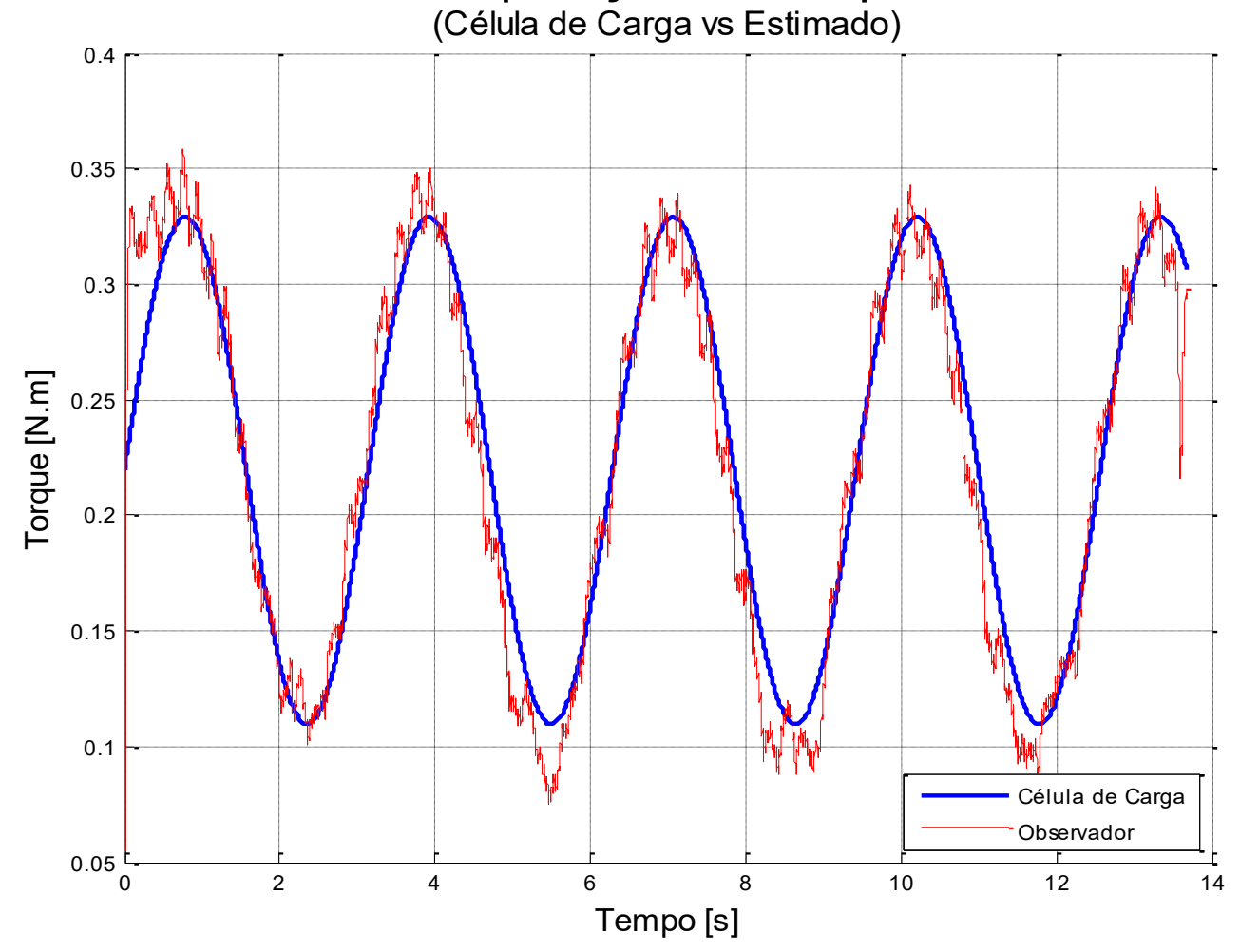

Fonte: Autor 
A aplicação do torque externo é feita por meio de uma manivela cuja massa não foi balanceada, o que induz no sistema uma oscilação não modelada. A frequência dessa oscilação é diretamente proporcional à velocidade angular do eixo onde está a manivela e com uma relação de aproximadamente 1:9, que é a relação das engrenagens do sistema mostrado na figura 15. Esse fenômeno pode ser observado no gráfico de velocidade da figura 30. A frequência fundamental de oscilação causada pelo desbalanceamento é facilmente identificada por inspeção visual, principalmente nas baixas velocidades. A tabela 3 contém os dados dos experimentos ilustrados com a figura 30. Nessa tabela é possível identificar que, com o aumento da velocidade, a frequência de oscilação também aumenta, fazendo isso de forma proporcional, comprovando assim um desbalanceamento ocasionado no eixo, devido à não simetria da manivela, mostrado na figura 17. Esse experimento foi feito, inserindo 4 valores de torque e, na saída, medido o valor da velocidade alcançada quando inseridos os torques, tanto as frequências de oscilação, quanto das frequências de rotação, foram medidos quando o sistema estava já em regime permanente. Note-se que o efeito desse desbalanceamento não pode ser tratado como um ruído, pois sua frequência está dentro da faixa de frequências cujas energias são significantes para o modelo. Logo, a filtragem desse sinal também removeria componentes importantes do modelo. 
Figura 29-Análise da frequência de oscilação da Manivela de torque

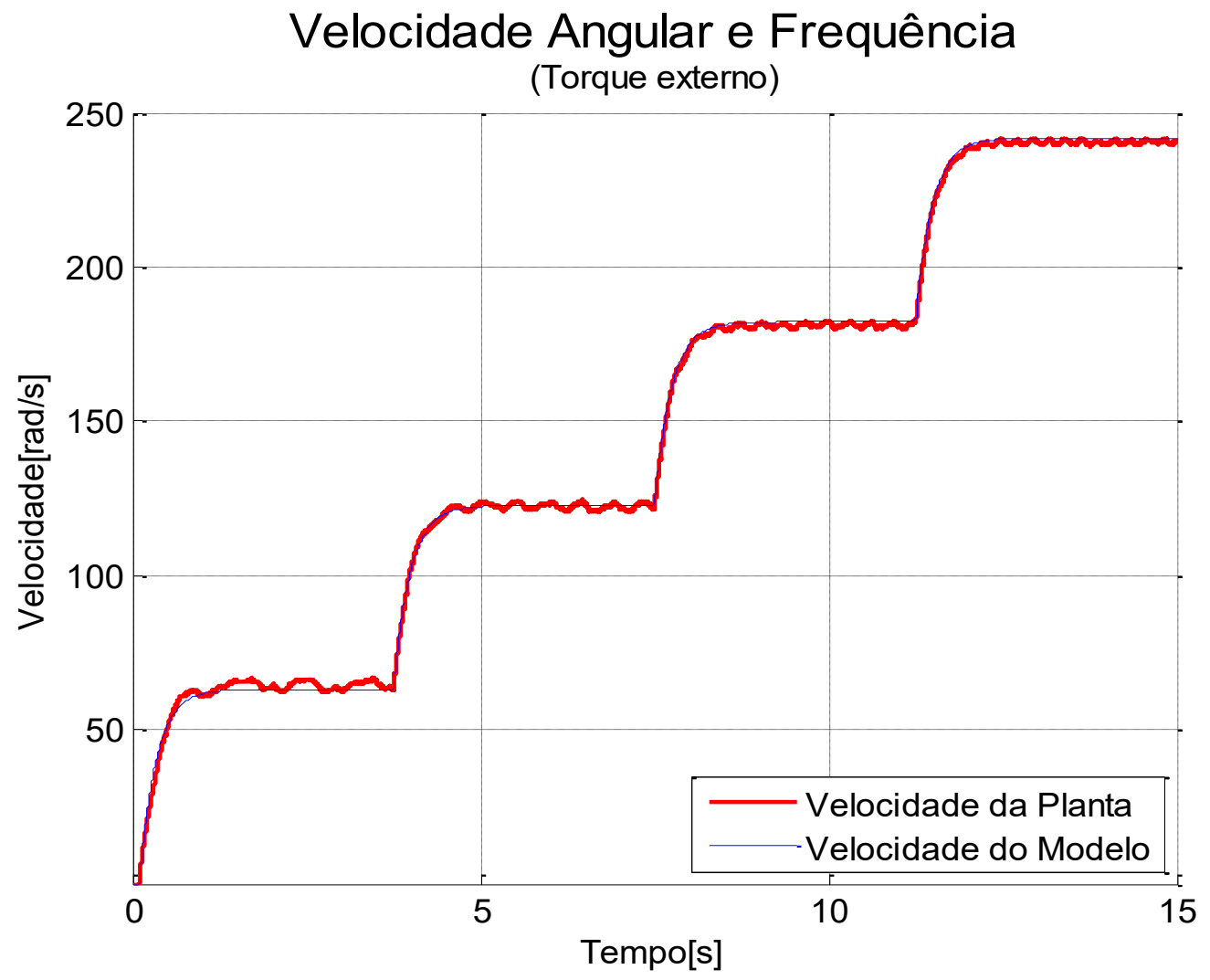

Fonte: Autor

Tabela 3-Velocidade angular $\omega$ e frequência $f$ da oscilação induzida pelo movimento da manivela de aplicação do torque externo

\begin{tabular}{|c|c|c|c|}
\hline \multicolumn{4}{|c|}{ Oscilação } \\
\hline \multicolumn{2}{|c|}{ Sistema } & \multicolumn{2}{c|}{ Manivela } \\
\hline$\omega[\mathrm{rad} / \mathrm{s}]$ & $\mathrm{f}[\mathrm{Hz}]$ & $\omega[\mathrm{rad} / \mathrm{s}]$ & $\mathrm{f}[\mathrm{Hz}]$ \\
\hline 64.5 & 10.3 & 7.1 & 1.13 \\
\hline 122.7 & 19.5 & 13.4 & 2.14 \\
\hline 181 & 28.8 & 18.7 & 2.97 \\
\hline 240.6 & 38.3 & 28.5 & 4.54 \\
\hline
\end{tabular}

Fonte: Autor

Os gráficos que seguem ilustram a consequência da alteração de parâmetros da impedância no sinal de resposta da velocidade do sistema quando o torque externo é um sinal do tipo degrau, gerado por meio de uma tensão equivalente aplicado à entrada do sistema LJ. 
O sinal utilizado, foi um conjunto de degraus com diferentes amplitudes, para que fosse possível observar como a alteração dos parâmetros influencia a reposta do sistema, tanto na aceleração como na desaceleração. O primeiro degrau tem amplitude de 0,27 Nm, aplicado no instante $0,5 \mathrm{~s}$ da simulação que é depois reduzido para $0,16 \mathrm{Nm}$. O gráfico da figura 31 ilustra os sinais de torques utilizados nos ensaios.

Figura 30 - Torque externo aplicado no sistema como forma similar ao torque aplicado pelo operador

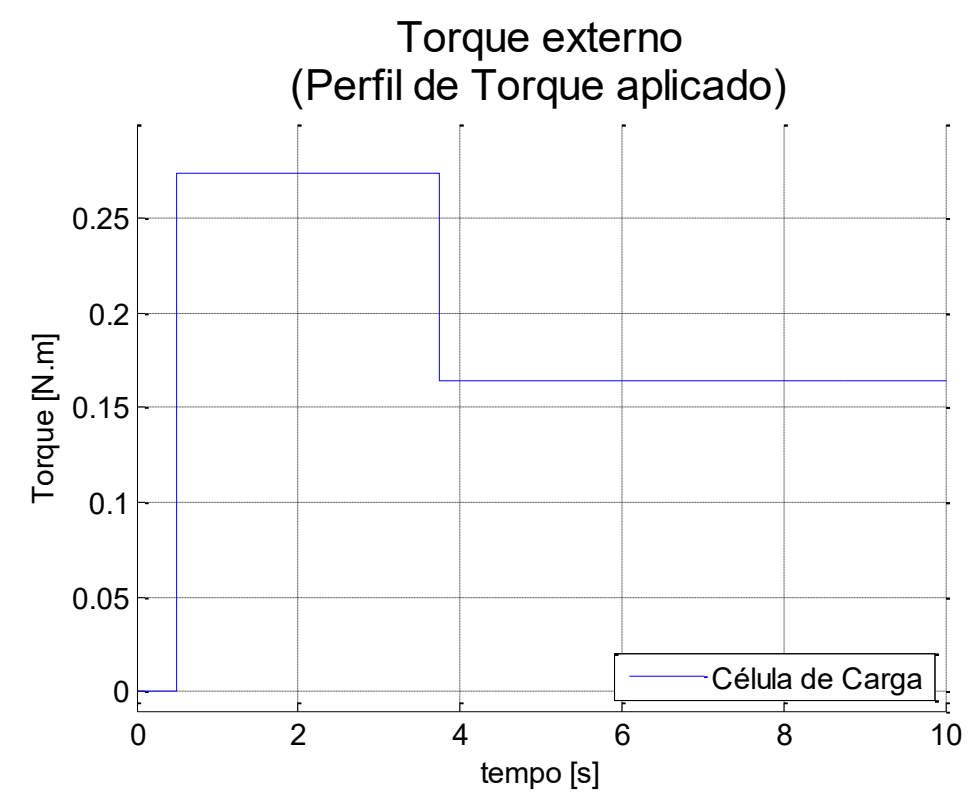

Fonte: Autor

Nas figuras a seguir, mostram-se também os gráficos da tensão de armadura, cuja máxima amplitude representa o máximo esforço de controle que é limitado a faixa entre $-5 \mathrm{~V}$ e 5V. Complementarmente mostra-se também o gráfico do torque externo, em função da velocidade angular do sistema e em função do tempo, ou seja, uma forma de representação 3D da impedância mecânica do sistema, onde são comparadas as impedâncias original, desejada e aquela obtida.

Denomina-se aqui esforço de controle, a tensão imposta pelo controlador para que o sistema seja realimentado. Como visto na figura 27, a tensão que está entrando no motor contém uma parcela de tensão propriamente dita que sai do controlador e outra que é uma tensão equivalente ao torque externo, embora dessa forma é uma maneira de se controlar para 
que o sistema não ultrapasse os $\pm 5 V$, entretanto, na prática a tensão equivalente ao torque externo não é uma tensão de fato, logo, ao invés de determinar esforço de controle, será denominado de Tensão de armadura, ou seja, a tensão necessária para tirar o motor do repouso, usando a tensão análoga ao torque externo, juntamente com a tensão de realimentação.

A lei de controle de impedância utilizada requer a informação da velocidade e da aceleração angulares. Entretanto, como não foi utilizado explicitamente um sensor para a aceleração angular, o sinal da velocidade angular foi derivado em relação ao tempo. Porém, o cálculo numérico da derivada introduz dinâmicas não modelada que se refletiram num sobressinal da resposta da velocidade do sistema a uma excitação tipo degrau, coisa que não é característica de sistemas de primeira ordem. Para contornar esse problema utilizou-se uma filtragem associada ao cálculo da derivada com um polo em $-90+0 j$ e uma frequência de amostragem de $2 \mathrm{kHz}$ na placa de aquisição de dados. Essa solução adotada conferiu respostas superamortecidas para as respostas de todos os experimentos realizados.

No experimento ilustrado pelos gráficos da figura 32, alterações do momento de inércia aparente são feitas incrementando e decrementando seu valor em relação à inércia nominal do sistema. No mesmo experimento, porém em instantes distintos, mostra-se também a consequência da redução do atrito de Coulomb. Nos primeiros 7,5 s, existe somente a alteração do momento de inércia, após isso o atrito de Coulomb é compensado em $100 \%$, ou seja, reduzido a um valor aparentemente nulo. 
Figura 31 - Velocidade e Tensão de armadura para alterações de $\pm 25 \%$ na Inércia e $-100 \%$ no atrito de Coulomb.
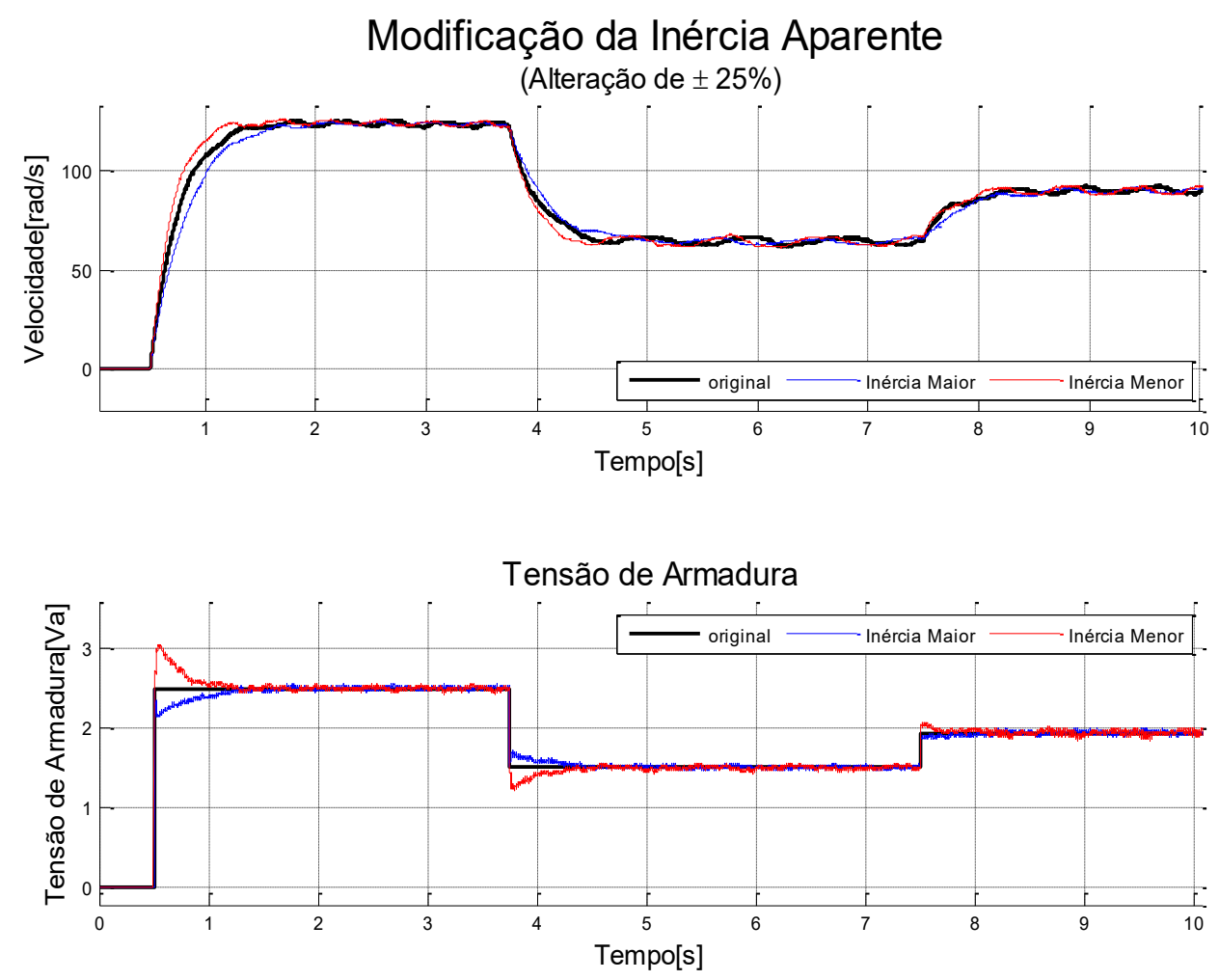

Fonte: Autor

Na figura 32, a constante de tempo possui uma variação proporcional à modificação da inércia aparente, porém após os 7,5 segundos iniciais, a compensação do atrito de Coulomb se reflete numa elevação do ganho do sistema que pode ser vista pela alteração da amplitude da resposta, conforme tabela 4. Embora essa compensação demande um esforço de controle maior, o motor não teve saturação. 
Tabela 4 - Dados da constante de tempo $\tau$ e da constante de ganho $\mathrm{k}_{\mathrm{g}}$ do sistema para uma alteração da Inércia aparente em $\pm 25 \%$ e $-100 \%$ no atrito de Coulomb.

\begin{tabular}{|c|c|c|c|c|}
\hline & \multicolumn{4}{|c|}{$J \pm 25 \%$} \\
\hline & \multicolumn{2}{|c|}{ com Atrito de Coulomb } & \multicolumn{2}{|c|}{ Atrito de Coulomb compensado } \\
\hline & $\mathrm{T}$ & $\mathrm{kg}$ & $\tau$ & $\mathrm{kg}$ \\
\hline Maior & 0.35 & 459.26 & 0.35 & 566.43 \\
\hline Original & 0.24 & 459.26 & 0.24 & 566.43 \\
\hline Menor & 0.19 & 459.26 & 0.19 & 566.43 \\
\hline
\end{tabular}

Fonte: Autor

$\mathrm{Na}$ figura 33, mostram-se os efeitos da variação de $\pm 50 \%$ da inércia aparente em relação ao valor nominal em relação ao tempo de acomodação.

Note-se que durante os primeiros 7,5 s dos gráficos da figura 33 o valor de regime permanente do esforço de controle não se altera, mas apenas sua resposta transitória. Devido à diminuição da inércia aparente em 50\%, o máximo esforço de controle ultrapassou o limite de $5 \mathrm{~V}$ do atuador, representando, de fato, uma saturação.

Novamente, após os 7,5 s iniciais, a compensação do atrito de Coulomb se reflete numa elevação do ganho do sistema que pode ser vista pelo aumento da amplitude da resposta na tabela 5 .

Nos gráficos da figura 34 estão representados os sinais que regem a equação diferencial da impedância mecânica: velocidade angular, torque aplicado, e tempo. Por esse motivo, esse tipo de representação será denominado neste trabalho por impedância mecânica. Nessa figura estão representadas a impedância mecânica original do sistema juntamente com as impedâncias resultantes das duas alterações feitas na planta real. 
Figura 32- Velocidade e Tensão de armadura para alterações de $\pm 50 \%$ na Inércia e $-100 \%$ no atrito de Coulomb.

\section{Modificação da Inércia Aparente}
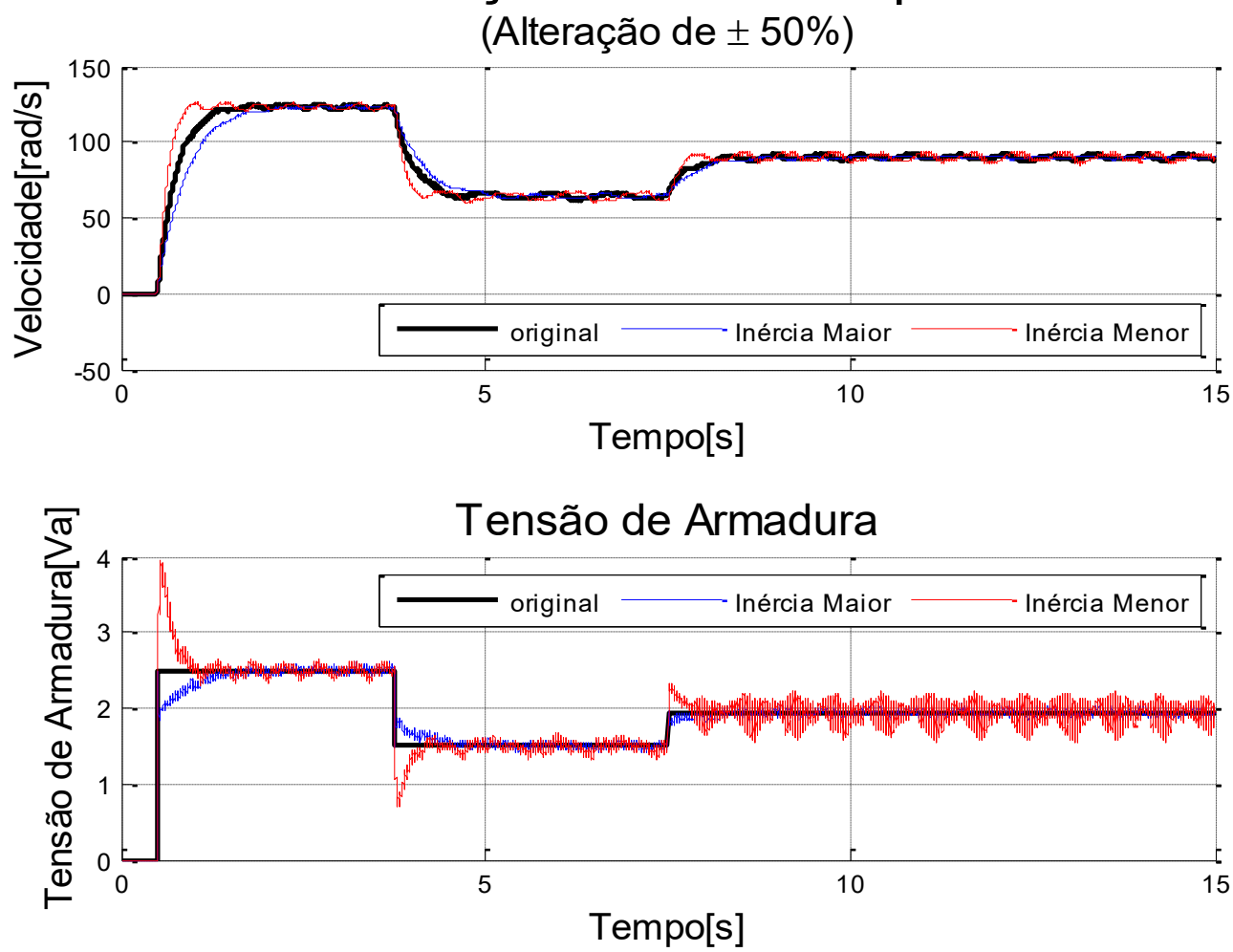

Fonte: Autor

Tabela 5 - Dados da constante de tempo $\tau$ e da constante de ganho $\mathrm{k}_{\mathrm{g}}$ do sistema para uma alteração da Inércia aparente em \pm 50\% e $-100 \%$ no atrito de Coulomb

\begin{tabular}{c|c|c|c|c}
\cline { 2 - 5 } & \multicolumn{4}{c}{$J \pm 50 \%$} \\
\cline { 2 - 5 } & \multicolumn{1}{c}{ com Atrito de Coulomb } & \multicolumn{2}{c}{ Atrito de Coulomb compensado } \\
\cline { 2 - 5 } & $\tau$ & $\mathrm{kg}$ & $\tau$ & $\mathrm{kg}$ \\
\hline Maior & 0.39 & 459.26 & 0.39 & 563.56 \\
\hline Original & 0.24 & 459.26 & 0.24 & 563.56 \\
\hline Menor & 0.14 & 459.26 & 0.14 & 563.56
\end{tabular}

Fonte: Autor 
Figura 33 - Impedância Mecânica para alterações de $\pm 25 \%$ na Inércia aparente.

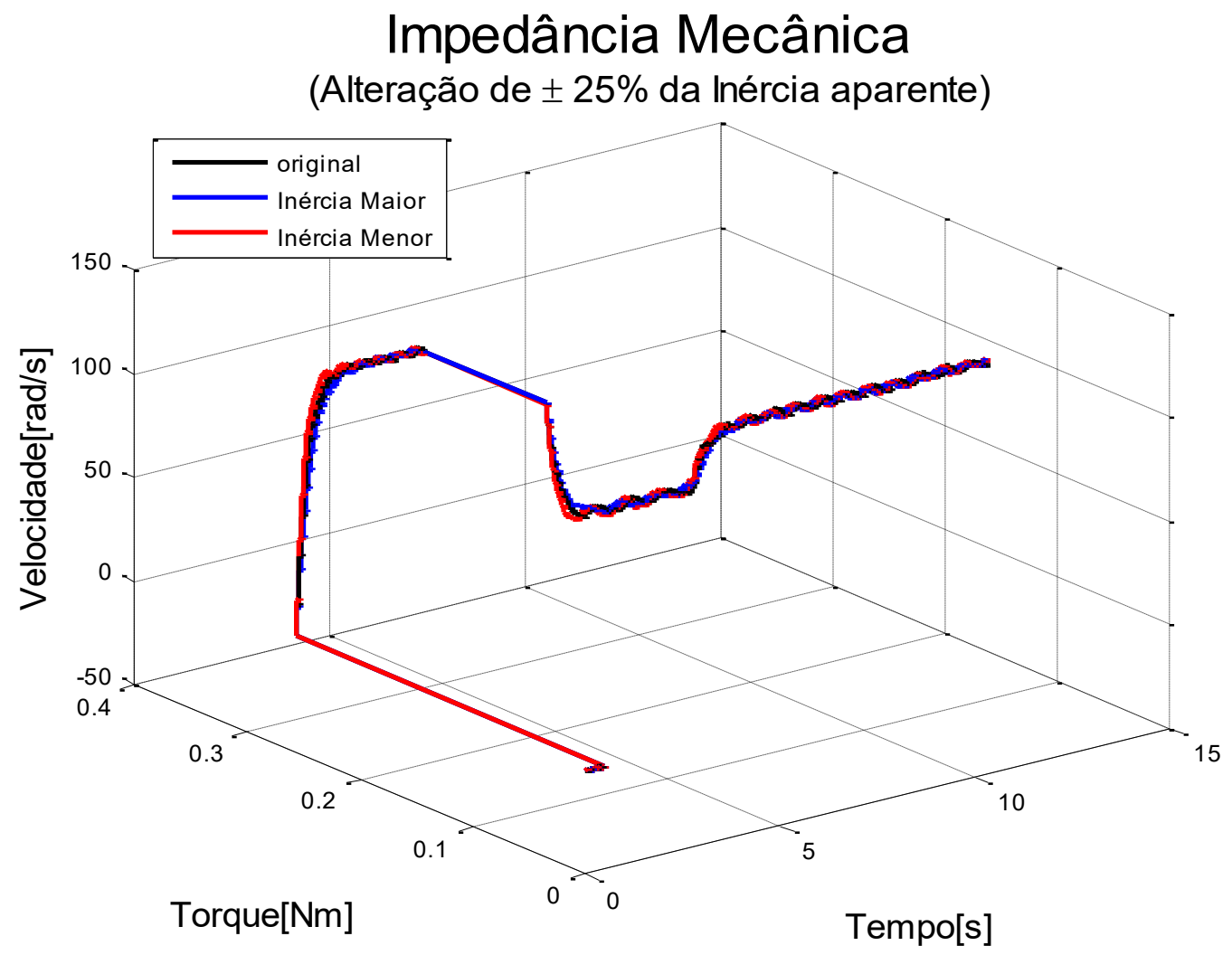

Fonte: Autor

Nos gráficos da figura 35, com a modificação do atrito viscoso, o sistema apresenta uma variação de acordo na constante de tempo e no seu valor final, por causa da alteração do ganho. Após os 7,5 s iniciais, a compensação de 100\% do atrito de Coulomb foi inserida, e se observou uma alteração correspondente no valor final da reposta de forma proporcional ao parâmetro alterado. Quando se impõe um aumento de $25 \%$ no coeficiente de atrito viscoso, o sistema passa a ter uma menor constante de tempo e com um regime permanente de amplitude menor que o do sistema original (menor ganho). Note-se que, nesse caso, o esforço de controle apresentou um transitório e um regime permanente inferior quando comparados com o do sistema original. Quando se impõe uma diminuição de $25 \%$ no coeficiente de atrito viscoso, o sistema passa a ter uma maior constante de tempo e com um regime permanente de amplitude maior que o do sistema original (maior ganho). Nesse caso, o esforço de controle apresentou um transitório e um regime permanente superior quando comparados com o do sistema original, até mesmo com a compensação do atrito de Coulomb. 
Figura 34- Velocidade e Tensão de armadura para alterações de $\pm 25 \%$ no coeficiente de atrito viscoso e $-100 \%$ no atrito de Coulomb.
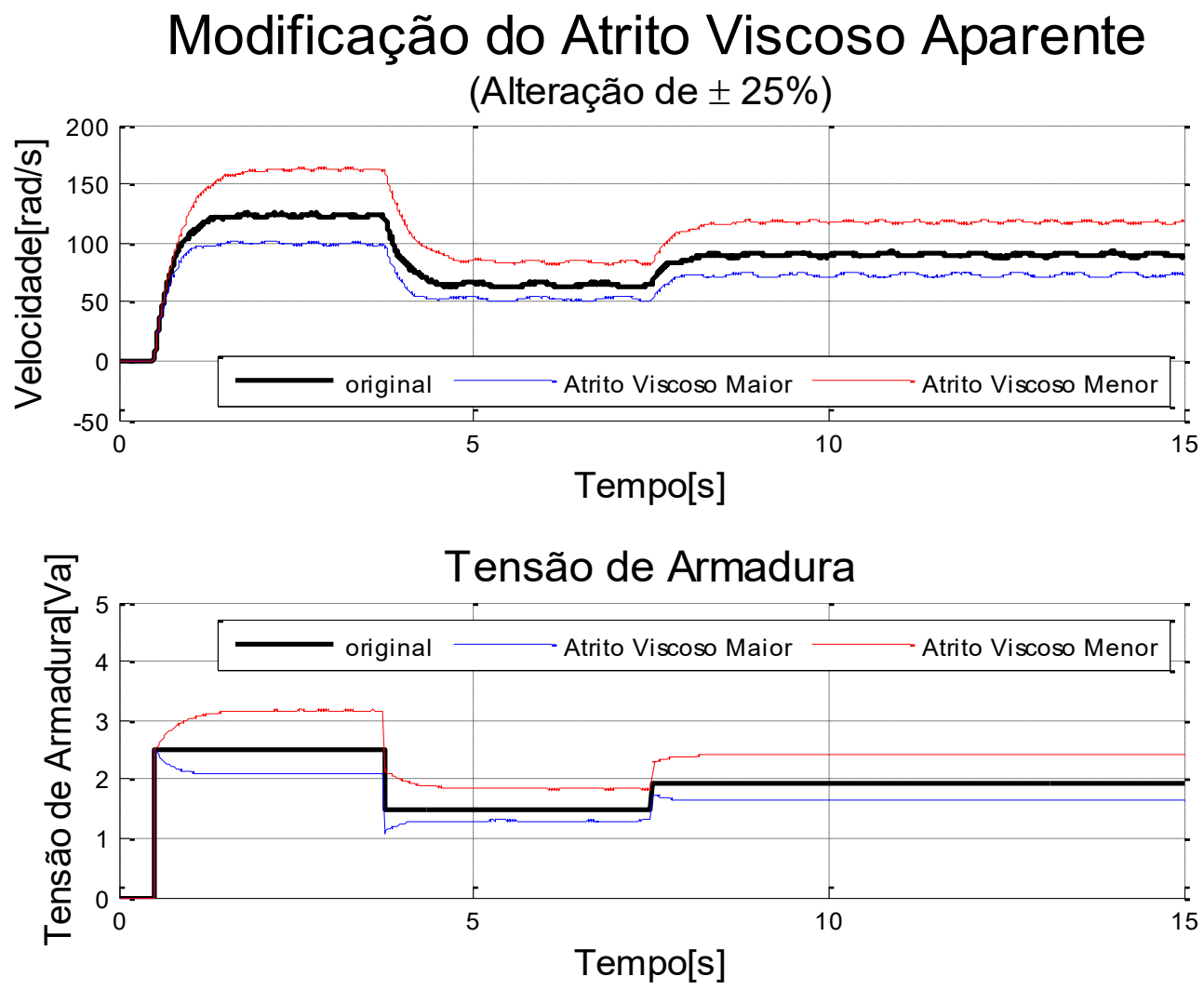

Fonte: Autor

Pode-se notar nos primeiros 7,5 s dos gráficos da figura 35 que, ao se diminuir o atrito viscoso em $25 \%$, se consegue um aumento do ganho verificado pelo valor final maior e uma constante de tempo menor, como resumido pelos dados da tabela 5. A compensação do atrito de Coulomb na fase partir dos 7,5 s teve como influência uma alteração do valor de regime da resposta do sistema. Na figura 36 mostram-se os gráficos da impedância mecânica relativos ao ensaio de alteração de $+25 \%$ no atrito viscoso aparente onde se pode conferir também as alterações do valor final devido à alteração proporcional do ganho na primeira fase do ensaio. 
Figura 35- Impedância mecânica para alterações de $+25 \%$ no atrito viscoso aparente $-100 \%$ no atrito de Coulomb

\section{Impedância Mecânica}

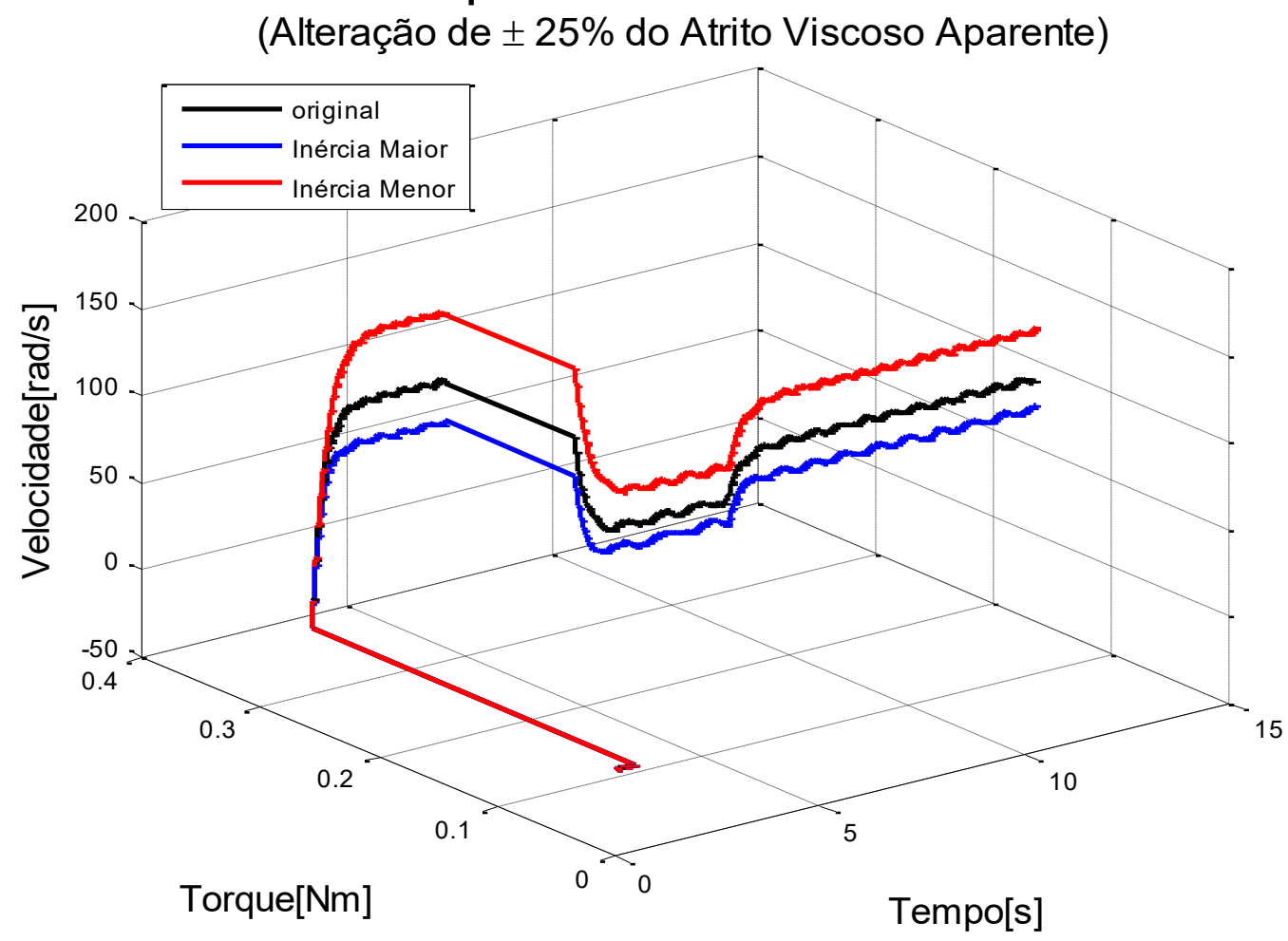

Fonte: Autor

Tabela 6 - Dados da constante de tempo $\tau$ e da constante de ganho kg do sistema para uma alteração do coeficiente de atrito viscoso aparente em $\pm 25 \%$ e $-100 \%$ no atrito de Coulomb

\begin{tabular}{c|c|c|c|c}
\cline { 2 - 5 } & \multicolumn{4}{c}{$C \pm 25 \%$} \\
\cline { 2 - 5 } & \multicolumn{1}{c}{ com Atrito de Coulomb } & \multicolumn{2}{c}{ Atrito de Coulomb compensado } \\
\hline Maior & 0.21 & 367.37 & 0.23 & $\mathrm{~kg}$ \\
\hline Original & 0.24 & 459.26 & 0.24 & 567.81 \\
\hline Menor & 0.34 & 603.70 & 0.30 & 740.63 \\
\hline
\end{tabular}

Fonte: Autor 
Conforme figura 37 nota-se que, ao aumentar o atrito viscoso aparente em 50\%, a amplitude do valor final diminuiu bastante, deixando o sistema com uma velocidade menor em regime permanente, e uma constante de tempo também menor. Com isso, a acomodação do sistema se torna mais rápida, alcançando os patamares de velocidade constante de forma mais ágil, conforme dados da tabela 7, que é possível identificar, que quando se altera o atrito viscoso aparente, existe um aumento dos dois parametros, $J$ e $C$. Já com a diminuição do atrito viscoso aparente, a amplitude do valor final e a constante de tempo tornaram-se maiores, deixando o sistema menos ágil nos transitórios, e exigindo menor esforço para manter o regime da movimentação.

Pode-se observar na figura 38 os gráficos da impedância mecânica original e das impedâncias aparentes impostas. Note-se que a alteração do valor final e, portanto, do ganho do sistema foi proporcional à alteração do atrito viscoso aparente na fase que vai até 7,5 s, e proporcional a alteração do atrito de Coulomb a partir desse instante.

Figura 36-Velocidade e Tensão de armadura para alterações de $\pm 50 \%$ no coeficiente de atrito viscoso e $-100 \%$ no atrito de Coulomb
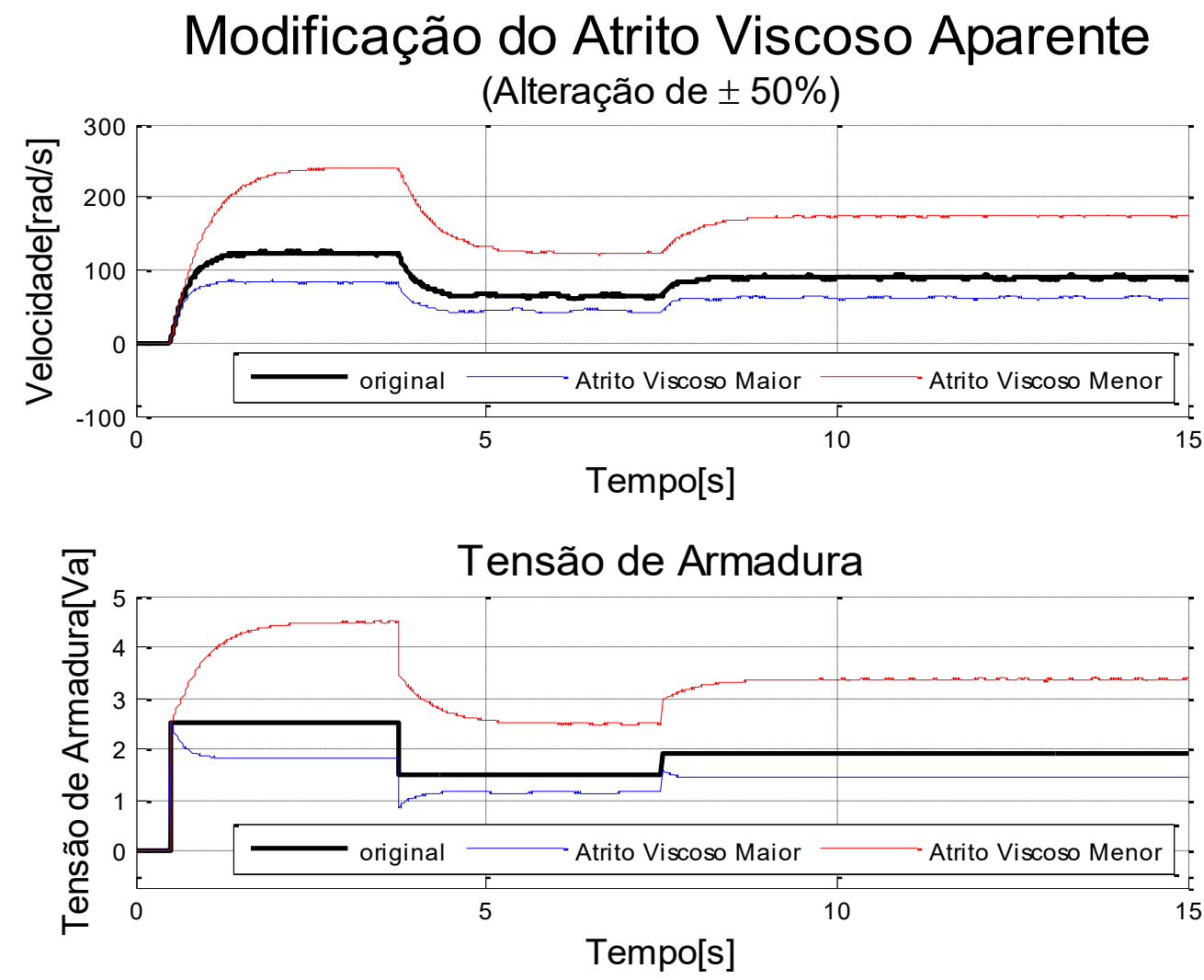

Fonte: Autor 
Tabela 7-Dados da constante de tempo $\tau$ e da constante de ganho $\mathrm{kg}_{\mathrm{g}}$ do sistema para uma alteração do Coeficiente do Atrito Viscoso aparente em $\pm 50 \%$ e $-100 \%$ no atrito de Coulomb.

\begin{tabular}{c|c|c|c|c}
\cline { 2 - 5 } & \multicolumn{4}{c}{$C \pm 50 \%$} \\
\cline { 2 - 5 } & \multicolumn{2}{c}{ com Atrito de Coulomb } & \multicolumn{2}{c}{ Atrito de Coulomb compensado } \\
\cline { 2 - 5 } & $\mathrm{T}$ & $\mathrm{kg}$ & $\tau$ & $\mathrm{kg}$ \\
\hline Maior & 0.19 & 312.96 & 0.16 & 394.06 \\
\hline Original & 0.24 & 451.85 & 0.24 & 575.00 \\
\hline Menor & 0.30 & 892.59 & 0.50 & 1087.50 \\
\hline
\end{tabular}

Fonte: Autor

Figura 37- Impedância mecânica para alterações de $\pm 50 \%$ no coeficiente de atrito viscoso e $-100 \%$ no atrito de Coulomb

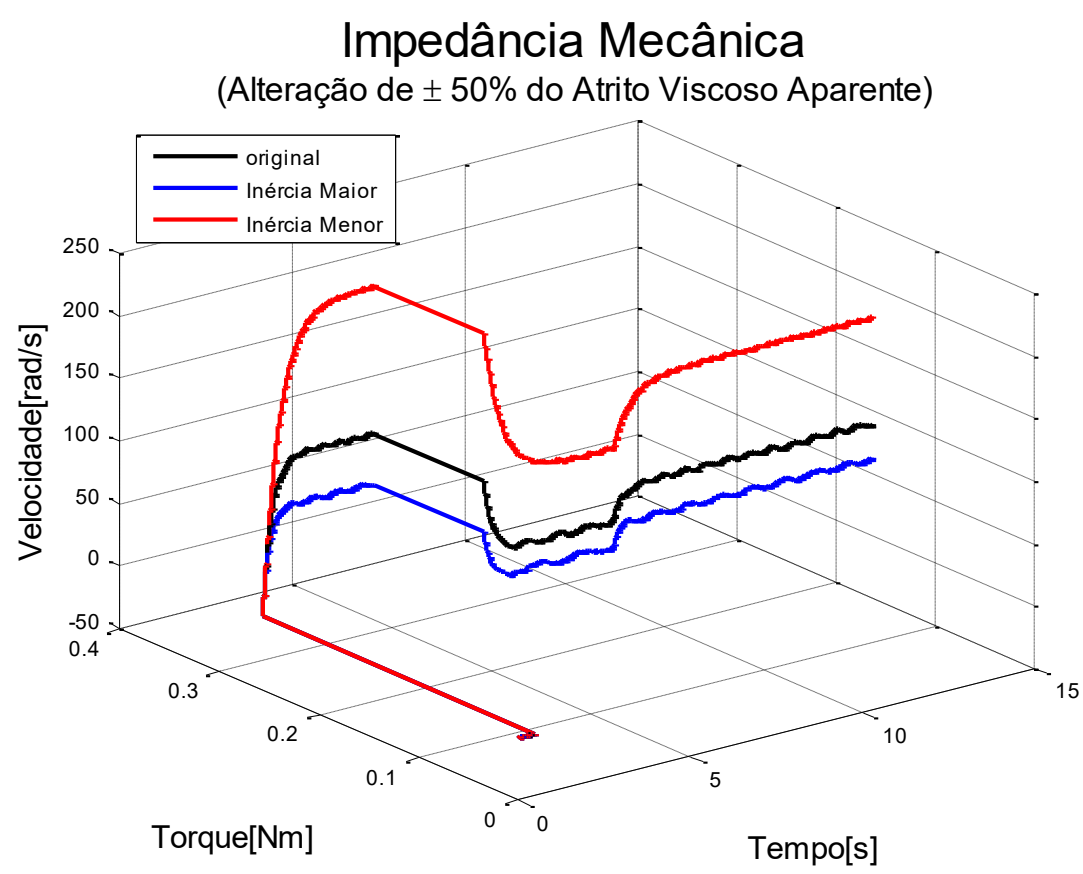

Fonte: Autor

Para analisar a contribuição que o atrito de Coulomb tem no sistema, mostram-se na figura 39 os resultados de um experimento com esse propósito. Nenhuma alteração no atrito de Coulomb é feita até os 7,5 e, após esse instante, o atrito de Coulomb é compensado com 4 valores de alteração, ou seja, $\pm 100 \%$ e $\pm 50 \%$. Pelos dados da tabela 8 , é possível observar que o ganho é proporcional ao valor do parâmetro alterado, juntamente com a constante de 
tempos, e, as tensões tem seus valores nominal em regime também maior. Pelos gráficos da figura 40, a impedância tanto do modelo quanto da planta, são muito próximos até o início da compensação do atrito de Coulomb. Após a compensação, a redução do atrito é percebida como um aumento de ganho que implica num aumento do valor final da resposta, e, o aumento do atrito é percebido como uma diminuição de ganho que implica numa diminuição do valor final da resposta, variações essas que são proporcionais às alterações do atrito de Coulomb, ou seja, aumento e diminuição em $\pm 100 \%$ e $\pm 50 \%$, conforme dados na tabela 8 .

Tabela 8-Variação da compensação do atrito de Coulomb analisado em regime permanente.

\begin{tabular}{c|c|c|c|c|c|c|c|c}
\cline { 2 - 9 } & \multicolumn{3}{c}{ Compensação do Atrito de Coulomb com velocidade angular em Regime } \\
\cline { 2 - 10 } & $\tau$ & $\mathrm{kg}$ & $\omega$ & $\mathrm{Va}$ & $\tau$ & $\mathrm{kg}$ & $\omega$ & $\mathrm{Va}$ \\
\hline Maior & 0.31 & 45.81 & 88.87 & 1.94 & 0.26 & 44.44 & 76.43 & 1.72 \\
\hline Original & 0.24 & 42.09 & 63.13 & 1.50 & 0.24 & 42.09 & 63.13 & 1.50 \\
\hline Menor & 0.20 & 35.49 & 37.62 & 1.06 & 0.21 & 39.78 & 50.92 & 1.28 \\
\hline
\end{tabular}

Figura 38-Velocidade e Esforço de Controle para alterações $\pm 100 \%$ e $\pm 50 \%$ no atrito de Coulomb. 

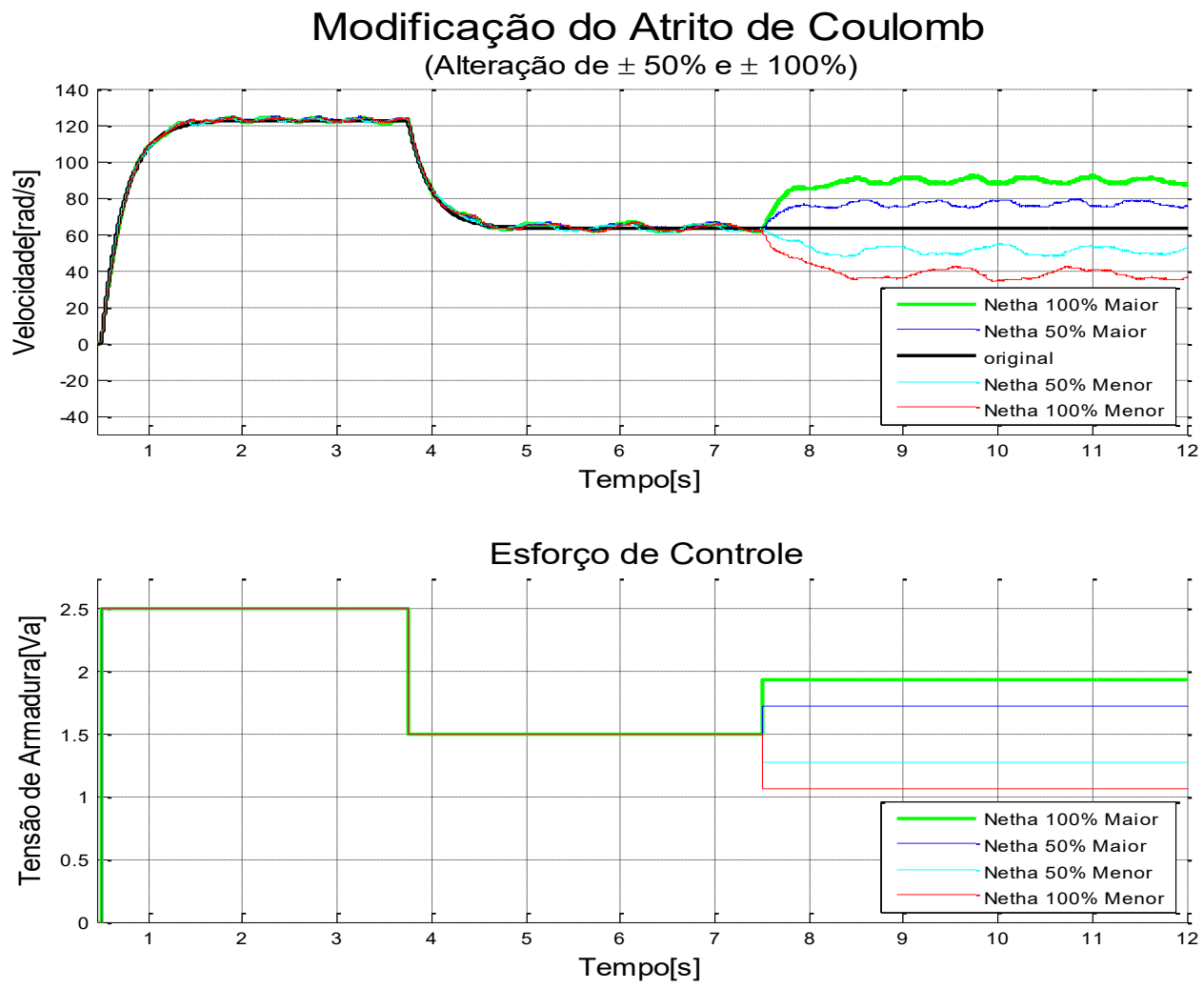

Fonte: Autor 
Figura 39- Impedância mecânica para alteração de $\pm 100 \%$ e $\pm 50 \%$ no atrito de Coulomb.

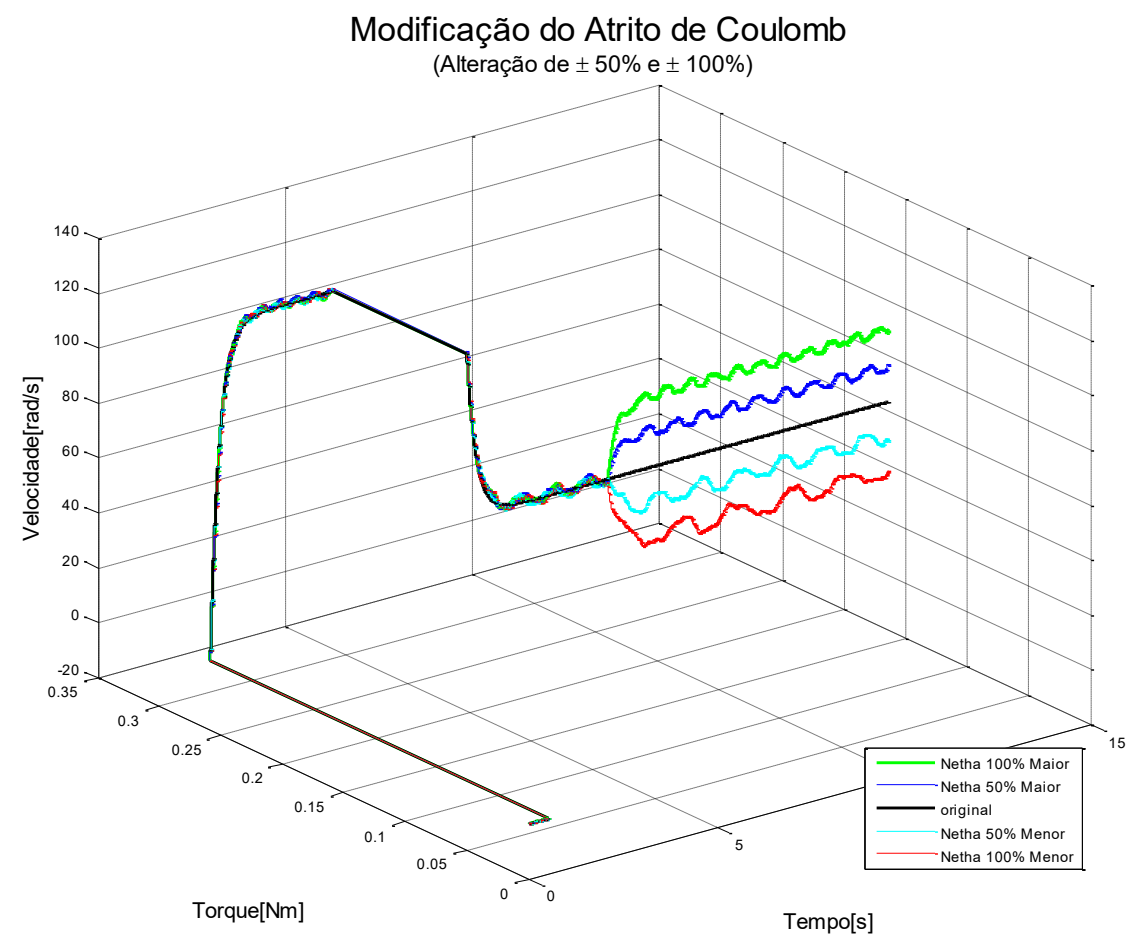

Fonte: Autor

Com as alterações dos parâmetros feitos no sistema, tem se a necessidade de selecionar quais são os conjuntos de parâmetros adequados para se aplicar, pois para cada necessidade, se usará um conjunto de parâmetros alterados, a escolha de deve aos principais fatos como: quando se desejar transportar cargas em espaços de pequena área, precisando de cuidados especiais com a carga e o ambiente, quando o veículo estiver em espaços abertos, podendo alcançar velocidades maiores ou até mesmo quando o veículo estiver em declive, em que a desaceleração seja fator importante. Conforme o gráfico da figura 41, é possível saber qual a faixa de variação dos parâmetros que poderá ser usado, sem que o motor esteja fora da região de trabalho, ou seja, $\pm 5 \mathrm{~V}$. O gráfico foi gerado com a alteração de $-95 \%$ até $+95 \%$ para $J_{1}, C_{1} e \eta_{1}$, e pode-se observar que a faixa em vermelho, está fora da margem de trabalho, portanto, não poderão ser utilizados os valores nessa região. 
Figura 40-Conjunto de possibilidades para aplicação dos parâmetros alterados

\section{Possibilidades de Combinações \\ dos \\ Parâmetros \\ $\left(J_{1}, C_{1}\right.$ e $\left.\eta_{1}\right)$}

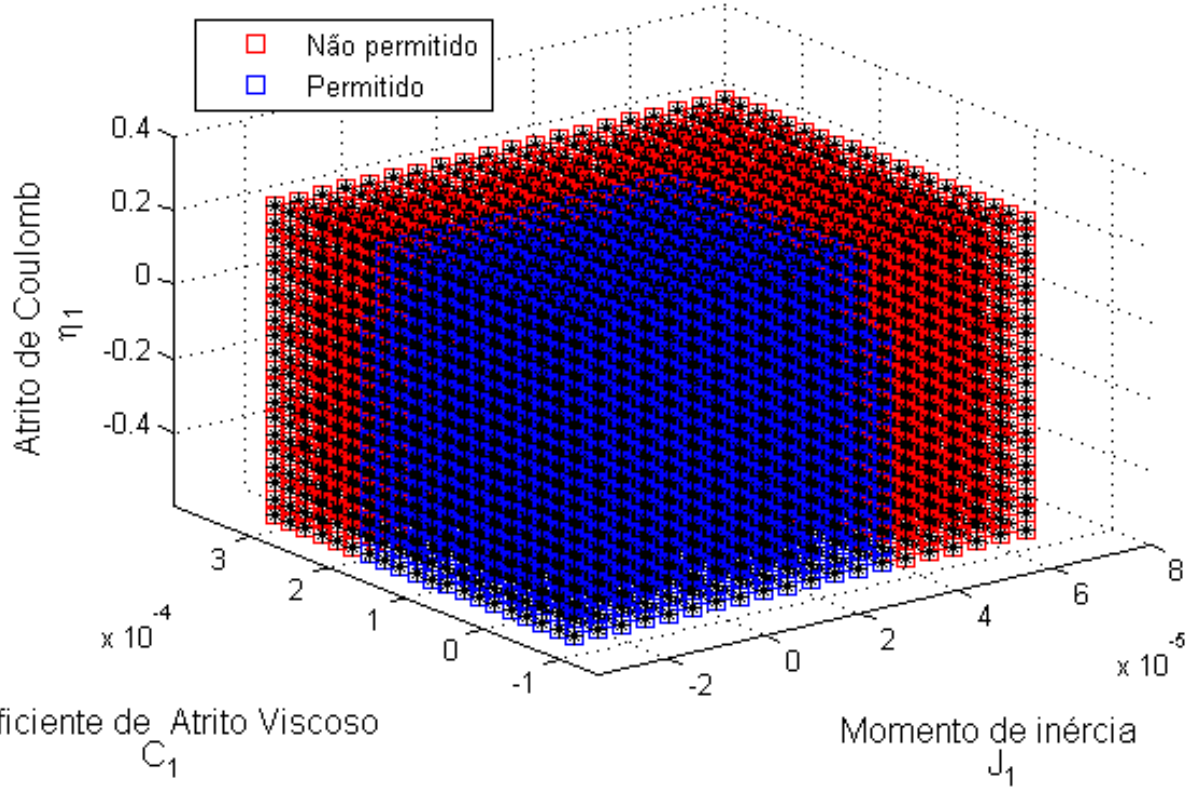

Fonte: Autor

\subsection{ANÁLISE DE RESULTADOS}

Como descrito no início do capitulo 4, nos testes experimentais foram realizadas oito simulações, onde foram alterados os parâmetros do controlador com o intuito de se modificar a inércia aparente, o atrito viscos aparente, e o atrito de Coulomb aparente. Optou-se em aplicar alterações percentuais em relação aos valores nominais dos parâmetros do sistema e essas simulações foram agrupados em gráficos que contém o sistema original, juntamente com as alterações feitas. Quando se aplica um torque externo manualmente, o sinal resultante de excitação não tem um padrão uniforme, dificultando a análise. Para facilitar a compreensão 
dos resultados, foram utilizados sinais elétricos conhecidos equivalentes aos torques externos aplicados, tal como aquele da figura 31. Para que se pudesse afirmar que esses sinais são análogos aos torques externos, utilizou-se um estimador de distúrbios para fins de validação. Na figura 29, mostra-se que um sinal senoidal imposto como excitação, e o correspondente torque estimado por meio de observador. Embora não se tenha feito uma análise quantitativa, nota-se que praticamente os sinais se sobrepõem, sugerindo que o sinal elétrico aplicado pode ser suposto aproximadamente como um torque externo aplicado.

Nota-se pelo gráfico da figura 30 e pelos dados da tabela 3 que oscilações são introduzidas no sistema. Isso ocorre devido a manivela utilizada para aplicação de torque externos não ser simétrica, ou seja, que a concentração da massa se dá apenas de um lado do eixo, provocando um desbalanceamento. O gráfico em degraus, faz com que seja possível identificar as frequências que são proporcionais a essas velocidades. Quanto maior a velocidade, maior a frequência, embora, ao confrontar a frequência que corresponde à velocidade angular com a frequência de oscilação, existe uma variação de aproximadamente 9 vezes, isso se deve ao fato de que a oscilação está no eixo onde se aplica o torque, e a velocidade medida no eixo do motor. Essa diferença é exatamente a relação das correias e polias do sistema.

O perfil de torque externo gerado no gráfico da figura 31, simula três condições de torque que o operador pode aplicar no sistema, sendo o primeiro, um perfil de maior amplitude, que pode ser usado no sistema com carga, para que seja tirado de repouso, um segundo perfil, simula uma desaceleração do sistema, quando o mesmo necessita de uma parada ou frenagem, e o terceiro perfil, serve para simular quando o sistema estiver em regime, pois haverá movimentações por um tempo sem modificações das características dos ambiente em que se encontra o sistema.

É possível identificar pelas figuras, 32 e 33 que, com apenas o aumento da inércia aparente, a tensão de armadura no regime permanente praticamente não se altera, mas o sistema se torna mais lento no transitório da resposta devido ao aumento aparente da constante de tempo, implicando numa possível degradação da manobrabilidade. Considera-se aqui manobrabilidade como a capacidade de fazer movimentações rápidas mesmo com diferentes velocidades intermediárias durante a manobra. Ao alterar a inércia aparente para um valor inferior ao do nominal, o sistema passa a ter uma constante de tempo menor, o que faz com que variações de velocidades sejam impostas mais rapidamente, aumentando a manobrabilidade do sistema. Entretanto, como a alteração da inércia aparente não interfere no valor final da resposta, o atrito viscoso aparente permanece inalterado. 
Pelos gráficos das figuras 37 e 38 é possível observar que, com alteração do coeficiente de atrito viscoso aparente, o consumo de energia para movimentar o sistema também se altera. Quando o coeficiente é alterado para mais, faz com que a resposta transitória seja mais rápida devido à diminuição aparente da constante de tempo. O contrário também é verdadeiro, ou seja, uma diminuição do coeficiente de atrito viscoso aparente, implica em uma velocidade maior em regime permanente devido à assistência feita pelo motor, apesar de transitório mais lento.

Apesar das alterações feitas na inércia aparente e no coeficiente de atrito viscoso aparente, a compensação do atrito de Coulomb tem influência na resposta do sistema, conforme ilustra o experimento da figura 39. Vale dizer que o atrito de Coulomb identificado é global, ou seja, inclui os atritos das correias, os atritos ocasionados pelas escovas do motor, etc. Aplicando-se a compensação de $\pm 100 \%$ e $\pm 50 \%$ desse atrito, é possível identificar uma proporcionalidade na amplitude do ganho, conforme visto na tabela 8. Esses ganhos fazem com que o sistema alcance maiores velocidades quando a compensação remove o atrito. Quando a compensação acrescenta atrito ao sistema, o sistema alcança uma velocidade menor.

Para que esses parâmetros alterados sejam usados adequadamente, várias possibilidades de combinações foram inseridas em um gráfico, figura 41, em que cada região pode ser utilizada para um certo objetivo. Quando se consegue um momento de inercia pequeno e um coeficiente de atrito viscoso maior, é possível utilizar o sistema para manobras em espaço de pequena área, pois a resposta de acomodação do sistema é rápida, e, o sistema não alcançará grandes velocidades, ou seja, terá ganhos menores.

Ao diminuir o coeficiente de atrito viscoso, o sistema terá um ganho maior, com isso a velocidade em regime será maior, o que é de interesse do operador que precisará de um torque menor para o deslocamento.

Já para que se tenha uma segurança ao utilizar o veículo em declives, utiliza-se a região com maiores valores de atrito de Coulomb, atrito viscoso, e com momento de inércia acentuado para que o veículo tenha em seu sistema uma frenagem capaz de permitir ao operador uma parada, ou uma desaceleração, sem exigir do operador, ou até mesmo dos motores. 


\section{CONCLUSÕES}

Este trabalho analisou por meio de simulações numéricas e experimentos o desempenho do sistema de controle do tipo casamento de impedância para aplicação em um sistema de movimentação de cargas como estratégia para assistência ao operador.

A técnica utilizada foi inspirada na linearização por realimentação (controle por torque calculado) e foi escolhida por não ser necessário o uso de sensores de força. Porém, como a lei de controle não processa um erro de casamento da impedância, o controle se mostrou ter baixa robustez em face a erros de modelagem. Ou seja, incertezas nos parâmetros do modelo se traduziram em uma impedância diferente da desejada. Conclui-se que dinâmicas não modeladas podem ter grande influência na resposta do sistema. Por exemplo, a dinâmica introduzida pela filtragem presente no estimador de aceleração angular, pode implicar em uma resposta sub amortecida do sistema. Por causa disso, os parâmetros dessa filtragem foram sintonizados empiricamente de forma a produzir um razoável efeito de filtragem aliado a uma pequena alteração dinâmica da resposta, ou seja, ainda superamortecida. Embora a falta de robustez tenha sido identificada, a influência dos erros de modelagem não foi formalmente quantificada nesta pesquisa.

A lei de controle proposta permitiu estabelecer de forma aproximada a relação dinâmica desejada entre o torque aplicado e a velocidade do sistema. Os resultados observados nas simulações e nos experimentos permitem afirmar que a impedância mecânica foi alterada aproximadamente conforme esperado, apesar de dinâmicas não modeladas, tal como aquela devido a indutância do circuito de armadura do motor e aquelas devido aos valores de rigidez das correias.

Para validação dos resultados foi utilizada uma célula de carga que serviu para comparar a impedância do modelo com a impedância real do sistema. Nesse processo de validação observou-se que em todas as alterações de impedâncias impostas, cujo esforço de controle esteve abaixo do limite imposto pela saturação do atuador, o resultado experimental foi bastante próximo aos valores previstos por simulação numérica. O ganho e constante de tempo tiveram variações proporcionais às alterações feitas, sugerindo uma boa qualidade do modelo.

Uma outra célula de carga de forma prismática, foi utilizada para determinar qual o torque do motor, pois, como a célula de carga usada quantifica micro deformações, foi 
possível determinar o torque do motor, aplicando pequenas tensões, garantindo que o sistema não saturaria. Posteriormente, esse torque mensurado, também foi validado analiticamente.

Em um script no Matlab, foi inserido a função de transferência que descreve o sistema, e, com os parâmetros alterados, serviu para gerar um gráfico, onde é possível determinar quais os parâmetros ótimos para a alteração apenas se referenciando pelos dados do gráfico, e, como proposta de continuidade desta pesquisa, sugere-se investigar formas de se definir quais parâmetros são mais adequados para uma dada aplicação, aplicando uma otimização dos parâmetros, tendo como penalidades, a saturação do motor, a manobrabilidade, e a dirigibilidade do sistema. Ou seja, estabelecer um critério para escolha dos valores aparentes de inércia, atrito viscoso e atrito de Coulomb. 


\section{REFERÊNCIAS}

ARVA, Julianna; FITZGERALD, Shirley G.; COOPER, Rory A.; BONINGER, Michael L.; Mechanical efficiency and user power requirement with a pushrim activated powerassisted wheelchair. Medical Engineering and Physics, 23, 699-705. Maio de 2001

BONIFACE, Keith; MCKAY, Mary Pat; LUCAS, Raymond; SHAFFER, Alison; SIKKA, Neal; Serious Injuries Related to the Segway Personal Transporter: A Case Series. Annals of Emergency Medicine, Volume 57, ano 4, April 2011.George Washington University, Washington, DC.

CHEN, Mao-Lin; Analysis and Design of Robust Feedback Control Systems for a Nonlinear Two-Wheel Inverted Pendulum system. International Symposium on Computer, Consumer and Control.2012

COOPER, Rory A., Observability and Controllability of Scooters. IEEE Transactions on Control Systems Technology, vol.1, pag 488-489, Baltimore novembro 1994.

COOPER, Rory A.; CORFMAN, Thomas A.; FITZGERALD, Shirley G.; BONINGER, Michael L.; SPAETH, Donald M.; AMMER, William; ARVA, Julianna; Performance Assessment of a Pushrim-Activated Power-Assisted Wheelchair Control System. IEEE Transactions on Control Systems Technology, Vol. 10, NO. 1, January 2002.

DELLABIANCIA, Fabio; PORCELLINI, Giuseppe; MEROLLA, Giovanni; Instruments and techniques for the analysis of wheelchair propulsion and upper extremity involvement in patients with spinal cord injuries: current concept review. Muscles, ligaments and tendons journal 2013; 3 (3) 150-156. Agosto de 2011

ELETROBRÁS; LODI, Instituto Euvaldo; PROCEL,Programa Nacional de Conservação de Energia Elétrica; CNI,Confederação Nacional da Indústria; PROCEL INDÚSTRIA, Eficiência Energética Industrial; Motor Elétrico: Guia Básico. Brasília, 2009. 190 p 
EPAC's, Pedelec's, eBikes and Bicycle Regulation European Cyclist's Federation Disponível no site: http://www.ecf.com/advocary/road-safety/high-powered-epacs/ acessado dia $25 / 07 / 2015$

FITZGERALD, A. E.; KINGSLEY, Charles; UMANS, Stephen D.; - Máquinas elétricas : com introdução à eletrônica de potência. $6^{\mathrm{a}}$ ed.. Porto Alegre : Bookman, 2008 . $648 \mathrm{p}$

JARDIM, Bruno; MARTINS, Heitor A.; SIQUEIRA, Adriano A.G.; Controle de Impedância Aplicado em uma Ortese Tornozelo-Pé Ativa. $2^{\circ}$ Encontro Nacional de Engenharia Bio-Mecânica. Maio, 2009. Florianópolis, SP

LEONARDI, Fabrizio. Projeto de sistemas de controle multivariáveis robustos com especificações no domínio do tempo. 2002.137 f. Tese. (doutorado em engenharia de sistemas). Universidade de São Paulo. 2002.

SILVA, Daniel L. F.; LEONARDI, Fabrizio; Impedance Control applied to the Selection of a passive shock absorber. 22nd International Congress of Mechanical Engineering , Novembro, 2013, Ribeirão Preto, SP, Brasil

FARIVARNEJAD, H.; MOOSAVIAN, S.A.; Ocean Engineering. 2014 Oct 1;89:82-98.; Multiple Impedance Control for object manipulation by a dual arm underwater vehiclemanipulator system. Ocean. Engineering 89, out 2014-p 82-98.

HOGAN, Neville. Impedance control. Journal of Dynamic Systems, Measurement, and Control, vol. 107. pag 1-24 March 1985

IBARRA, Juan C. Pérez; SIQUEIRA, Adriano A. G.;Impedance Control of Rehabilitation Robots for Lower Limbs. Conference on SBR-LARS Robotics Symposium and Robocontrol, 2014 
IWASE, Tomohiro; ZHANG, Rui; KUNO, Yoshinori; Robotic Wheelchair Moving with the Caregiver. International Joint Conference. Bexco, Busan, Korea. 2006.

MAYA, Paulo Álvaro; LEONARDI, Fabrizio; Controle Essencial, $2^{\mathrm{a}}$ ed. São Paulo: Pearson Education do Brasil, 2014. 347p.

Manual Placa NI PCI-6221, Disponível no site:

http://www.ni.com/pdf/manuals/375303a.pdf acessado dia 06/09/2015.

Manual Toolbox Simulink Real Time Windows Target Disponivel no site:

http://www.etf.unssa.rs.ba/ slubura/medode $\% 20$ modeliranja $\% 20 \mathrm{i} \% 20$ simulacije/rtwt.pdf acessado dia 06/09/2015

MEHLing, Joshua S.; O’MAlLEY, Marcia K.; A Model Matching Framework for the Synthesis of Series Elastic Actuator Impedance Control. Mediterranean Conference on Control and Automation (MED) University of Palermo. Palermo, Italy. 2014

MONTEIRO, Ruth Simioni; Conselhos. São Paulo, 1955

NAKAMURA, Soichi; IKEURA, Ryojun; WASAKA, Takahiro; MIZUTANI, Kazuki; SAWAI, Hideki; HIRATA, Hitoshi; A Study on Impedance Control using Passive Elements for Human Assist System. SICE Annual Conference, The University ElectroCommunications, Japão,20-22 Agosto 2008

NISE, Norman S.; Engenharia de Sistemas de Controle. 5a ed. Rio de Janeiro: LTC, 2007. OKAMURA, Allison M.; SMABY, Niels; CUTKOSKY, Mark R.; An overview of dexterous manipulation. Robotics and Automation, 2000. IEEE International Conference on. Vol. 1. IEEE, 2000. 
PEDRO, L. M.; FERNANDES, G.; SANTOS, W. M. dos; SIQUEIRA, A. A. G.; CAURIN, G. A. de Paula; Um estudo de desempenho do controle de impedância para tarefas de contato utilizando robôs industriais. XI SBAI-Simpósio Brasileiro de Automação Inteligente. Fortaleza, Ceará Brasil, outubro,2013

POPA, John; LIU, Gustavo; Human Assisted Impedance Control of Overhead Cranes . International Conference on Control Aplication. Cidade do México, 2001.

SAGAWA Jr. Yoshimasa; HAUPENTHAL, Alessandro; BORGES Jr, Noé G.; SANTOS, Daniela P.; WATELAIN, Eric; Wheelchairs propulsion analysis: review. Fisioterapia em movimento vol. $25 n^{\circ} 01$ jan. /mar. 2012

SAWATZKY, Bonita; DENISON, Ian; LANGRISH, Shauna; RICHARDSON, Shonna; HILLER, Kelly; SLOBOGEAN, Bronwyn; The Segway Personal Transporter as an Alternative Mobility Device for People with Disabilities. Arch Phys Med Rehabil Vol 88, Novembro de 2007

SEGWAY veículo transportador de pessoas, Disponível no site: http://www.praguesegway.com acessado dia 06/12/2015.

SHIBATA, Tsuyoshi; MURAKAMI, Toshiyuki; Power-Assist Control of Pushing Task by Repulsive Compliance Control in Electric Wheelchair. IEEE Transaction on Industrial Electronics, Vol.59, No.1, Jan. 2012

SKOGESTAD, S.; POSTLETHWAITE, I. Multivariable Feedback Control: Analysis and Design. New York, John Wiley, 1996.

SLOTINE, Jean-Jacques; LI, Weiping Applied Nonlinear Control. Prentice-Hall do Brasil, Ltda, Rio de Janeiro, 1991.

WINTER, David A.; Biomechanical motor patterns in normal walking. Journal of motor behavior 15.4 1983.302-330. 
YI, S. Y.; CHONG, K. T.; Impedance control for a vehicle platoon system. Mechatronics, 15(5), 2005-p 627-638. 
APÊNDICE A: SCRIPT DO MATLAB 


\section{Programa para gerar os dados}

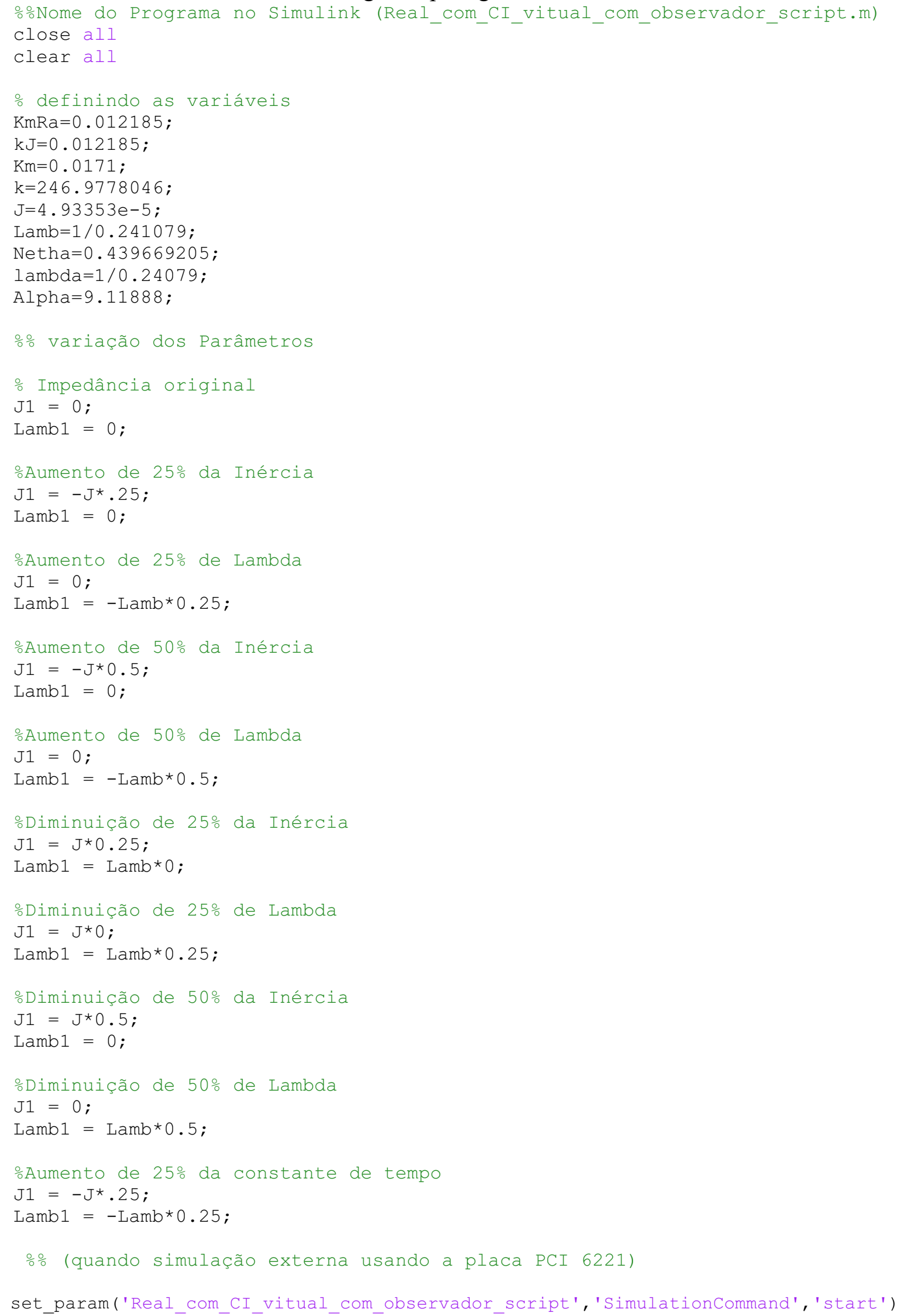




\section{Programa para gerar os gráficos}

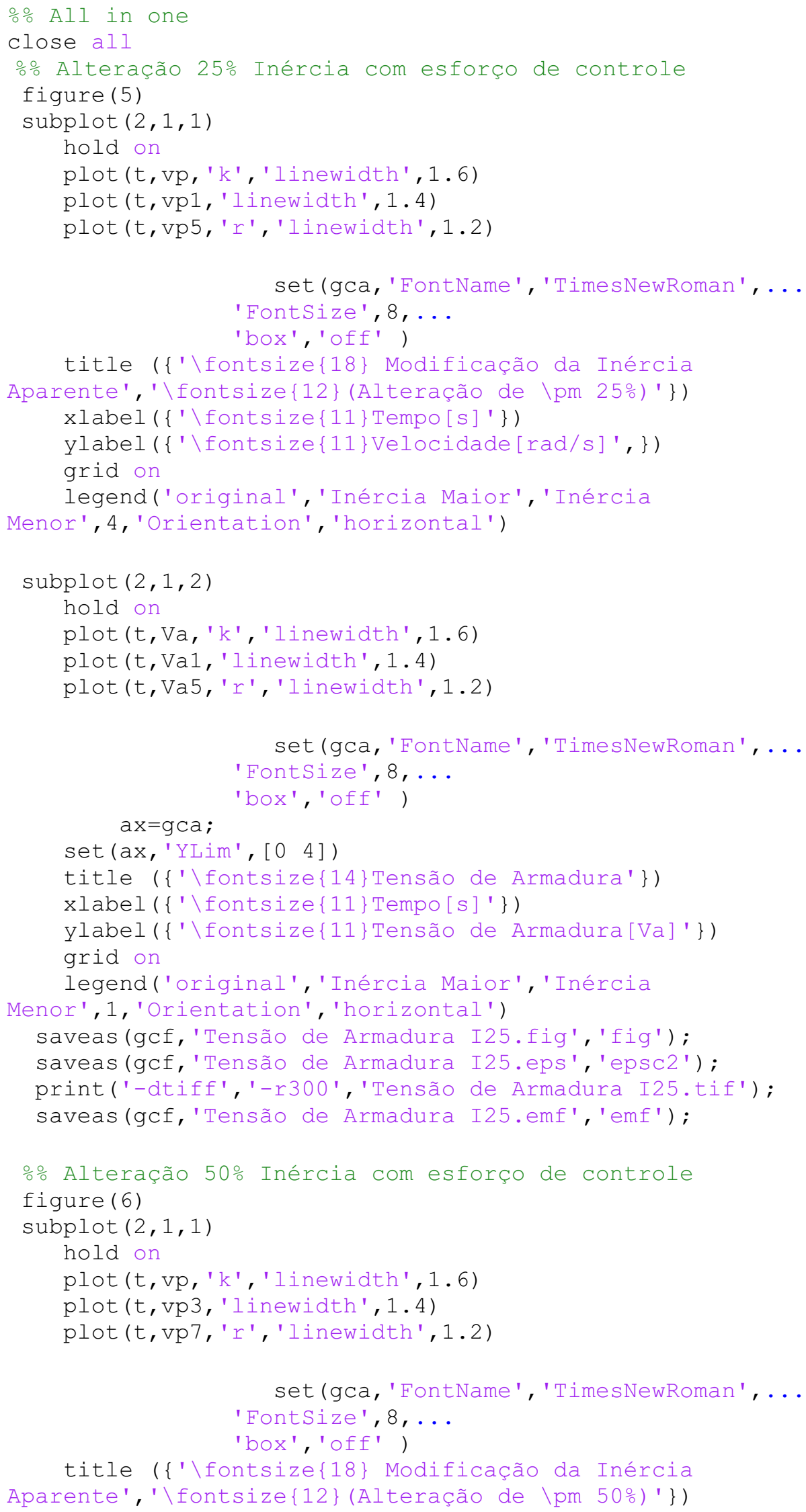


xlabel ( $\{$ ' fontsize $\{11\}$ Tempo [s] ' $\}$ )

ylabel ( $\{\backslash$ fontsize $\{1\}$ Velocidade [rad/s] ', \})

grid on

legend('original', 'Inércia Maior', 'Inércia

Menor', 4, 'Orientation', 'horizontal')

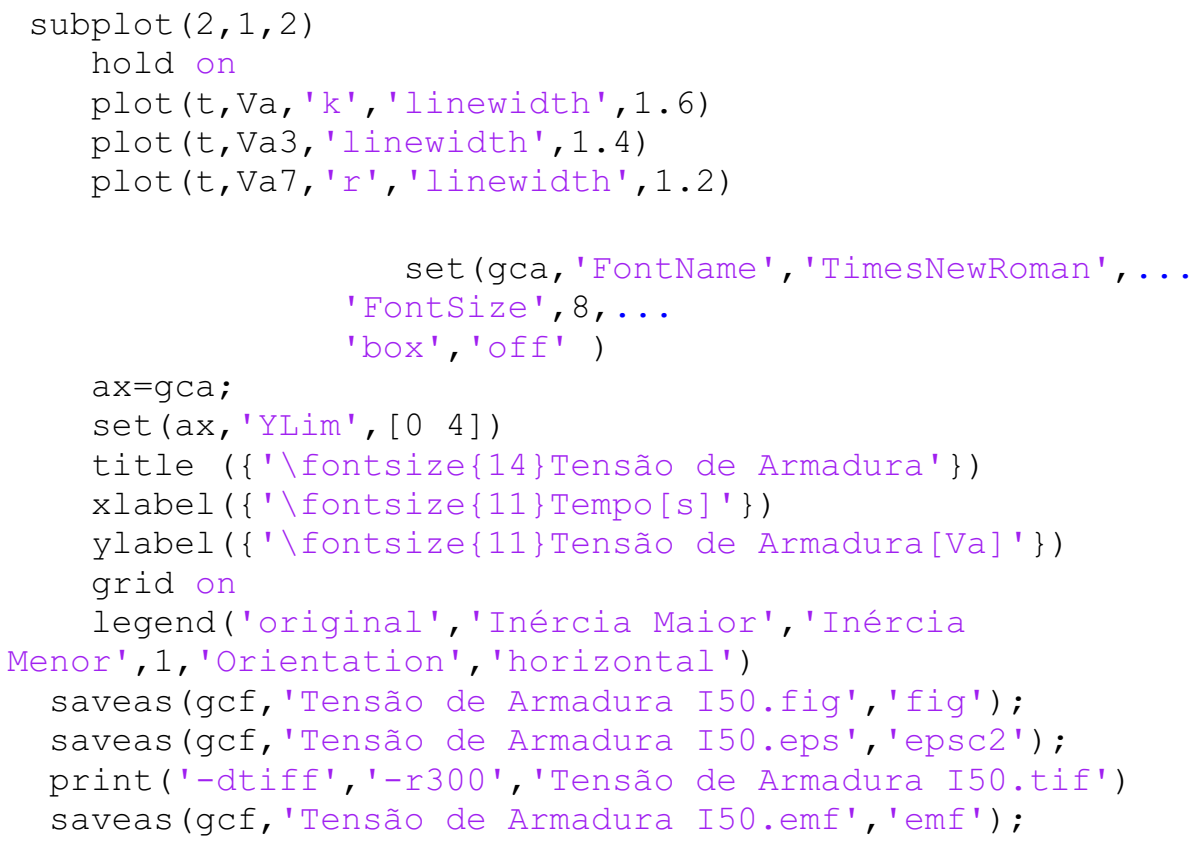




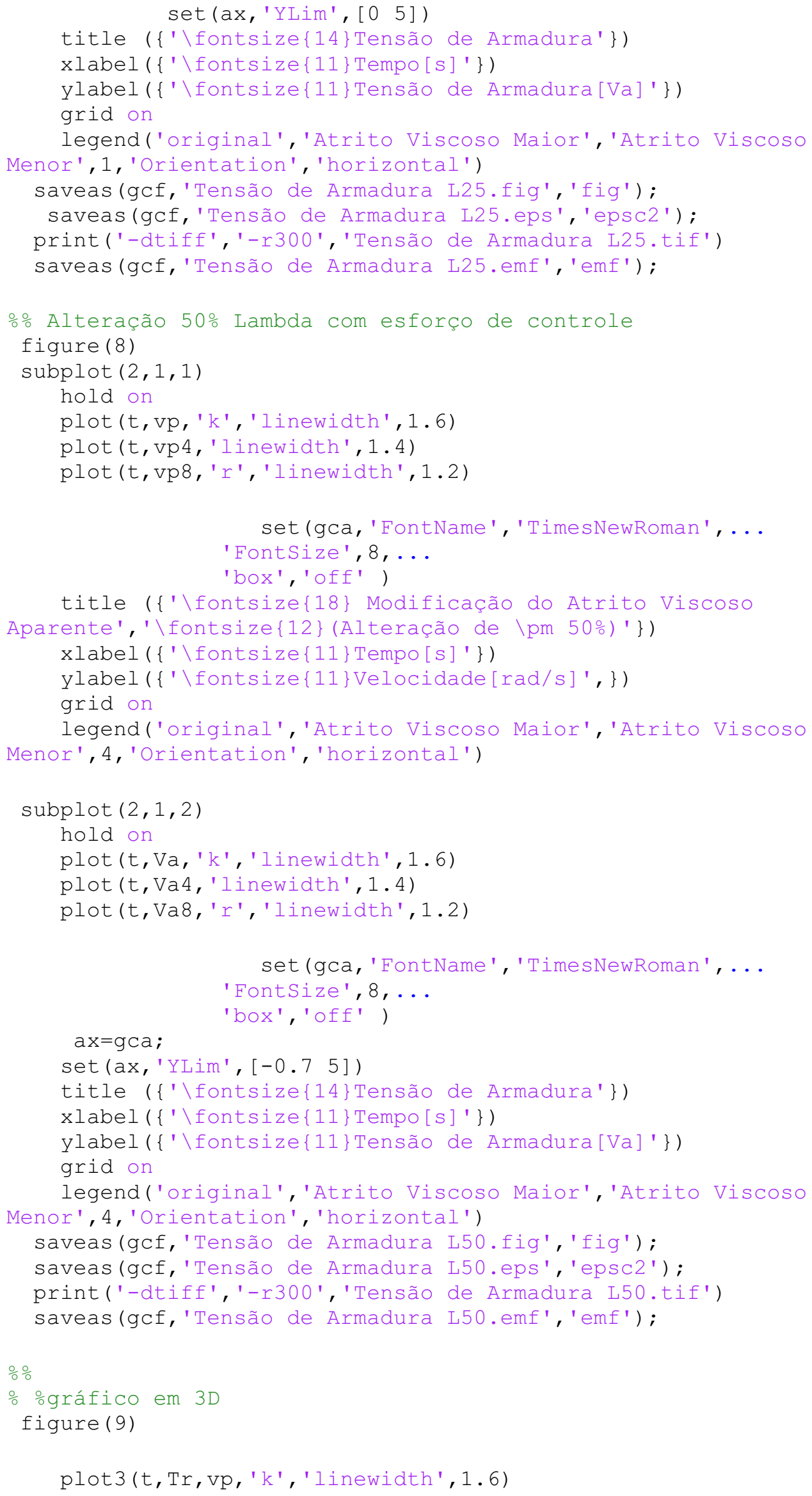


hold on

plot3 (t, Tr1, vp1, 'b' ' ' linewidth', 1.6)

hold on

plot3(t, Tr5, vp5,'r', 'linewidth', 1.6)

hold on

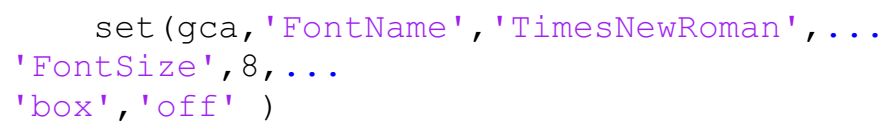

title ( $\{\backslash$ fontsize 18$\}$ Impedância Mecânica', '\fontsize $\{12\}$ (Alteração de \pm 25\% da Inércia aparente)'\})

xlabel ( $\{$ ' fontsize $\{1\}$ Tempo [s]' ' )

ylabel ( $\{$ ' fontsize $\{11\}$ Torque [Nm ] ' \})

zlabel ( $\{\backslash$ fontsize $\{11\}$ Velocidade [rad/s ] ', \})

grid on

hold on

legend('original', 'Inércia Maior', 'Inércia Menor',2)

saveas (gcf,'impedancia 3D inercia 25.eps','epsc2');

saveas (gcf,'impedancia 3D inercia 25.fig','fig');

print('-dtiff','-r300', 'impedancia 3D inercia 25.tif');

saveas(gcf,'impedancia 3D inercia 25.emf','emf');

응 $\frac{0}{0}$

\% gráfico em 3D

figure (10)

plot3 (t, Tr, vp, 'k', ' linewidth', 1.6)

hold on

plot3 (t, Tr3,vp3, 'b', ' linewidth', 1.6)

hold on

plot3 (t, Tr7, vp7,'r', 'linewidth', 1.6)

hold on

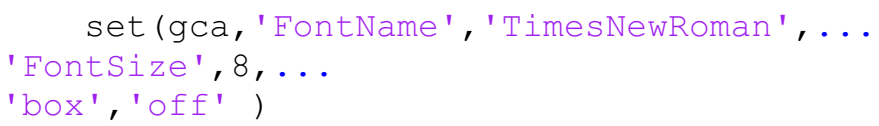

title ( $\{\backslash$ fontsize\{18\} Impedância Mecânica', '\fontsize\{12\} (Alteração de $\backslash \mathrm{pm}$ 50\% da Inércia aparente)'\})

xlabel ( $\{$ ' fontsize $\{1\}$ Tempo[s] ' $\}$ )

ylabel ( $\{$ ' fontsize $\{11\}$ Torque $[\mathrm{Nm}]$ ' $\}$ )

zlabel ( $\{\backslash$ fontsize $\{1\}$ Velocidade $[\mathrm{rad} / \mathrm{s}]$ ' , \})

grid on

hold on

legend('original', 'Inércia Maior', 'Inércia Menor',2)

saveas (gcf,'impedancia 3D inercia 50.eps', 'epsc2');

saveas(gcf,'impedancia 3D inercia 50.fig','fig');

print('-dtiff','-r300', 'impedancia 3D inercia 50.tif');

saveas(gcf,'impedancia 3D inercia $50 . e m f ', ' e m f ')$;

응 $\frac{10}{0}$

응áfico em 3D

figure (11)

plot3 (t, Tr, vp, 'k', ' linewidth' , 1.6)

hold on

plot3 (t, Tr2, vp2, 'b' ', 'linewidth', 1.6)

hold on

plot3 (t, Tr6, vp6, 'r', ' linewidth', 1.6)

hold on

set (gca, 'FontName' ,'TimesNewRoman' '...

'FontSize', 8, .. 
'box', 'off' )

title ( $\{$ ' fontsize 18$\}$ Impedância Mecânica', '\fontsize $\{12\}$ (Alteração de \pm 25\% do Atrito Viscoso Aparente)' \})

xlabel ( $\{$ ' fontsize $\{11\}$ Tempo [s]' $\}$ )

ylabel ( $\{$ ' fontsize $\{11\}$ Torque $[\mathrm{Nm}]$ ' $\}$ )

zlabel ( $\{\backslash$ fontsize $\{11\} V e l o c i d a d e[r a d / s] '$,$\} )$

grid on

legend('original', 'Inércia Maior', 'Inércia Menor',2)

saveas (gcf,'impedancia 3D Atrito 25.eps', 'epsc2');

saveas (gcf,'impedancia 3D Atrito 25.fig','fig');

print('-dtiff','-r300', 'impedancia 3D Atrito 25.tif');

응

saveas (gcf,'impedancia 3D Atrito 25.emf','emf');

\% ográfico em 3D

figure (12)

plot3 (t, Tr, vp, 'k', ' linewidth ', 1.6)

hold on

plot3 (t, Tr4, vp4, 'b' ' ' linewidth', 1.6)

hold on

plot3 (t, Tr8, vp8, 'r', ' linewidth', 1.6)

hold on

set (gca, 'FontName', 'TimesNewRoman ', ...

'FontSize', 8, ...

'box', 'off' )

title ( $\{$ ' fontsize\{18\} Impedância Mecânica', '\fontsize $\{12\}$ (Alteração de \pm 50\% do Atrito Viscoso Aparente)'\})

xlabel ( $\{$ ' fontsize $\{11\}$ Tempo [s]' ' \})

ylabel ( $\{\backslash$ fontsize $\{11\}$ Torque $[\mathrm{Nm}]$ ' $\}$ )

zlabel ( $\{\backslash$ fontsize $\{1\}$ Velocidade $[\mathrm{rad} / \mathrm{s}]$ ' , \})

grid on

hold on

legend('original', 'Inércia Maior', 'Inércia Menor', 2)

saveas (gcf,'impedancia 3D Atrito 50. eps', 'epsc2');

saveas (gcf,'impedancia 3D Atrito 50.fig','fig');

print('-dtiff','-r300', 'impedancia 3D Atrito 50.tif');

saveas (gcf,'impedancia 3D Atrito 50.emf','emf'); 
APENNDICE B: ARQUIVO DO SIMULINK 
Figura 41-Diagrama de blocos com subsistemas no Simulink

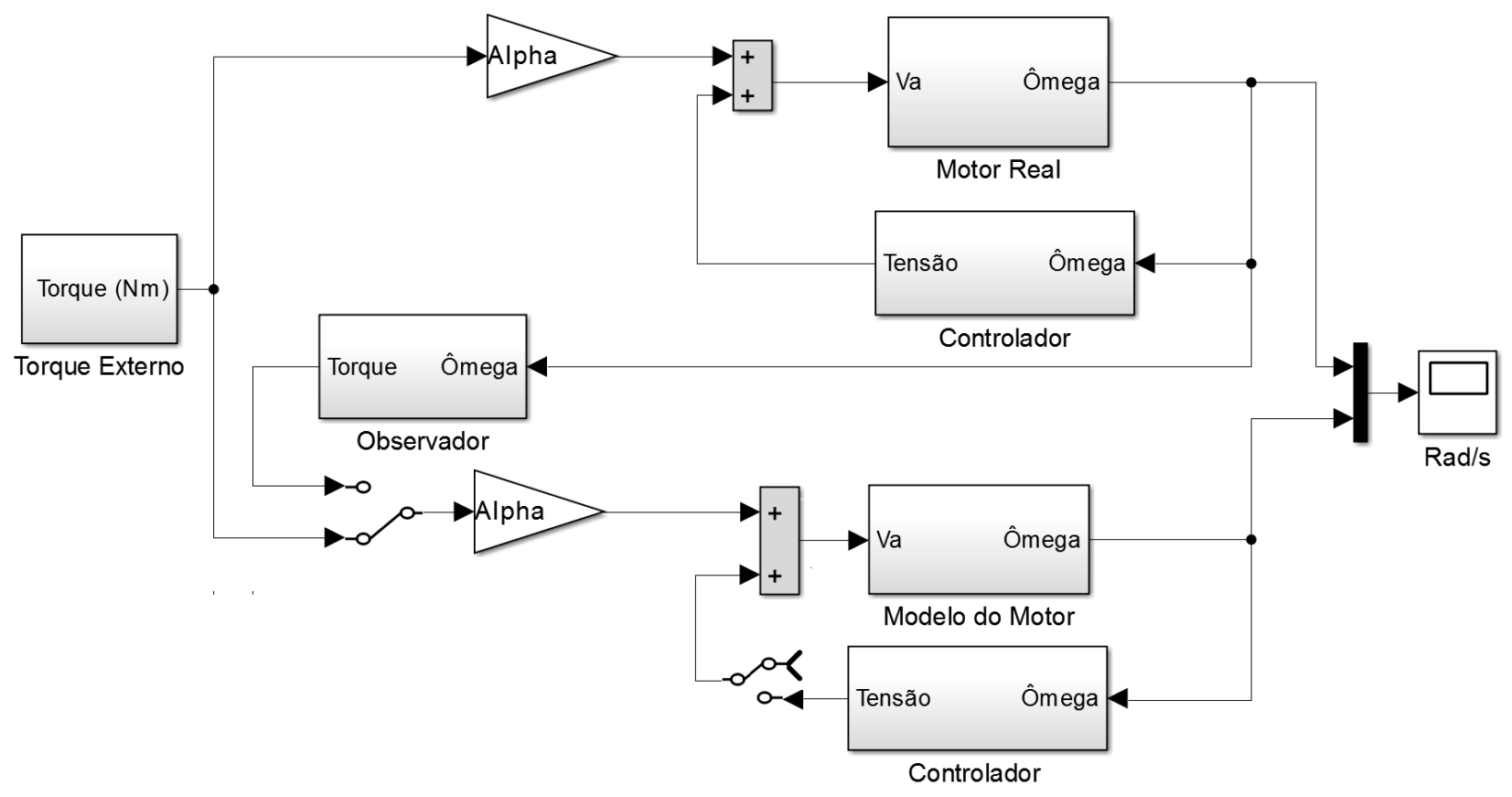

Fonte: Autor

Figura 42-Controlador de Impedância

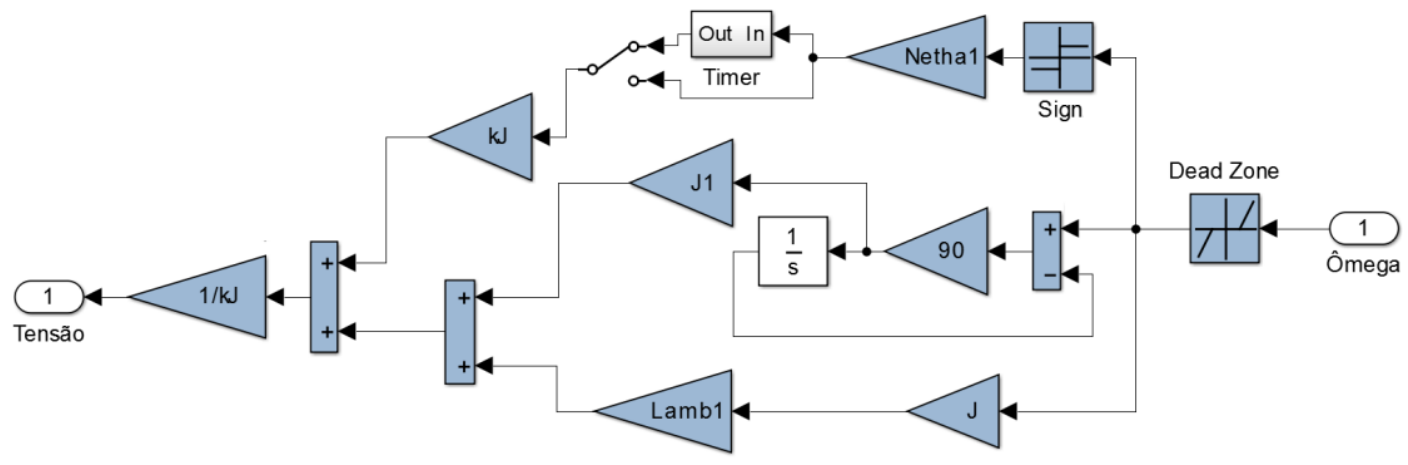

Fonte: Autor 
Figura 43-Modelo do Motor

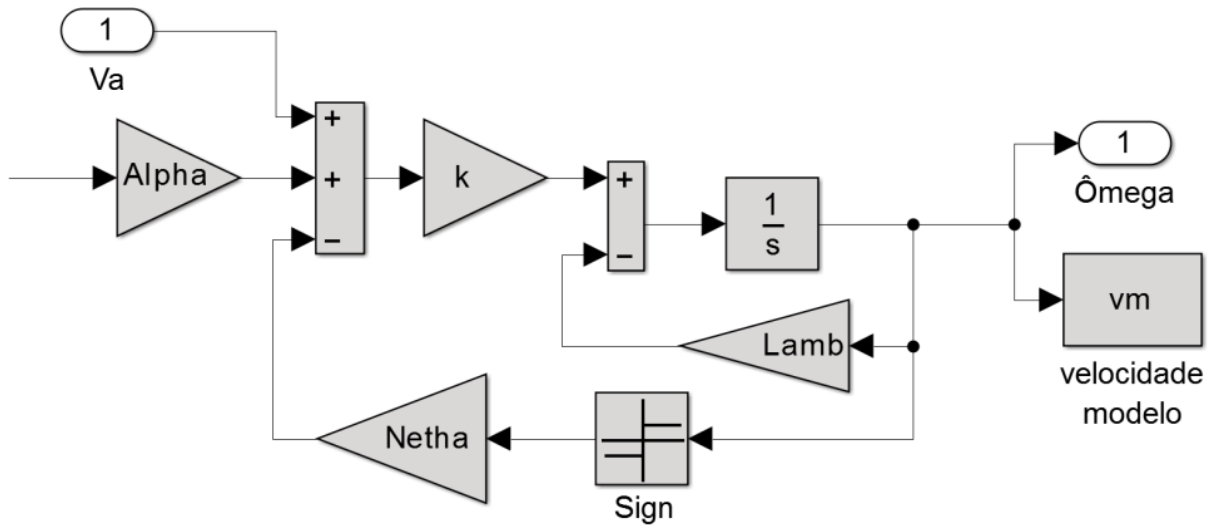

Fonte: Autor

Figura 44-Motor real (entrada e saída da Placa HBM 6221)

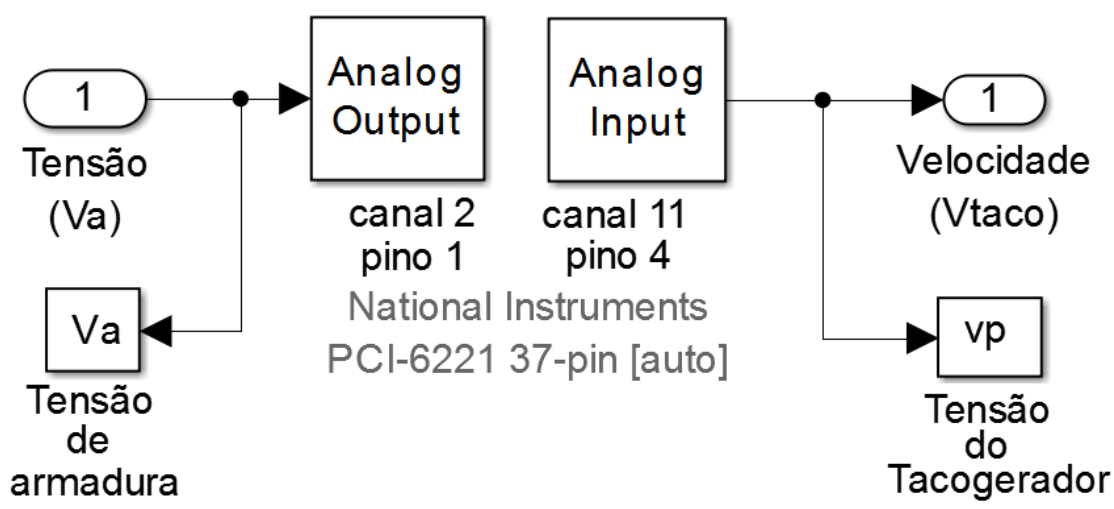

Fonte: Autor 
Figura 45-Observador de torque

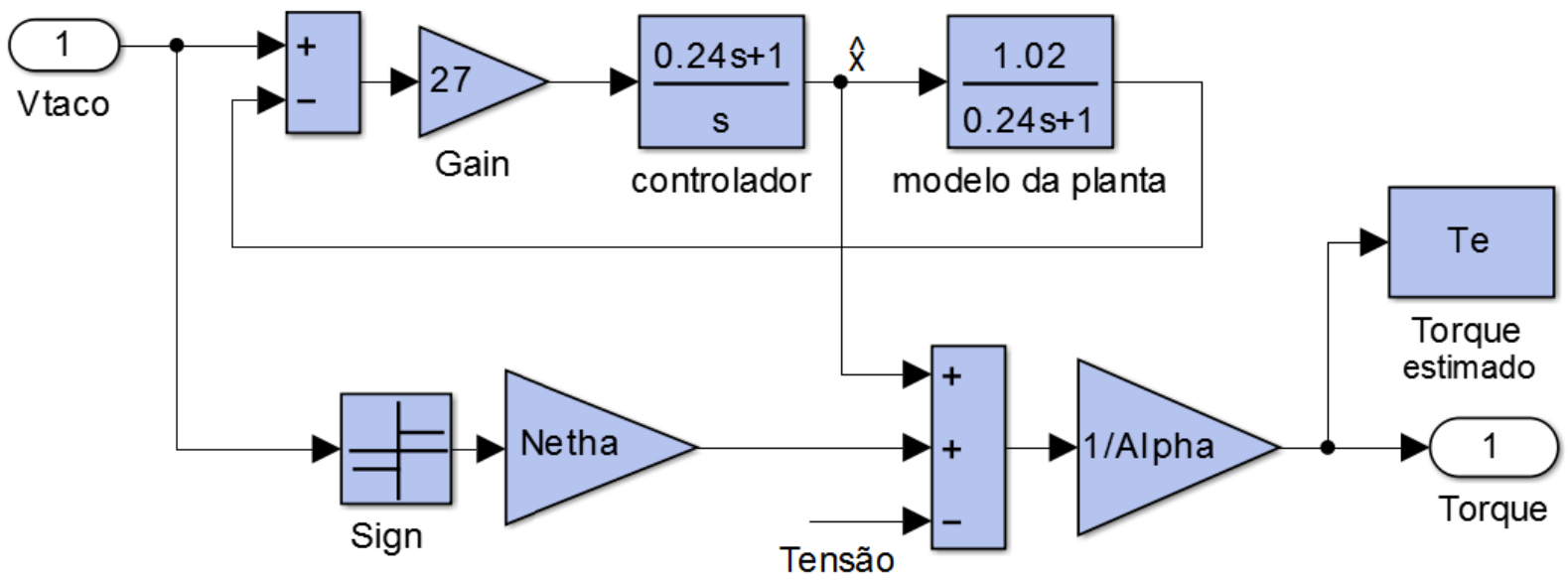

Fonte: Autor

Figura 46-Simulador de torque externo

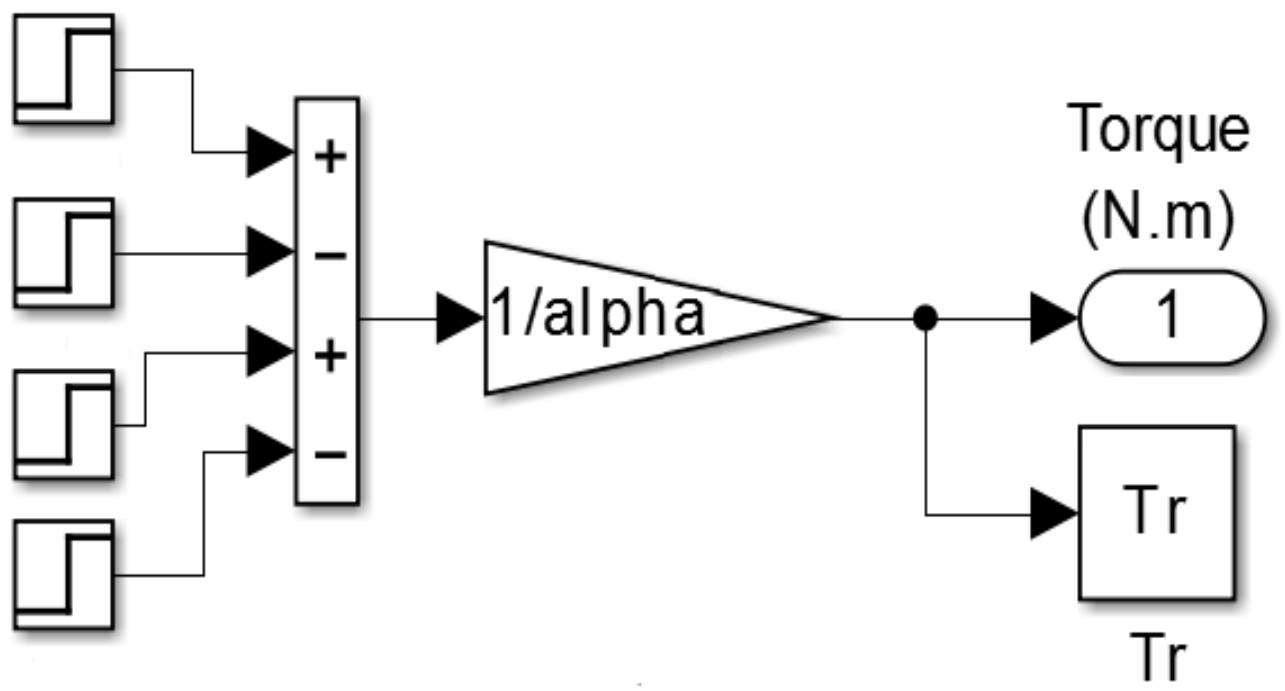

Fonte: Autor 
APÊNDICE C: CÉLULA DE CARGA 
A célula de carga (vide figura 17) usada para validar o casamento da impedância foi construído com 4 strain-gauge, ligados em ponte completa (ponte de Wheatstone) para a medição de torção e foi projetada de acordo com o eixo de entrada de torque. A primeira etapa consiste da determinação de

$$
W_{t}=\frac{\pi D^{4}}{32}
$$

onde, $W_{t}\left[\mathrm{~mm}^{4}\right]$ é o momento de inércia polar do eixo de diâmetro $D$. Logo, a tensão é dada por

$$
\sigma=\frac{M_{t}}{W_{t}}
$$

sendo $M_{t}[\mathrm{Nm}]$ o momento torsor e $\sigma[M P a]$ a tensão máxima. Pela lei de Hooke, a tensão máxima também pode ser dada por

$$
\sigma=G \gamma
$$

onde $G[G P a]$ é o módulo de elasticidade do eixo e $\gamma[\mathrm{rad}]$ é a deformação de cisalhamento. A deformação é medida por meio da variação de resistência elétrica dos pequenos filamentos de um strain-gauge. Igualando (38) e (39), o torque aplicado é detectado pelo strain-gauge colado sobre o eixo.

Para a célula de carga usada na aquisição do parâmetro $\frac{K_{m}}{R_{a}}$, foi utilizada uma célula de carga que mede flexão, constituída de 4 strain-gauge ligados em ponte completa. O princípio de equacionamento é semelhante à célula de torque, sendo que a variação da resistência se dá na área deformada. Na figura 47 ilustra-se o processo de deformação e a forma de variação das resistências, utilizada para ambas células de cargas.

Figura 47- Célula de Carga para medição de flexão.

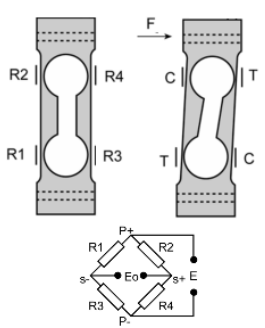

Fonte: Autor 